University of Montana

ScholarWorks at University of Montana

Graduate Student Theses, Dissertations, \&

Professional Papers

1995

\title{
Natural background determination and impact quantification in trace metal contaminated river sediments
}

Steven O. Helgen

The University of Montana

Follow this and additional works at: https://scholarworks.umt.edu/etd

Let us know how access to this document benefits you.

\section{Recommended Citation}

Helgen, Steven 0., "Natural background determination and impact quantification in trace metal contaminated river sediments" (1995). Graduate Student Theses, Dissertations, \& Professional Papers. 8167.

https://scholarworks.umt.edu/etd/8167

This Thesis is brought to you for free and open access by the Graduate School at ScholarWorks at University of Montana. It has been accepted for inclusion in Graduate Student Theses, Dissertations, \& Professional Papers by an authorized administrator of ScholarWorks at University of Montana. For more information, please contact

scholarworks@mso.umt.edu. 



\title{
Natural Background Determination
}

\author{
and Impact Quantification in
}

Trace Metal Contaminated

River Sediments

\author{
by \\ Steven O. Helgen \\ B.A. Carleton College, 1990 \\ presented in partial fulfillment of the requirements \\ for the degree of \\ Master of Science \\ The University of Montana \\ 1995
}

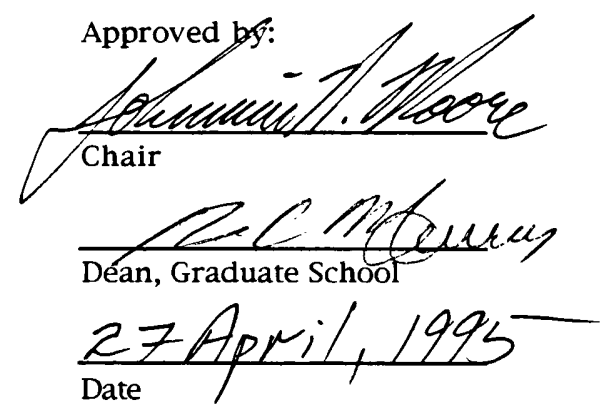


All rights reserved

\section{INFORMATION TO ALL USERS}

The quality of this reproduction is dependent upon the quality of the copy submitted.

In the unlikely event that the author did not send a complete manuscript and there are missing pages, these will be noted. Also, if material had to be removed, a note will indicate the deletion.

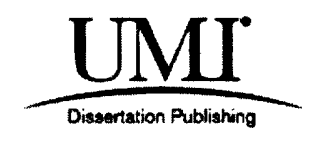

UMI EP38968

Published by ProQuest LLC (2013). Copyright in the Dissertation held by the Author. Microform Edition @ ProQuest LLC.

All rights reserved. This work is protected against unauthorized copying under Title 17, United States Code

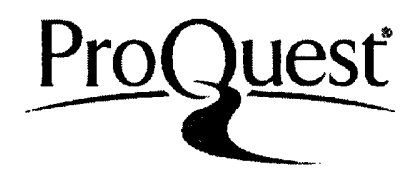

ProQuest LLC.

789 East Eisenhower Parkway

P.O. Box 1346

Ann Arbor, MI 48106 - 1346 
Natural Background Determination and Impact Quantification in Trace Metal Contaminated River Sediments ( 89 pp.)

Chair: Johnnie N. Moore

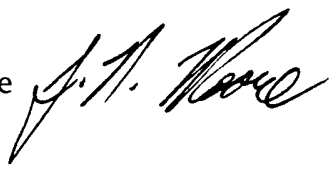

Historic and current mining activities have contaminated stream sediments around the world with toxic heavy metals. A historic lack of pre-mining baseline data makes it difficult to quantify the extent of contamination and set realistic remediation goals. These problems can be solved by modeling the downstream dispersion of metal anomalies based on dilution mixing of anomalous and tributary sediments. The model allows calculation of the dispersion curves of metals in stream sediments both before and after mining. The model also allows the quantification of the anthropogenic exaggeration of an anomaly. Mining activities were found to amplify naturally occurring metal anomalies up to three orders of magnitude, extending downstream dispersion trains from a natural limit around 20 kilometers to as much as $\mathbf{5 0 0}$ kilometers. The dilution mixing model provides a useful tool for calculating pre-mining dispersion trains and helping to quantify the effects of mining on a river basin. These pieces of information are important to the understanding, litigation, and remediation of contaminated rivers around the world. 


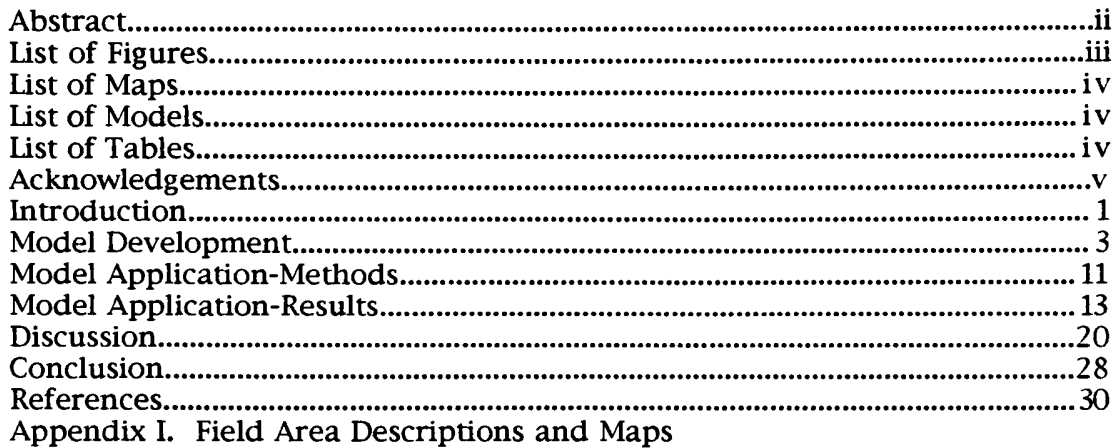

A. Senate Mine-Ivanhoe Lake Area............................................................................... 35

B. New World District................................................................................................................37

C. Flint Creek...........................................................................................................................44

Appendix II. Models of Unmined Ore Deposits
A. Ivanhoe Lake.
B. Miller Creek...............................................................................................................49
C. Models of Literature Data........................................................................................... 52
Appendix III. Models of Mined Ore Deposits
A. Clark Fork River. .58

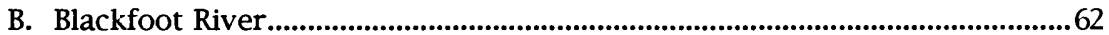

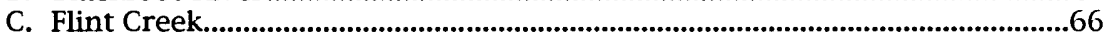

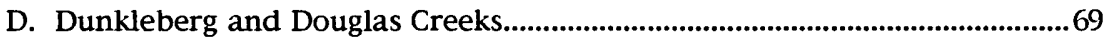
E. Fisher and Little Daisy Creeks.............................................................................. 74
F. Senate Mine................................................................................................................. 79

Appendix IV. Complete Methods

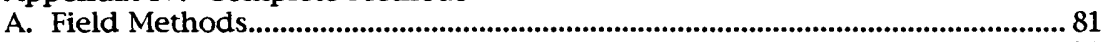

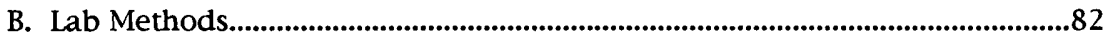

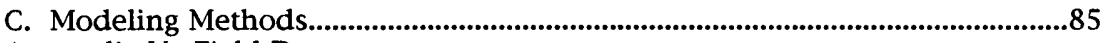

Appendix V. Field Data

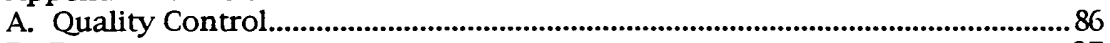

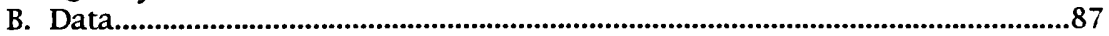

\section{List of Figures}

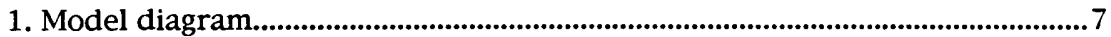

2. Effects of increasing Ax.................................................................................................... 8

3. Effects of increasing Cx........................................................................................

4. Effects of various $\mathrm{AxCx}$ combinations.................................................................10

5. Drainage data.....................................................................................................................12

6. Model fits to unmined deposits.....................................................................................16

7. Model fits to mined deposits...........................................................................17

8. Calculated background dispersion trains............................................................... 18

9. Areal Grades.........................................................................................................................19

10. Model fits with violated assumptions.......................................................................2 


\section{List of Maps}

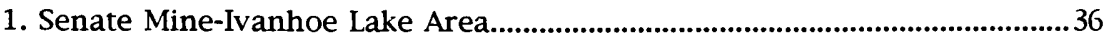

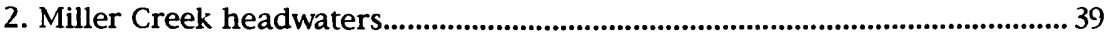

3. Miller Creek downstream...........................................................................................4 40

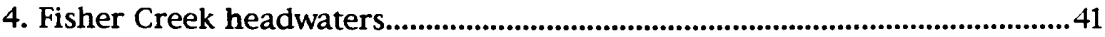

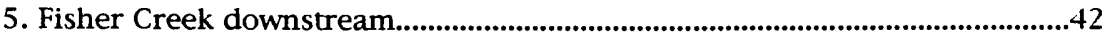

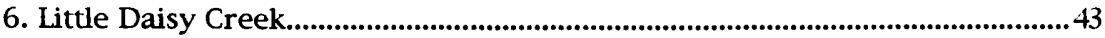

7. Flint Creek..................................................................................................................................45

\section{List of Models}

1. Ivanhoe Lake-no dilution above anomaly........................................................47

2. Ivanhoe Lake-dilution from above anomaly..................................................... 48

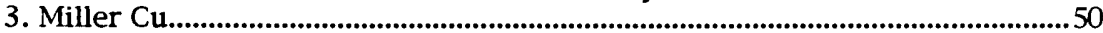

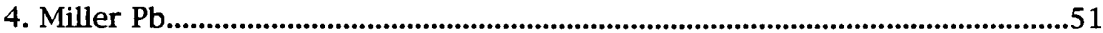

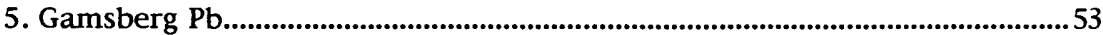

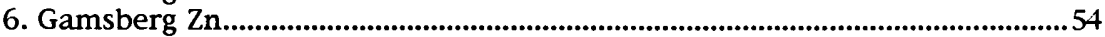

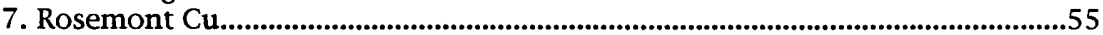

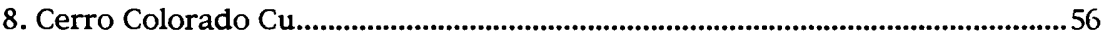

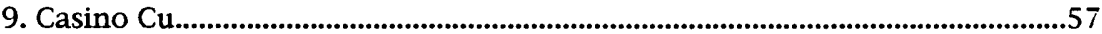

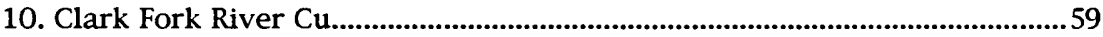

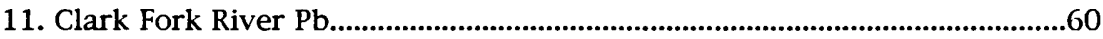

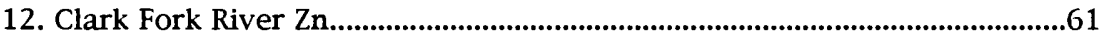

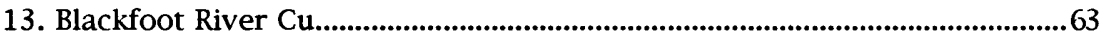

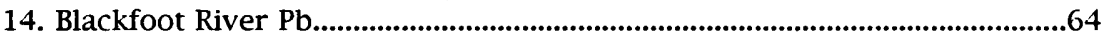

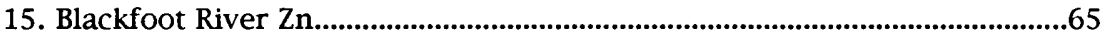

16. Flint Creek Pb...............................................................................................................67

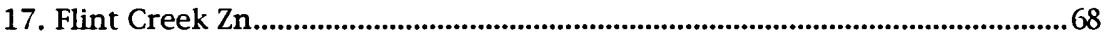

18. Dunkleberg Creek Pb......................................................................................................... 70

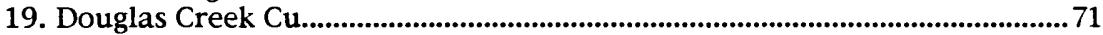

20. Douglas Creek Pb..................................................................................................72

21. Douglas Creek Zn.........................................................................................................73

22. Fisher Creek Cu......................................................................................................... 75

23. Fisher Creek Pb......................................................................................................76

24. Little Daisy Creek Cu........................................................................................................ 77

25. Little Daisy Creek Pb................................................................................................... 78

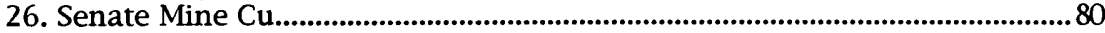

List of Tables

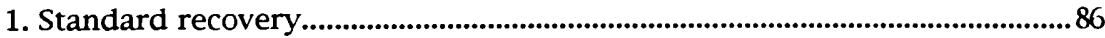

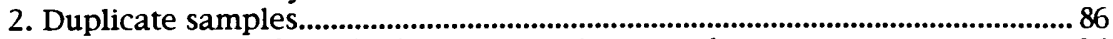

3. Spike recovery from high concentration samples..............................................8

4. Spike recovery from background concentration samples................................86

5. Senate Mine (A) and Ivanhoe Lake (B) data............................................................8

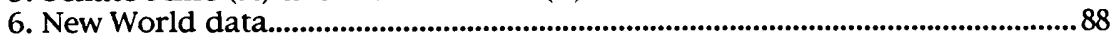

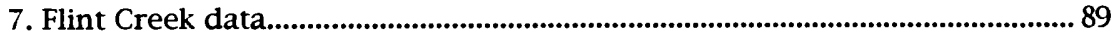




\section{Acknowledgments}

I would like to thank everyone that helped me in the field and the members of my committee for taking the time to assist me in this project, with special thanks to Johnnie Moore for providing encouragement and insight throughout the project. I would also like to thank Samuel N. Luoma of the United States Geological Survey and the University of Montana for partially funding this project through a USGS-UM Cooperative Agreement. 
Introduction

Mining activities have left countless streams and rivers contaminated with toxic heavy metals (Davies and Lewis, 1974; Horowitz et al., 1988; Moore and Luoma, 1990; James, 1991). In many historic mining districts metals released from mining wastes have completely obscured the natural contribution of metals to stream sediments. The natural component of the metal load may be overwhelmed by metals released from finely ground mill tailings, which were historically discharged directly into a local stream. The discharge of metal-rich tailings often overwhelmed the sediment-transport capacity of a stream, resulting in aggradation of the streambed and floodplain (Bradley and Cox, 1986; James, 1989; Moore et al., 1989; Nimick, 1990). Long after mining has ceased, or mining practices have been altered, metals stored on the floodplain may continue to enter the stream via cut-bank erosion and groundwater inputs (Axtmann et al., 1990). Metals from waste rock dumps and tailings ponds may also enter the stream through physical erosion and geochemical inputs as well. A lack of sediment baseline data in historic mining districts makes it difficult to quantify the increase in the metal load and set realistic remediation goals. In the absence of any baseline data arbitrarily set remediation goals may be subject to protracted legal debate as some argue that the cleanup goals are too stringent, while others argue they are not stringent enough. There is a need for an accepted method of determining pre-mining conditions in stream sediments in order to set realistic remediation goals and quantify the increased metal load to stream sediments.

Recent work has addressed the problem of determining the natural background geochemistry of water in mined areas (Runnels et al., 1992), but not of sediment. Water geochemistry is of particular interest in areas subject 
to acid-mine drainage, where high concentrations of metals are transported away from the site in the solute phase (Filipek et al., 1987; Eychaner, 1991). At non-acid producing sites the downstream transport of metals is primarily in the sediment load due to the low solubility of metals in water at neutral or higher pH (Benjamin and Leckie, 1981; Forstner, 1982). Even in streams receiving acid-mine drainage, the solute metal load is rapidly precipitated or adsorbed onto sediment as the $\mathrm{pH}$ rises to neutral, usually within a few kilometers of the source (Davis and Leckie, 1978; Pagenkopf and Cameron, 1979). From this point on, the problem primarily becomes one of sediment transport, rather than aqueous geochemistry. However, the sediment-bound metal load receives much less attention even though it is generally responsible for the majority of downstream transport, and can have longlasting effects on the aquatic biota (Gibbs, 1973; Jenne and Luoma, 1977; Feltz, 1980; Giddings, 1983; Axtmann et al., 1990).

It is important to establish the nature of the downstream dispersion of metal anomalies prior to mining in order to help quantify the impact of mining and set realistic remediation goals. This can be accomplished by modeling the downstream dispersion of both natural and anthropogenic metal anomalies by dilution mixing with un-enriched tributary sediments. This type of modeling allows the calculation the downstream dilution curves, commonly referred to as dispersion trains, observed in stream sediments. This paper presents a method to model the dispersion trains of metal anomalies both before and after mining. This information can then be used to quantify the increased metal load to stream sediments and help set realistic remediation goals in contaminated river basins. 


\section{Model Development}

The conceptual basis for modeling the dispersion trains of natural and anthropogenic metal anomalies requires an understanding of the processes governing the downstream dispersion of metals. Prior to mining, an ore deposit weathers and erodes naturally, contributing metal-rich sediment into the local drainage. Metal-rich sediment is quickly diluted by un-enriched tributary sediments, attenuating the anomaly a short distance downstream. Even the largest ore deposits rarely have dispersion trains detectable more than 10-20 kilometers downstream, a fact well documented in the exploration geochemistry literature (Bradshaw, 1975; Bogoch and Brenner, 1977; Lovering and McCarthy, 1978; McLaurin, 1978; Bussey et al., 1993). Exploration geochemists studying dispersion trains first realized that the downstream dispersion of naturally occurring metal anomalies was primarily governed by dilution mixing with tributary sediments.

Exploration geochemists developed an equation to predict the size of an undiscovered anomaly based on an anomalous stream sediment sample. The equation calculates the product of the area and grade of the anomaly based on the concentration of an anomalous sediment sample collected downstream from the anomaly. This equation can easily be reversed and used to calculate the concentration of a particular sediment sample based on the area and grade of an upstream anomaly. The equation is based on the concept that the concentration of metal at a particular point in a stream represents steady-state mixing of sediments of anomalous and background concentrations eroded in the upstream basin. If a few simplifying assumptions are made, the metal concentration of a sediment sample can be related mathematically to the sum of the relative portions of basin area at background and anomalous concentrations. The assumptions are: 1 ) there is a uniform average erosion 
rate over the entire basin, 2) there is a single source of anomalous sediment in the basin, 3) the metal behaves conservatively in the river sediment, and 4) the sediment sample represents steady-state mixing of tributary sediments. These assumptions allow the units of mass and time (erosion rate) to be removed from the equation, leaving only units of area and concentration, where area conceptually represents a quantity of sediment. The resulting formula relates the metal concentration of a sediment sample to the sum of the relative portions of background and anomalous area (Hawkes, 1976; Marcus, 1987):

$$
[M e]_{l o n}=C_{b} \frac{A_{t}-A_{o}}{A_{\imath}}+C_{o} \frac{A_{o}}{A_{t}}
$$

Where $[M e]_{k m}$ is the sediment metal concentration at a particular river kilometer, $C_{b}$ is the average background concentration of the basin, $A_{t}$ is the total area of the basin upstream from the sample location, $A_{O}$ is the area of the surface anomaly of the ore deposit, and $C_{O}$ is the concentration of the surface anomaly of the ore deposit. This equation and its assumptions have been found to represent the natural dispersion trains of elements such as lead and copper in climates ranging from arid to tropical. This equation has also been used to aid in the interpretation of data from stream sediment surveys conducted for exploration (Meyer et al., 1979).

Equation 1 can closely approximate the dispersion trains of undisturbed ore deposits but cannot account for the additional input of metals resulting from mining activities. Large-scale metal extraction generates large quantities of waste rock and finely-ground tailings. Metals may be released from these wastes by physical or geochemical processes, resulting in an exaggerated input of metal-rich sediment to a stream. This exaggerated input can be thought of as an amplification of the natural erosion rate of the ore 
deposit, or since the model assumes a uniform erosion rate, the additional metal input can be represented as an increase in the area of the anomaly. A new term, referred to as the exaggerated area $\left(A_{X}\right)$, is used to account for the increased quantity of metal-rich sediment entering a stream. The increased sediment input often contains a higher concentration of metal than the natural input because the ore brought to the surface during mining is usually of a higher grade than the overlying surface material (Coolbaugh, 1979; Fleming and Neale, 1979). A second term, referred to as the exaggerated concentration $\left(C_{X}\right)$, is required to account for any increase in metal concentration of the anomalous sediment due to mining. Each of the new terms is distinctive and representative of actual field parameters. When the exaggerated area and exaggerated concentration are considered, equation 1 can be modified as follows to account for metal inputs from mining/milling:

$$
[M e]_{l o n}=C_{b} \frac{A_{1}-A_{o}}{A_{1}+\left(A_{x}-A_{o}\right)}+C_{x} \frac{A_{x}}{A_{t}+\left(A_{x}-A_{b}\right)}
$$

Where the new terms $A_{\boldsymbol{X}}$ and $C_{\boldsymbol{X}}$ represent the exaggerated area and exaggerated concentration, respectively, of the metal anomaly due to mining activities (Figure 1). These parameters represent an amplified anomaly that includes the anthropogenic increases in quantity and concentration of anomalous sediment. Equation 2 contains the following modifications: 1) $C_{X}$ was substituted for $\left.C_{O}, 2\right) A_{X}$ was substituted for $A_{O}$ in the numerator of the right-hand portion of the equation, and 3) the exaggerated area not already included in $A_{t}$ was added to the denominators of both portions of the equation. The total area had to be increased in order to account for the increased input of sediment. Mining activities result in an increased sediment load that cannot be explained by uniform erosion of the anomaly and basin. $A_{X}$ is used to 
account for the increased sediment load; $A_{X}$ represents the area required to generate the increased quantity of anomalous sediment at the erosion rate assumed to apply in the basin. When $A_{X}$ and $C_{X}$ are set equal to $A_{O}$ and $C_{O}$ equation 2 reverts to equation 1 . With the addition of the terms $A_{X}$ and $C_{X}$, equation 2 can now account for varying amounts of anthropogenic input resulting from mining activities.

Increasing either $A_{X}$ or $C_{X}$ alters the shape of the dispersion curve in different ways. Figure 2 shows the effects of increasing $A_{X}$ over three orders of magnitude. As $A_{X}$ increases the curvature of the dispersion train decreases, but the origin is not altered. On the other hand, as $C_{X}$ increases the origin moves upward but the lower end of the curve is not altered as dramatically (Figure 3). Holding the product of $A_{X} C_{X}$ constant but altering the individual values also results in an alteration of the shape of the mixing curve, a result that may not be immediately apparent from casual observation of equation 2 . The downstream portion of the curve remains undisturbed, but the origin rises and falls with $C_{X}$ (Figure 4). As a result, there will be a unique solution of $A_{X}$ and $C_{X}$ that provides the closest approximation of the model to an actual dispersion train. 


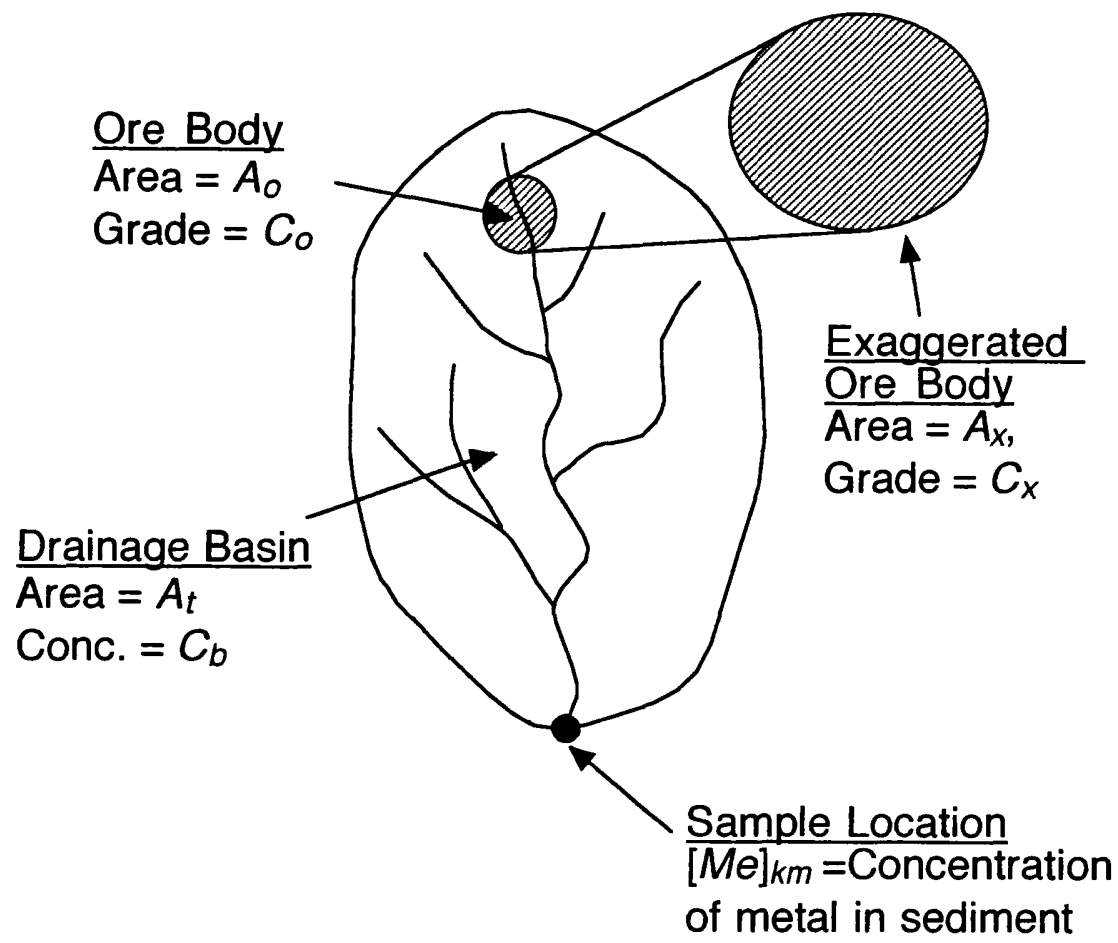

Figure 1. Visual definition of terms used in equations 1 and 2. 


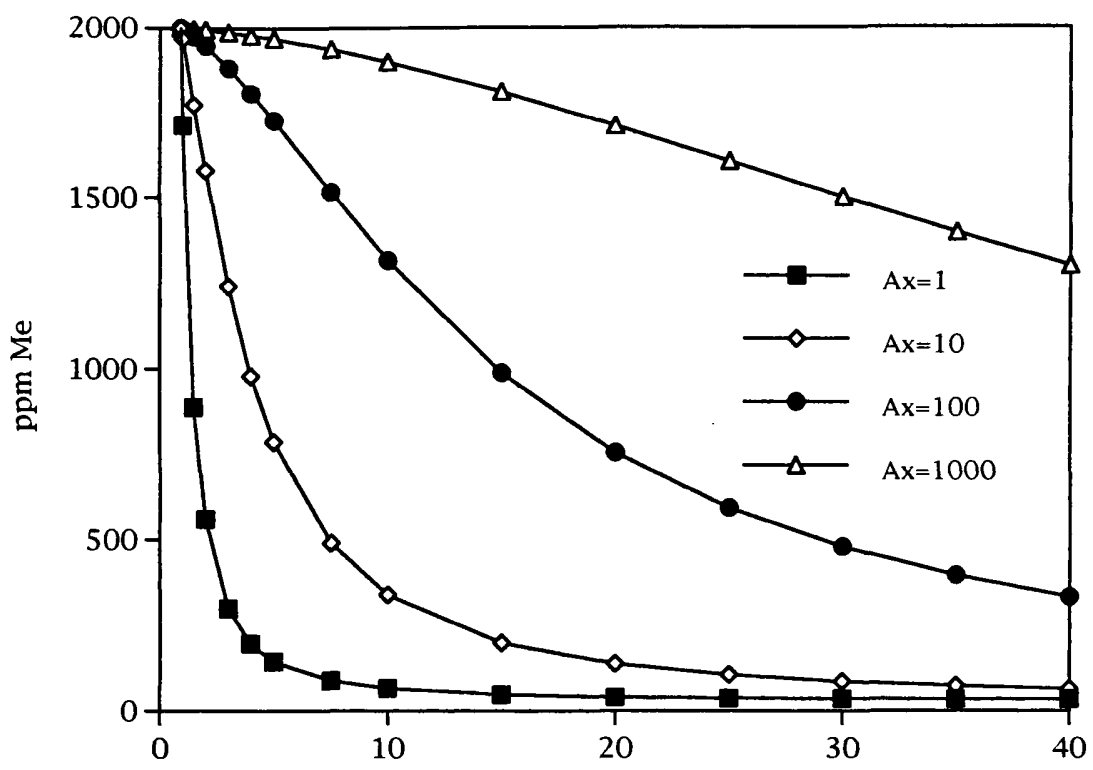

Kilometer Downstream

Figure 2. Effects on the dispersion curve of increasing $A_{X}$ three orders of magnitude. 


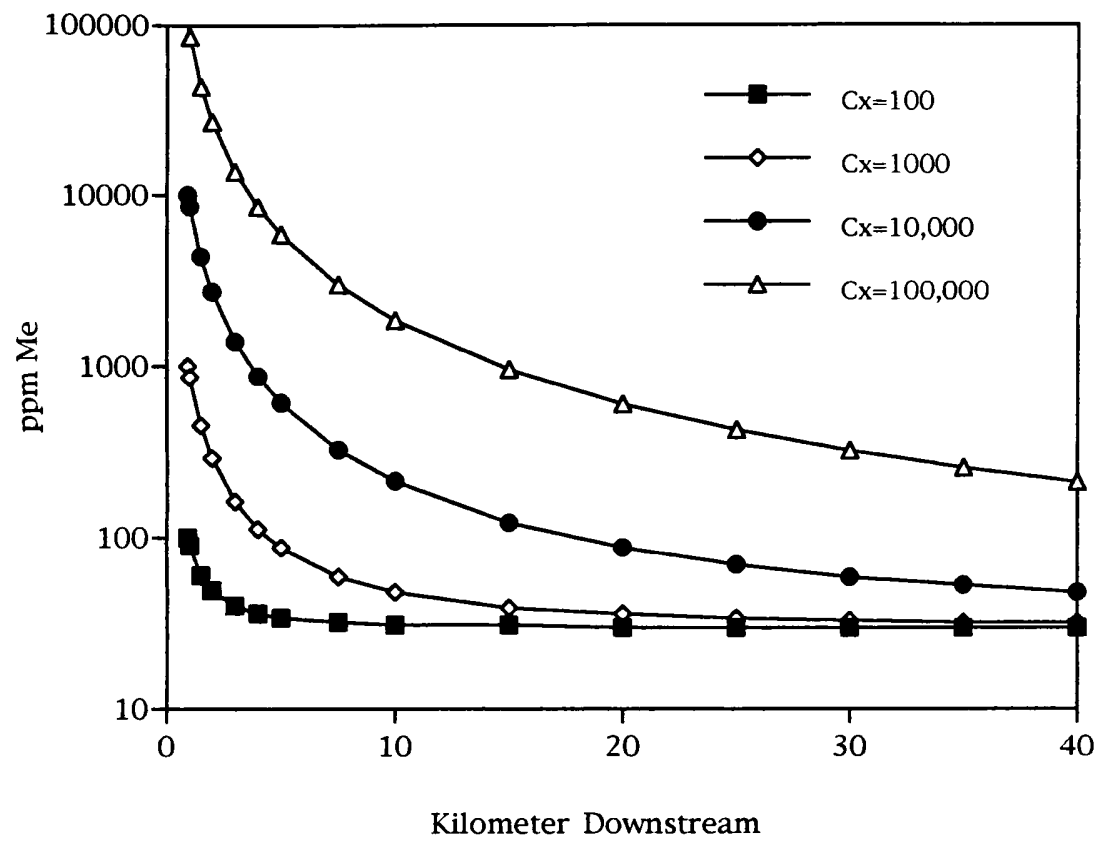

Figure 3. Effects on the dispersion curve of increasing $C_{\boldsymbol{X}}$ three orders of magnitude. 


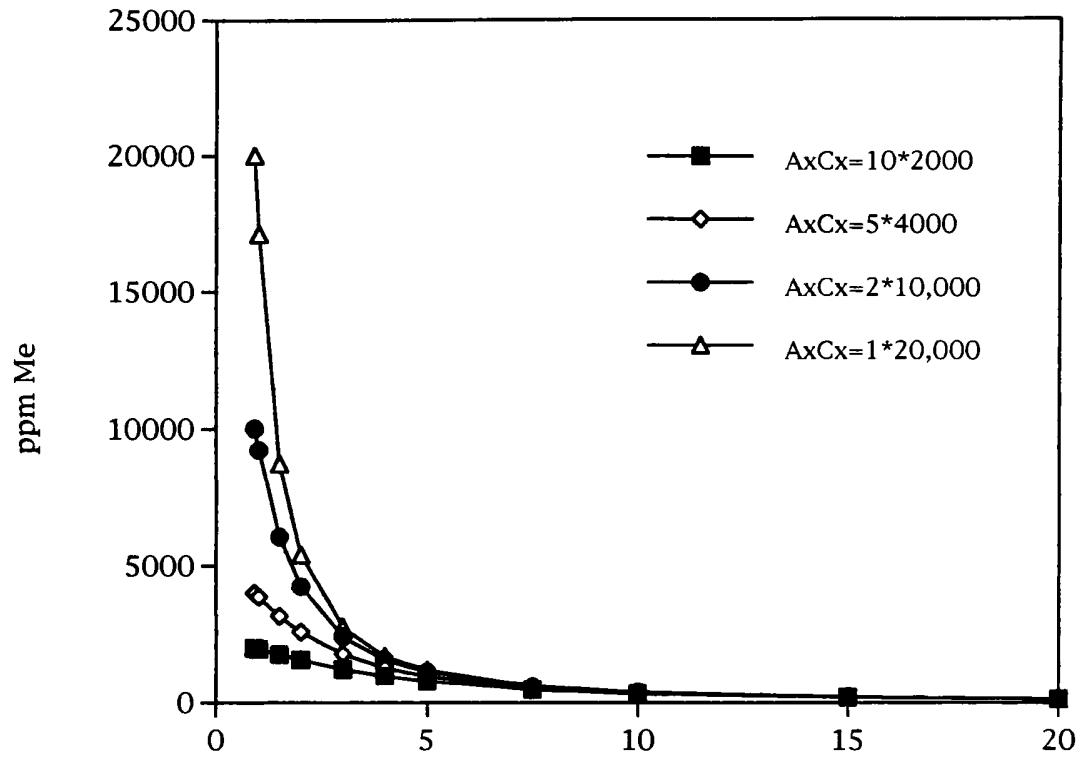

Kilometer Downstream

Figure 4. Effects on the dispersion curve of holding the product of $A_{X}$ and $C_{X}$ constant at 20,000 while varying the individual values. 


\section{Model Application}

Methods

The model was applied to several data sets from streams with both mined and unmined ore deposits in their headwaters to see how accurately the model approximates actual dispersion trains. Data sets from several Montana streams and rivers were used along with data sets from the exploration literature. Fine-grained sediment samples were chosen for field sampling in order to minimize grain size effects on metal concentration caused by the tendency of trace metals to partition into the fine-grained sediment fraction (Chao and Theobald, 1976; Horowitz and Elrick, 1987). Sediment samples were wet sieved in situ through a $63 \mu \mathrm{m}$ mesh using ambient stream water. Samples were stored on ice and dried immediately upon returning to the lab. The dried sediment was powdered and digested using a microwave aqua-regia technique. Multi-element analysis was performed by inductively coupled argon plasma spectroscopy (ICP) and modeling was performed in a spreadsheet.

The first step in modeling a dispersion train is the determination of the measurable model parameters. All of the parameters except $A_{X}$ can be measured with some degree of accuracy. Basin area $\left(A_{t}\right)$ can be measured accurately from maps, or an equation can be used to generate area for any desired river kilometer. There is an established relationship between river kilometer and basin area (Figure 5) that has been shown to apply to all drainages, regardless of geologic control (Hack, 1957). The area equation was used to allow greater model flexibility. The area of mineralization $\left(A_{O}\right)$ can be measured accurately from geologic maps of the ore deposit. Tributary sediment samples can provide an average value for the background concentration in the basin $\left(C_{b}\right)$, and mining reports can provide information on $C_{O}$ and $C_{X}$. It may also be possible to measure $C_{X}$ directly by sampling 
tailings deposits or contaminated tributaries within the source. Once the measurable parameters are set, a non-linear least squares routine can be employed to provide the best-fit value for $A_{X}$.

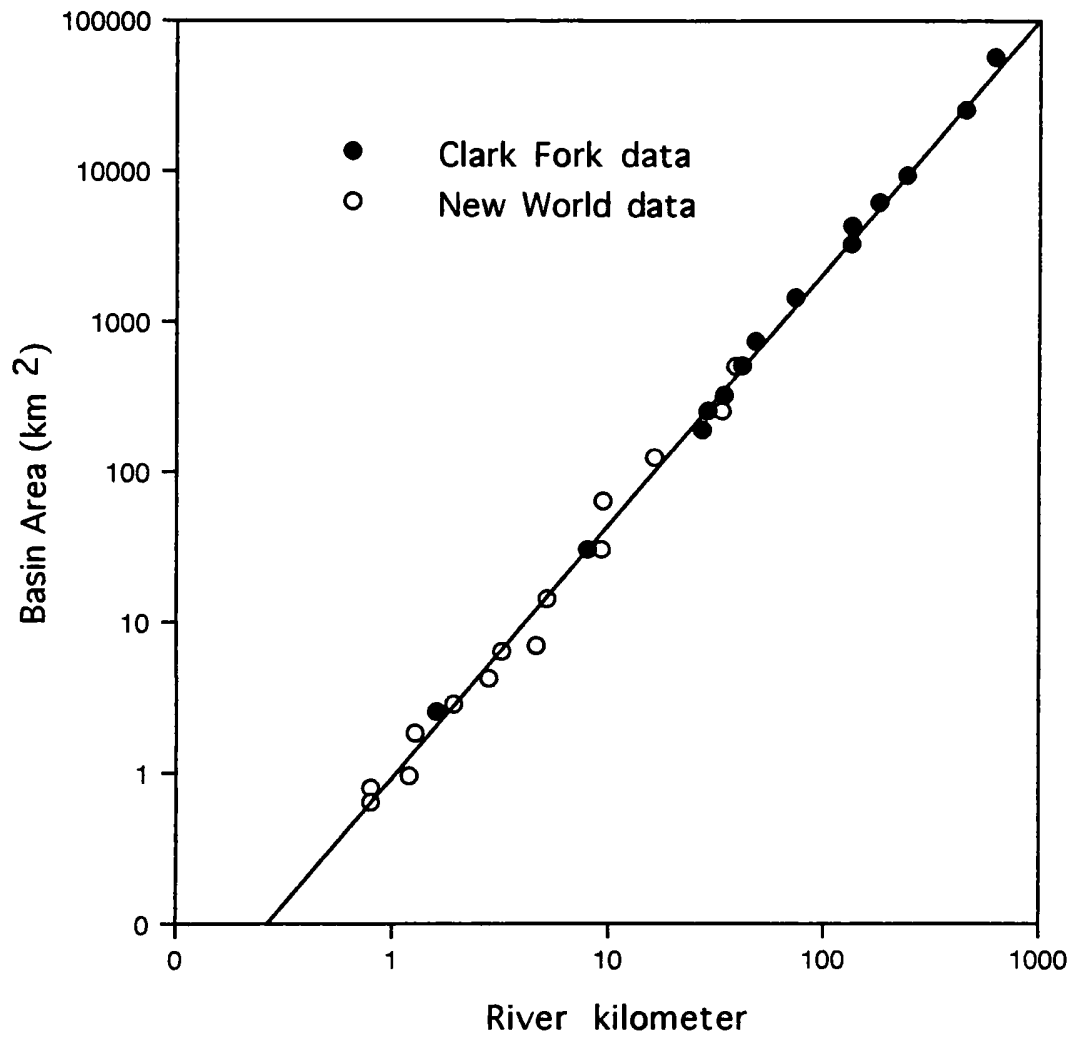

Figure 5. Area vs. river kilometer data from the Clark Fork River basin in western Montana, and two small basins in the New World mining district outside Cooke City, Montana. Relationship shown is almost identical to that found to hold true for all types of drainages, regardless of geologic control (Hack, 1957). 
Model Application

Results

The model was first applied to data sets from streams draining unmined ore deposits in order to show that it can accurately approximate the dispersion trains of undisturbed anomalies. The various parameters of the anomalies were determined and entered into the model. The resulting curves were found to closely approximate the dispersion trains observed in sediment data from four undisturbed deposits (Figure 6). Similar results were reported in other studies (Hawkes, 1976; Meyer et al., 1979; Marcus, 1987).

The model was then applied to streams and rivers with disturbed ore deposits in their drainages to see if it could accurately represent exaggerated anomalies. In each of the drainages, tailings from historic mining act as a continuing source of metals, providing strong exaggerated anomalies. Figure 7 shows model fits to four contaminated rivers. In each case, an acceptable fit to the sediment data was achieved using the measured parameters and a bestfit $A_{X}$, showing that the model is capable of approximating the dispersion trains of highly disturbed anomalies. After the various model parameters have been determined, the pre-mining dispersion train can be calculated and the exaggeration of the anomaly quantified.

An idealized pre-mining dispersion train can be calculated by setting $A_{X}$ equal to $A_{O}$ and $C_{X}$ equal to $C_{O}$. The resulting curve should closely approximate the natural dispersion train of the deposit prior to mining, as shown previously in the model fits to unmined ore deposits. Idealized premining dispersion trains are shown for four contaminated Montana streams and rivers in Figure 8. The lengths of the calculated dispersion trains are within the range of reported dispersion trains for undisturbed ore deposits. Prior to mining, metal levels greater than twice the regional background 
rarely extend more than 20 kilometers downstream, even for the largest ore deposits (Bradshaw, 1975; Bogoch and Brenner, 1977; Lovering and McCarthy, 1978; McLaurin, 1978; Bussey et al., 1993). By contrast, metal levels of twice the regional background were found to extend $500 \mathrm{~km}$ downstream in one of the contaminated river systems examined (Figure 8A). When the parameters of an anomaly are known both before and after mining it is possible to actually quantify the exaggeration of the anomaly.

There are various ways to conceptualize and quantify the exaggeration of an anomaly, the most obvious being the ratio of the exaggerated anomaly to the natural anomaly. This ratio is referred to as the enrichment factor $\left(E_{f}\right)$ where $E_{f}$ is defined as follows:

$$
E_{f}=A_{X} C_{X} / A_{O} C_{O}
$$

The enrichment factor is a dimensionless term expressing how many times the natural anomaly the exaggerated anomaly represents. The enrichment factor provides a relative measure of the increase in the metal load to stream sediments. Enrichment factors ranged from 70-1400 for the exaggerated anomalies examined. The exaggeration of copper and zinc anomalies was found to be as much as two orders of magnitude greater than the exaggeration of the lead anomaly for the same deposit, a result attributed to the greater geochemical mobility of copper and zinc out of the source material. The enrichment factor quantifies relative enrichment, but does not quantify the magnitude of the exaggerated anomaly. Another term is required in order to quantify the magnitude of the exaggerated anomaly.

A quantitative value representing the magnitude of an anomaly can be calculated by taking the product of the area and concentration of the anomaly. This quantity is referred to as the areal grade, a term similar to the gradetonnage term used to describe ore reserves, only two dimensional. The areal 
grade $\left(G_{O}\right)$ and exaggerated areal grade $\left(G_{X}\right)$ are defined as the product of the area and concentration of the anomaly before and after mining, respectively. $G_{O}$ represents the areal grade of an anomaly prior to mining:

$$
G_{O}=A_{O} C_{O}
$$

$G_{X}$ represents the exaggerated areal grade of the anomaly after mining:

$$
G_{\mathrm{X}}=A_{\mathrm{X}} C_{\mathrm{X}}
$$

The areal grades conceptually represent sediment metal loads, all that is needed to convert them into actual metal loads is the average erosion rate of the basin. Figure 9 shows the areal grades for a number of undisturbed ore deposits, as well as the exaggerated areal grades for four of the disturbed anomalies examined. Exaggerated areal grades ranged from 300-1,500,000 $\mathrm{km}^{2} \mathrm{ppm}$ for the disturbed anomalies examined. In contrast, the areal grades for a number of naturally occurring anomalies ranged from only $0.5-11,000$ $\mathrm{km}^{2} \mathrm{ppm}$. In three out of the four cases examined, the exaggerated anomalies exceeded the range of naturally occurring anomalies by as much as two orders of magnitude. The areal grades and enrichment factor provide two ways to quantify the impact of mining on stream sediments. 


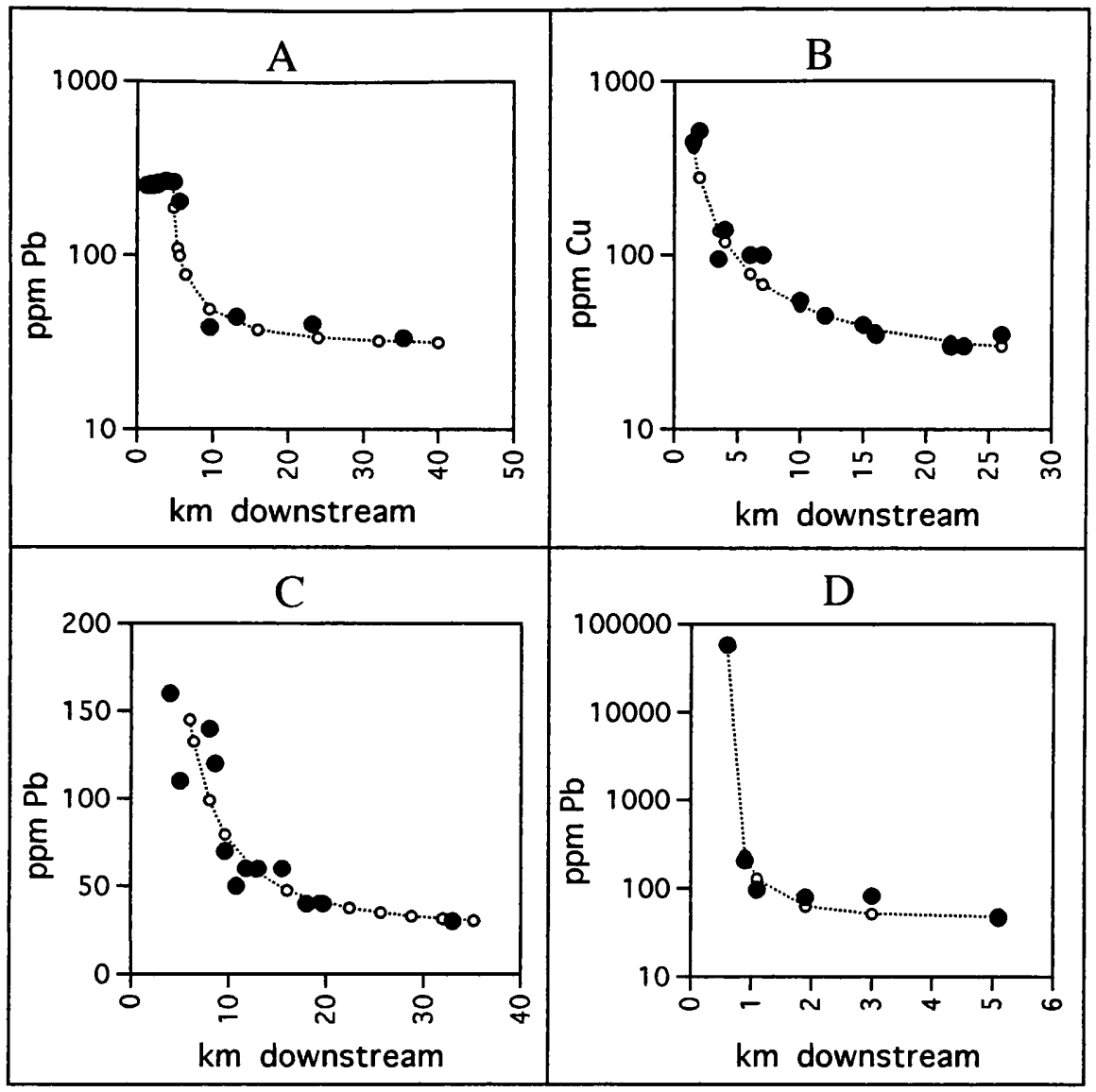

Figure 6. Model fits to relatively undisturbed ore deposits shown by open circles with dashed lines, field sediment data shown by solid circles. (A) Model fit to sediment data from Miller Creek, draining a large sulfide deposit at Cooke City, Montana. (B) Model fit to sediment data from a stream draining the Rosemont copper porphyry deposit, Arizona (Hawkes, 1976). (C) Model fit to sediment data from a stream draining the Gamsberg stratiform zinc deposit, South Africa (McLaurin, 1978). (D) Model fit to sediment data from Ivanhoe Creek, draining a small lead prospect in the Anaconda-Pintlar Wilderness, Montana. 


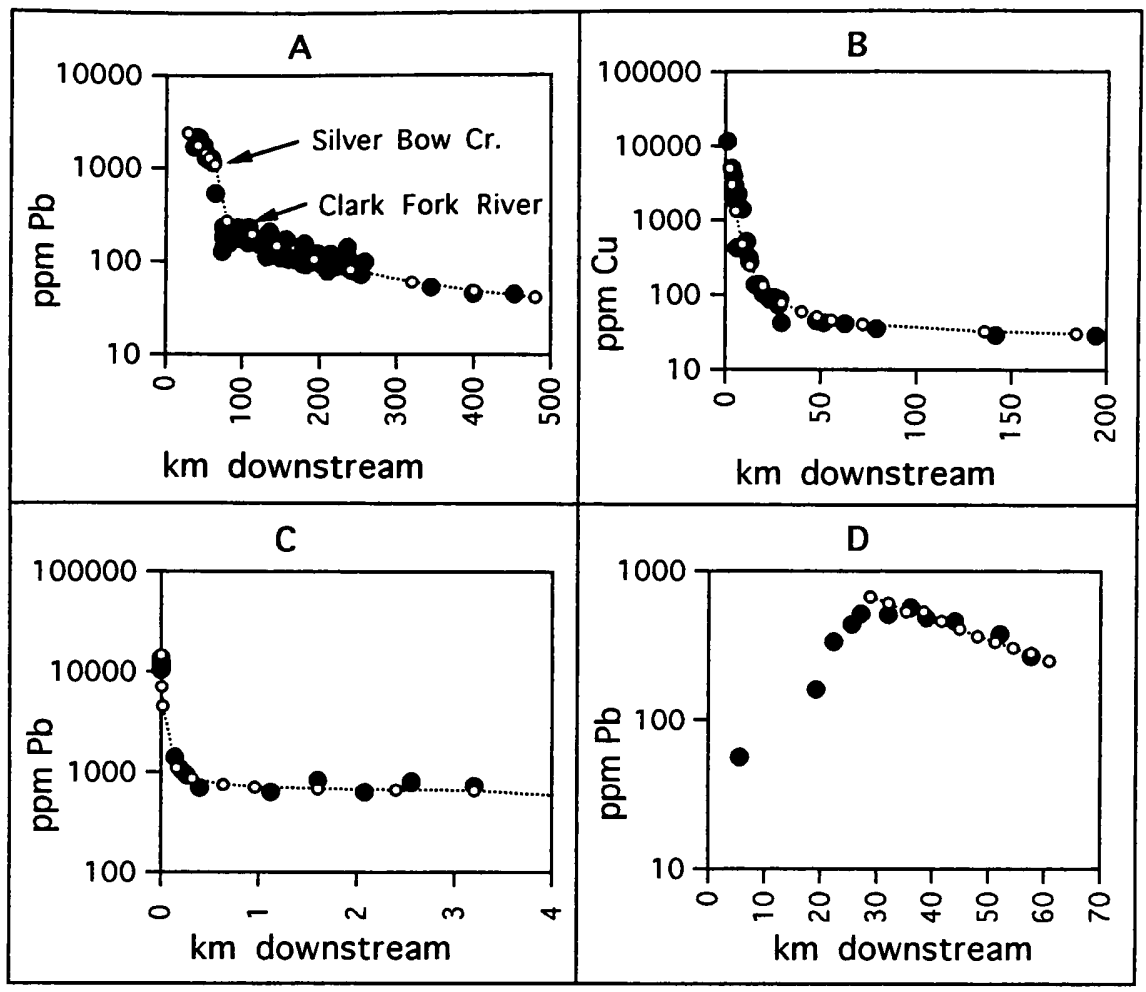

Figure 7. Model fits to contaminated rivers shown by open circles with dashed lines, field data shown by solid circles. (A) Model fit to Silver Bow CreekClark Fork River, headwaters host a very large $\mathrm{Cu}$ porphyry deposit at Butte, Montana with a 125 year mining history (Meyer et al., 1968). Silver Bow Creek, above tailings ponds, $E_{f}=156, G_{X}=1,556,000 \mathrm{~km}^{2}$ ppm Pb; Clark Fork River, below tailings ponds, $E_{f}=70, G_{X}=700,000 \mathrm{~km}^{2} \mathrm{ppm} \mathrm{Pb}$. Values obtained using an estimated $A_{O}$ of $33 \mathrm{~km}^{2}$ and $C_{O}$ of $300 \mathrm{ppm} \mathrm{Pb}$. (B) Model fit to the Blackfoot River, Montana, headwaters contain the Heddleston mining district where Ag$\mathrm{Pb}-\mathrm{Zn}$ veins were mined in the early 1900s (McClernan, 1983; Moore et al., 1991). $E_{f}=750, G_{X}=27,600 \mathrm{~km}^{2} \mathrm{ppm} \mathrm{Cu}$. Values obtained using an estimated $A_{O}$ of $0.004 \mathrm{~km}^{2}$ and $C_{O}$ of $10,000 \mathrm{ppm} \mathrm{Cu}$. (C) Model fit to Dunkleberg Creek, Montana, draining a limestone hosted $\mathrm{Ag}-\mathrm{Pb}-\mathrm{Zn}$ vein mined from 1884-mid 1900s (Pardee, 1917; Johnson, 1994), $E_{f}=500, G_{X}=256 \mathrm{~km}^{2} \mathrm{ppm} \mathrm{Pb}$. Values obtained using an estimated $A_{O}$ of $0.00003 \mathrm{~km}^{2}$ and $C_{O}$ of $20,000 \mathrm{ppm} \mathrm{Pb}$. (D) Model fit to Flint Creek, Montana. The Phillipsburg mining district, site of extensive Mn vein mining in the early to mid 1900s, lies midway down the drainage (Goddard, 1940; Mohsen, 1969), $E_{f}=325, G_{X}=233,000 \mathrm{~km}^{2} \mathrm{ppm} \mathrm{Pb}$. Values obtained using an estimated $A_{O}$ of $0.026 \mathrm{~km}^{2}$ and $C_{O}$ of $28,000 \mathrm{ppm} \mathrm{Pb}$. 


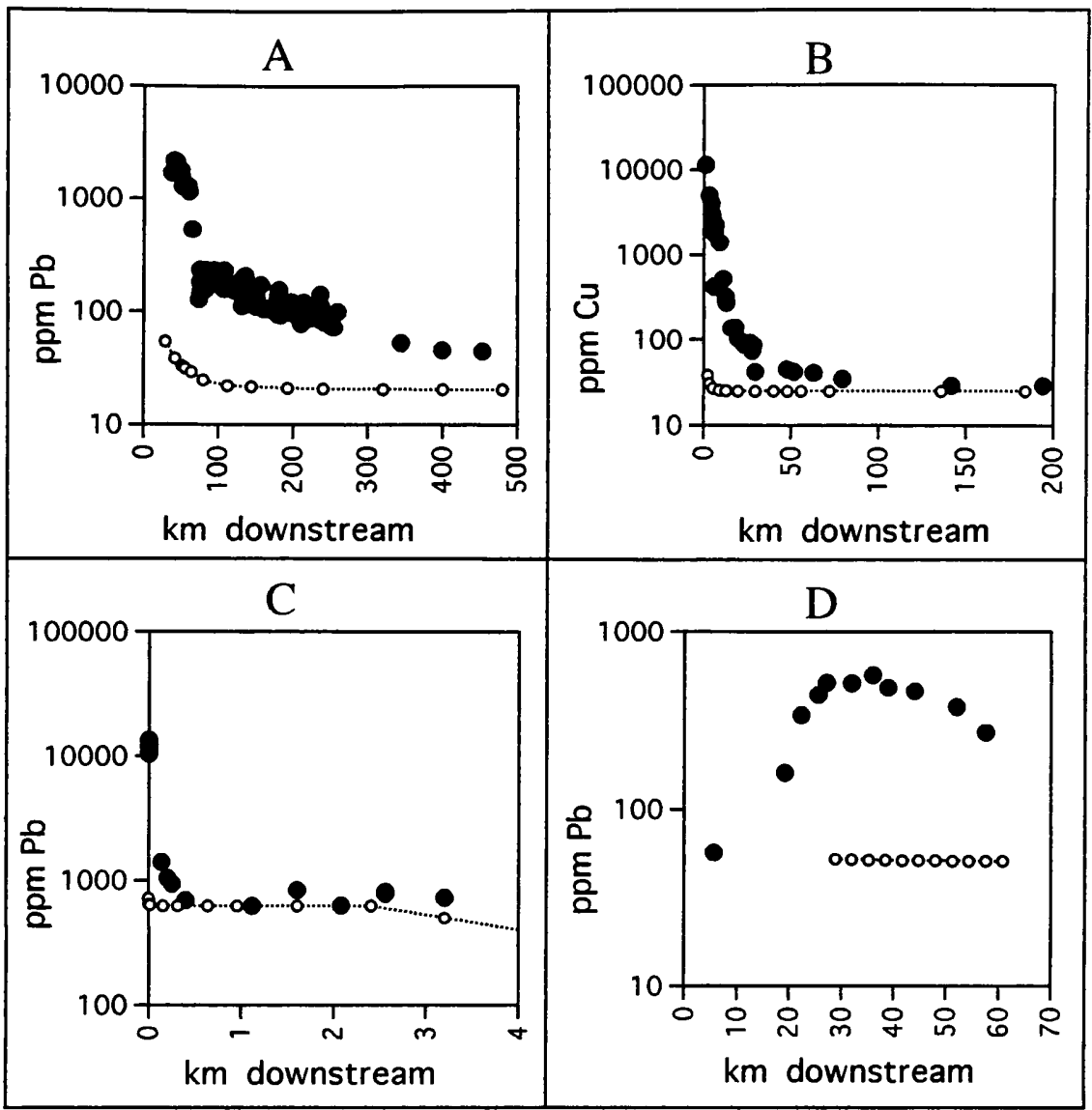

Figure 8. Calculated pre-mining dispersion curves shown by open circles with dashed lines, field data shown by solid circles. (A) Silver Bow Creek/ Clark Fork River; metal levels of twice background calculated to have originally extended only $15 \mathrm{~km}$ downstream from the ore deposit at Butte, Montana. (B) Blackfoot River; metal levels greater than twice background calculated to have occurred only in the immediate vicinity of the vein deposits with no significant dispersion train present. (C) Dunkleberg Creek; mined vein calculated to have been insignificant by itself, but high regional background in the mineralized zone dominated the downstream trend. (D) Flint Creek; due to significant area of drainage upstream from the deposit, calculated metal levels in Flint Creek barely influenced at all by the veins at Phillipsburg. 


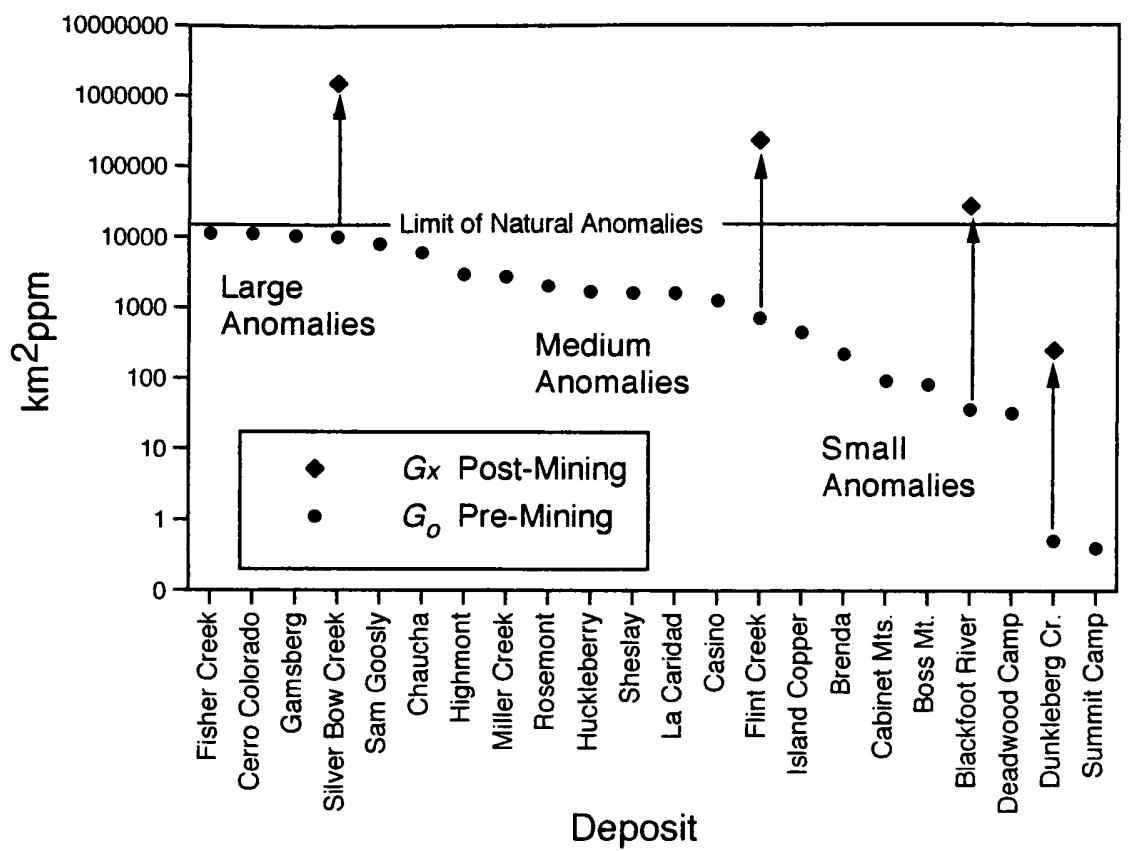

Figure 9. Pre-mining areal grades of the surface anomalies of a number of ore deposits showing the range and distribution of natural anomalies (Bradshaw, 1975; Hawkes, 1976; Lovering and McCarthy, 1978; McLaurin, 1978; Coolbaugh, 1979). Arrows show the amplification of the natural anomalies due to mining activities for the four contaminated streams and rivers examined. Three of the river basins presently contain metal anomalies that exceed the range of naturally occurring anomalies by as much as two orders of magnitude. 
Discussion

Estimation of the pre-mining dispersion train and quantification of the exaggerated anomaly are important pieces of information relative to the understanding, litigation, and remediation of contaminated rivers around the world. An idealized pre-mining dispersion train allows realistic remediation goals to be set. Without this type of data there is a risk that unrealistic remediation goals may be implemented. It would be virtually impossible to attain metal concentrations below those of the estimated pre-mining dispersion train. The pre-mining dispersion train also allows the quantification of the exaggerated anomaly resulting from mining. The exaggeration of an anomaly can be quantified using the enrichment factor and the areal grades. Some small deposits may be found to be exaggerated several hundred times but still be well within the range of naturally occurring anomalies, while some large deposits with a long history of mining may be found to far exceed the range of naturally occurring anomalies. This type of information is useful for assigning cleanup priorities and categorizing impacted sites based on the extent of contamination.

The accuracy of the calculated pre-mining dispersion train and the quantification of the amplification of an anomaly are primarily limited by the accuracy of the various model parameters and the validity of the model assumptions in a particular drainage. The parameters $A_{t}, A_{O}$, and $C_{b}$ can be measured accurately, but $C_{O}, C_{X}$, and $A_{X}$ may have varying degrees of uncertainty associated with them. The concentration of the exaggerated anomaly $\left(C_{X}\right)$ can be limited to the range between the highest observed sediment concentration and the grade of the processed ore. Values for $C_{\boldsymbol{X}}$ may also be found in mining reports that include the grade of tailings, or it may be possible to collect samples directly from tailings deposits. Any chance to 
directly sample $C_{O}$ has usually been obliterated by mining, so an estimation must be relied upon.

The original concentration of the surface anomaly $\left(C_{O}\right)$ is the most difficult parameter to determine. A mined ore deposit generally has detailed records of the grade and tonnage of ore mined, but the surface material is rarely described in detail. It may then be necessary to estimate a likely concentration for $C_{O}$ from data that is available. Some published case histories provide the results of stream sediment surveys, soil and rock surveys, and core drilling for individual deposits (Leggo, 1977; Coolbaugh, 1979; Fleming and Neale, 1979; Ribeiro et al., 1979; Friedrich et al., 1984; Learned et al., 1985). Such case studies provide insight into the probable surface conditions at similar deposits in similar geologic terrain. The concentration of a residual soil anomaly depends on the geochemical traits of the metal in question as well as local soil and climate characteristics. Fast erosion rates usually result in higher concentrations near the surface than slower rates. Strong residual soil anomalies are often present over deposits in tropical climates, even for more mobile elements such as copper, despite the deep weathering encountered (Mosser and Zeegers, 1988). The weakest surface anomalies often occur where erosion rates are low and meteoric water infiltrates the ground carrying metals down to a supergene enrichment zone above the main ore stock. Despite these general trends observed in the case studies, each deposit is unique and care must be taken not to generalize too greatly about probable values for $C_{O}$ without fully investigating all available data on a deposit. Regardless of the geologic setting, the range of concentrations available for $C_{O}$ is limited by the ore grade at the high end, and the regional background at the low end. Within these bounds a reasonable estimation, or range of estimations, 
must be determined. Fortunately, small variations in $C_{O}$ do not dramatically effect the shape of the calculated dispersion train.

Another factor affecting the accuracy of a model fit is the validity of the model assumptions in a particular drainage. One such assumption is that the metal chosen for modeling remains conservative within the sediment. The reactivity of a metal under surface geochemical conditions determines the validity of this assumption for a particular metal. Less reactive elements such as lead are thought to primarily enter stream sediments through physical erosion, while more mobile elements such and copper and zinc usually have a substantial geochemical input as well. Tailings and waste rock deposits often contain geochemical conditions favorable to the release and groundwater transport of more reactive metals, resulting in the precipitation and adsorption of metals onto stream sediments at the groundwater-surface water interface (Blowes and Jambor, 1990; Callender et al., 1991). Once precipitated or adsorbed onto stream sediments many metals, such as lead, copper and zinc, generally behave conservatively under surface water conditions (Gibbs, 1973; Meyer et al., 1979; Forstner, 1982; Horowitz and Elrick, 1987). Both lead and copper appeared to remain conservative in the stream sediments modeled, while zinc was noted to be somewhat reactive under surface conditions, but still conservative enough for modeling. Manganese was found to be too reactive for modeling.

The most commonly encountered violation of the assumption of conservation occurs in streams with acid drainage in their headwaters. In streams with acidic headwaters, significant transport of metals occurs in the solute fraction until the $\mathrm{pH}$ is neutralized sufficiently to allow precipitation and adsorption of metals onto the sediment load (Davis et al., 1991). This usually takes place within the first few kilometers from the source, but the 
model cannot accurately account for the sediment metal concentrations within the acidic reach (Figure 10A). The model does not allow fractionation between the solute and sediment loads and is not representative when there is active feedback between the two, as is the case during neutralization of an acidic stream. The model could be expanded to include pH-based partitioning of metals between the solute and sediment loads, but the effect of $\mathrm{pH}$ on metals partitioning would be specific to each metal as well as to the geochemical environment of the river (Nordstrom, 1991; Smith et al., 1991). Accurate quantification of the new variables required would involve detailed investigation of the geochemical processes affecting each metal of interest, and would add great complexity in exchange for an increase in accuracy only in acidic reaches.

A less significant violation of the assumption of conservation may occur if river sediments stagnate for several months allowing the gradual transfer of metals from the sediment to the solute load. The assumption that a metal behaves conservatively is most representative when sediment is actively moving in the main channel and its tributaries. If sampling is carried out after an extended period of low water with little or no sediment transport, the observed dispersion train may be at a lower concentration than when sediment is being actively transported. To avoid this type of problem, active channel sediments should be sampled only during or soon after periods of sediment transport.

The opposite effect can result from the formation of hydromorphic anomalies caused by the direct precipitation and adsorption of metals onto stream sediment by groundwater input. This type of anomaly may form in certain stream reaches in mineralized or contaminated areas. If a hydromorphic anomaly forms in active stream sediments, the model will still 
be applicable, but when hydromorphic anomalies form in stagnant stream sediments with no active mixing or transport, the model may be unable to account for the magnitude of the anomaly. Interference from hydromorphic anomalies can also be minimized by sampling only during or shortly after periods of active sediment transport.

The assumptions of uniform erosion or uniform background can also affect the accuracy of a model fit, but the effects are scale-dependent. In large-scale basins spatial variability of the erosion rate or background concentration has little influence on the observed concentration of metals in stream sediments because the variations are averaged over a large area. However, in small-scale drainages spatial variability in the erosion rate and background value may influence the observed concentration of metals in sediments if the scale of observation is such that the spatial variations are significant. Variations in background can be corrected for in the model, but large variations in the erosion rate have the potential to cause deviations from the calculated dispersion train in small-scale drainages.

Another assumption affecting the accuracy of the model fit is that there is a single source of metal-rich sediment in the drainage. This assumption may not seem representative in some contaminated rivers where the primary source of metals is dispersed tailings deposited on the floodplain downstream from the mineralized zone. However, tailings stored on the floodplain of a river can mimic an upstream point source several decades after mining practices have been altered or mining has ceased. The concentrations of metals stored on the floodplain during periods of aggradation reflect the downstream trend in metals at the time of deposition since the same principles of downstream dilution applied when tailings were being actively discharged into the river. Cut-bank erosion and groundwater inputs can act as 
continuing sources of these metals (Hermann and Neumann-Mahlkau, 1985; Axtmann et al., 1990), mimicking an upstream point source. Eventually tailings stored on a floodplain are expected to exhaust themselves, but the time scale may be much greater than anticipated. For example, little or no overall change is seen in metal input over a period of several years in the Clark Fork River, despite it having been several decades since the construction of tailings ponds designed to prevent the downstream transport of metals. Given the quantity of tailings estimated to be stored on the Clark Fork River floodplain (Axtmann et al., 1990), a rough estimation is that it would take several thousand years to completely exhaust the metal supply stored on the floodplain at the current rate of sediment transport (Lambing, 1991). The metal supply stored on the floodplain is capable of maintaining the currently observed dispersion train the entire time.

The assumption of a single source of anomalous sediment may occasionally be violated by secondary anomalies. Secondary anomalies may alter the shape of the dispersion train, especially within the mineralized zone (Figure 10B). Some deposits, particularly stratabound or vein-type deposits, may be made up of several smaller anomalies rather than one large anomaly common in porphyry-type deposits. Multiple anomalies can be modeled starting at the downstream edge of the entire mineralized zone, or if desired, the additional sources can be incorporated into the model as additional terms using the same relative area principles the rest of the model works on. If the secondary source is of much lower magnitude than the primary source, it can often be ignored.

A less commonly encountered physical process capable of causing deviations from the calculated dispersion train may result from attempting to model metals transported in a dense mineral phase. Metals primarily 
transported in a dense mineral phase, such as tin in the mineral cassiterite, are subject to hydraulic effects that concentrate the mineral in certain stream reaches. Natural sluicing action in high gradient reaches has been shown to concentrate cassiterite to surprisingly high levels far downstream from the source (Yim, 1981; Fletcher et al., 1987). Accordingly, it is important to be aware of the phase a metal is transported in prior to modeling. Modeling difficulties may arise if metals are transported in a dense mineral or elemental phase, such as tin or gold. The best results will be achieved with metals that partition into the fine-grained sediment load, which is commonly the case (Meyer et al., 1979; Horowitz and Elrick, 1987). 


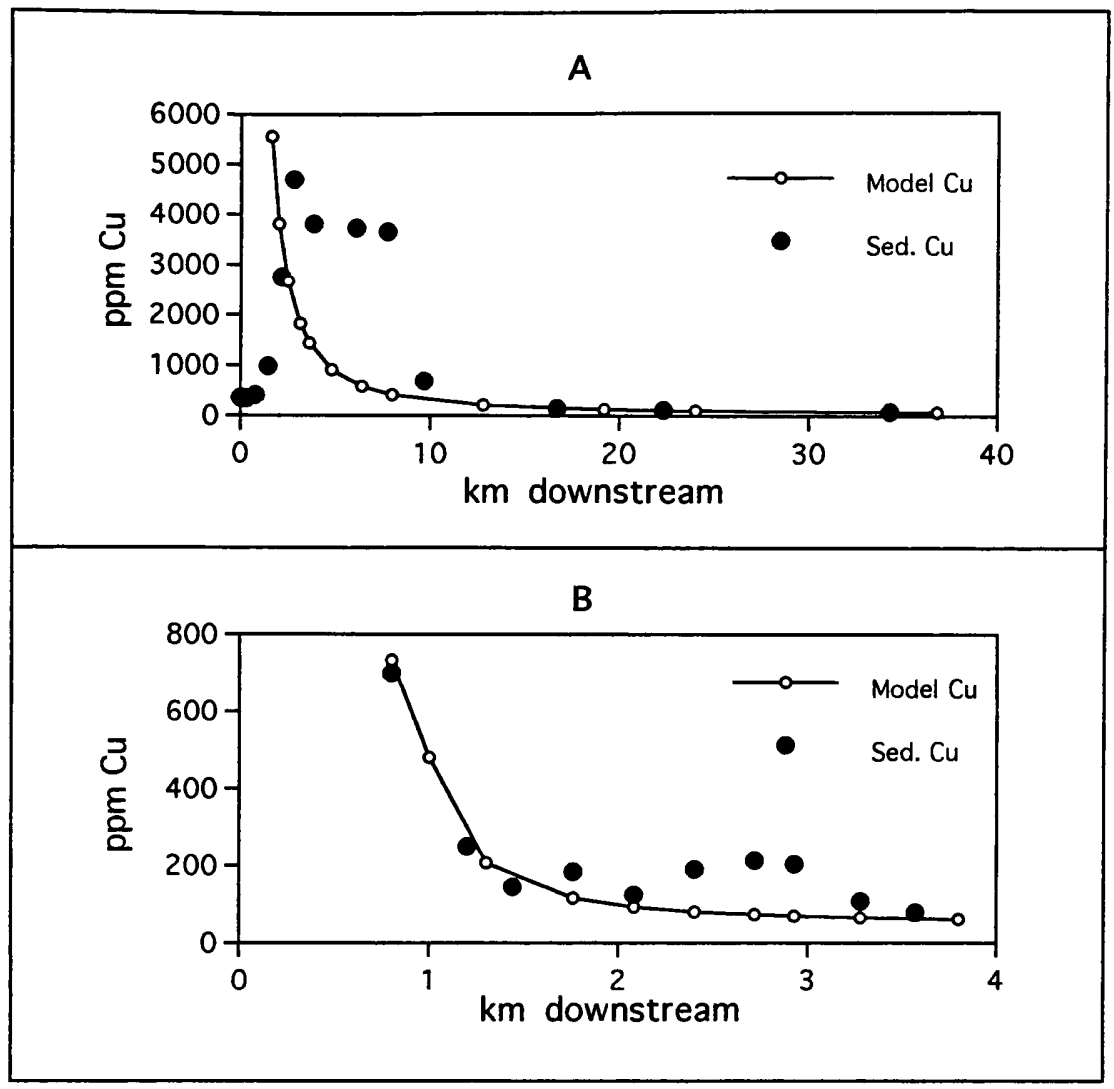

Figure 10. (A) Model fit to Fisher Creek in the New World district outside Cooke City, Montana. Historic mining of sulfide ore in the headwaters of Fisher Creek (Eyrich, 1969) was observed to be causing acid drainage. Stream water $\mathrm{pH}$ as low as three was measured in the headwaters of Fisher Creek.

Significant solute transport of metals occurs in the acidic reach causing a deviation of the field data from the model prediction. (B) Model fit to a small stream draining a stratabound $\mathrm{Cu}$ deposit in the Cabinet Mountain Wilderness (Cazes, 1981). Multiple outcrops of the deposit cause secondary anomalies resulting in deviations from the calculated mixing curve. 
Conclusion

The main goal of the dilution mixing model presented here is the accurate approximation of natural and exaggerated dispersion trains while maintaining simplicity and global applicability. Testing of the model showed it capable of providing reasonable approximations of natural and exaggerated dispersion trains in a variety of drainages. Model fits in drainages with no obvious violations of the assumptions were quite acceptable, and even in some of the drainages exhibiting violations of the assumptions model fits were still within reason. The model could be expanded to accommodate more commonly encountered violations of the assumptions, but the resulting model would be complicated and site-specific, which has been avoided in this paper. The model presented here is simple and widely applicable, yet still capable of accurately representing most natural and exaggerated dispersion trains. The ability of the model to provide acceptable fits in a variety of drainages emphasizes the dominance of dilution mixing and anomaly size as the primary variables governing the downstream dispersion of metal anomalies. The basic concepts of the dilution mixing model are supported by data from a variety of climates and the model is an important tool for determining pre-mining dispersion trains and quantifying the impact of mining.

Modeling the dispersion trains of metal anomalies before and after mining provides useful information relevant to the understanding, litigation, and remediation of contaminated rivers. The model allows the calculation of an idealized pre-mining dispersion curve, as well as relative and absolute quantification of the exaggerated anomaly resulting from mining activities. This information illustrates how mining activities can amplify metal anomalies well beyond their naturally occurring range, extending the environmental impact of increased trace metals far downstream. The model 
also provides a greater understanding of the processes affecting the downstream dispersion of metals in stream sediments. This increased understanding along with the pre-mining dispersion curve and quantification of the exaggerated anomaly can be use to prioritize contaminated sites and establish realistic remediation goals. The information provided by the model is relevant to the understanding, litigation, remediation, and regulation of metal contaminated rivers around the world. 
Axtmann, E. V., Cain, D. J. and Luoma, S. N., 1990, Distribution of trace metals in fine-grained bed sediments and benthic insects in the Clark Fork River, Montana. Clark Fork River Symposium, Missoula, MT, pp. 1-18.

Benjamin, M. M. and Leckie, J. O., 1981, Multiple-site adsorption of Cd, $\mathrm{Cu}, \mathrm{Zn}$, and $\mathrm{Pb}$ on amorphous iron oxyhydroxide. J. Colloid Interface Sci. 79(1): pp. 209-221.

Blowes, D. W. and Jambor, J. L., 1990, The pore-water geochemistry and the mineralogy of the vadose zone of sulfide tailings, Waite Amulet, Quebec, Canada. Appl. Geochem. 5: pp. 327-346.

Bogoch, R. and Brenner, I. B., 1977, Distribution and dispersion of lead and zinc in anomalous soils and stream sediments, Mount Hermon Area, Israel. J. Geochem. Explor. 8: pp. 529-535.

Bradley, S. B. and Cox, J. J., 1986, Heavy metals in the Hamps and Manifold Valleys, North Staffordshire, U.K.: Distribution in flood-plain soils. Sci. Total Environ. 50: pp. 103-128.

Bradshaw, P. M. D., 1975, Conceptual models in exploration geochemistry. J. Geochem. Explor. 4(1): pp. 1-213.

Bussey, S. D., Taufen, P. M., et al., 1993, Soil and stream sediment geochemical dispersion over the Bell Springs Deposit, Hog Ranch Mine, Washoe County, Nevada. J. Geochem. Explor. 47: pp. 217-234.

Callender, E., Kimball, B. A. and Axtmann, E. V., 1991, Transition metal geochemistry of the Upper Arkansas River, Colorado. U.S. Geol. Surv. Toxic Substances Hydrology Program; Proceedings of the Technical Meeting, Monterey, CA, U.S. Geol. Surv. pp. 392-397.

Cazes, D. K., 1981, Geochemical analyses of stream sediments and heavy mineral concentrates collected near a stratabound $\mathrm{Cu}-\mathrm{Ag}$ occurence in the Cabinet Mountains Wilderness, Montana. U.S. Geol Surv., Open File Report 81-665.

Chao, T. T. and P K Theobald, J., 1976, The significance of secondary iron and manganese oxides in geochemical exploration. Econ. Geol. 71: pp. 1560-1569.

Coolbaugh, D. F., 1979, Geophysics and geochemistry in the discovery and development of the La Caridad porphyry copper deposit, Sonora, Mexico. Geophysics and Geochemistry in the Search for Metallic Ores Ed. Hood, P. J. Geologic Survey of Canada. pp. 721-725.

Davies, B. E. and Lewis, J., 1974, Chronosequences in alluvial soils with special reference to historic lead polltion in Cardiganshire, Wales. Environ. Pollut. 6: pp. 49-57. 
Davis, A., Olsen, R. L. and Walker, D. R., 1991, Distribution of metals between water and entrained sediment in streams impacted by acid mine discharge, Clear Creek, Colorado. Appl. Geochem. 6: pp. 333-348.

Davis, J. A. and Leckie, J. O., 1978, Effect of adsorbed complexing ligands on trace metal uptake by hydrous oxides. Environ. Sci. Technol. 12(12): pp. 1309-1315.

Elliot, J.E. and Close, T.J., 1984, Anaconda-Pintlar Wilderness, Montana. in Wilderness mineral potential Eds. Marsh, S.P., Kropschot, S.J., and Dickenson, R.G., U.S. Geol. Surv. Prof. Paper 1300 Vol. 2: pp. 661-664.

Eychaner, J. H., 1991, The Globe, Arizona, research site-contaminants related to copper mining in a hydrologically integrated environment. U.S. Geol. Surv. Toxic Substances Hydrology Program; Proceedings of the Technical Meeting, Monterey, CA, U.S. Geol. Surv. pp. 439-447.

Eyrich, H. T., 1969, Economic geology of part of the New World Mining District, Park County, Montana. Doctoral Thesis, Washington State University.

Feltz, H. R., 1980, Significance of bottom material data in evaluating water quality. Contaminants and Sediments Ed. Baker. pp. 271-279.

Filipek, L. H., Nordstrom, D. K. and Ficklin, W. H., 1987, Interaction of acid mine drainage with waters and sediments of West Sqaw Creek in the West Shasta Mining District, California. Environ. Sci. Technol. 21(4): pp. 388-396.

Fleming, A. W. and Neale, T. I., 1979, Geochemical exploration at Yandera porphyry copper prospect, Papua New Guinea. J. Geochem. Explor. 11: pp. 33-51.

Fletcher, W. K., Dousset, P. E. and Ismail, Y. B., 1987, Elimination of hydraulic effects for cassiterite in a Malaysian stream. J. Geochem. Explor. 28: pp. 385-408.

Forstner, U., 1982, Accumulative phases for heavy metals in limnic sediments. Hydrobiologia 91: pp. 269-284.

Friedrich, G., Herzig, P., et al., 1984, The distribution of $\mathrm{Hg}, \mathrm{Ba}, \mathrm{Cu}$ and $\mathrm{Zn}$ in the vicinity of cupriferous sulfide deposits, Troodos Complex, Cyprus. J. Geochem. Explor. 21: pp. 167-174.

Gibbs, R. J., 1973, Mechanisms of trace metal transport in rivers. Science 180: pp. 71-73.

Giddings, J. M., 1983, Assessing the effects of contaminants on the structure and function of aquatic ecosystems. Environment and Solid Waste, Characterization. Treatment, and Disposal Eds. Francis, C. E. and Stanley, A. I. pp. 245-258. 
Goddard, E. N., 1940, Manganese deposits at Phillipsburg Granite County, Montana. U.S. Geol. Surv. Bulletin 922-G.

Hack, J. T., 1957, Studies of longitudinal stream profiles in Virginia and Maryland. U.S. Geol Surv. Professional Paper 294-B.

Hawkes, H. E., 1976, The downstream dilution of stream sediment anomalies. J. Geochem. Explor. 6: pp. 345-358.

Hermann, R. and Neumann-Mahlkau, P., 1985, The mobility of zinc, cadmium, copper, Lead, iron and arsenic in ground water as a function of redox potential and $\mathrm{pH}$. The Science of the Total Environment 43: pp. 1-12.

Horowitz, A. J. and Elrick, K. A., 1987, The relation of stream sediment surface area, grain size and composition to trace element chemistry. Appl. Geochem. 2: pp. 437-451.

Horowitz, A. J., Elrick, K. E. and Callender, E., 1988, The effect of mining on the sediment-trace element geochemistry of cores from the Cheyenne River Arm of Lake Oahe, South Dakota, USA. Chem. Geol. 67: pp. 17-33.

James, L. A., 1989, Sustained storage and transport of hydraulic gold mining sediment in the Bear River, California. Ann. Assoc. Amer. Geograph. 79(4): pp. 570-592.

James, L. A., 1991, Quartz concentration as an index of sediment mixing; hydraulic mine-tailings in the Sierra Nevada, California. Geomorphology 4: pp. 125-144.

Jenne, E. A. and Luoma, S. N., 1977, Forms of trace elements in soils, sediments, and associated waters: An overview of their determination and biological availability. Biological Implications of Metals in the Environment: CONF-750929, NTIS Springfield, VA, United States Geological Survey pp. 109-140.

Johnson, J., 1994, Sediment transport of metals in Dunkleberg Creek, MT. Senior Thesis, University of Montana.

Lambing, J. H., 1991, Water-quality and transport characteristics of suspended sediment and trace elements in streamflow of the Upper Clark Fork Basin from Galen to Missoula, Montana, 1985-90. U.S. Geol.Surv. Water Resources Investigations Report 91-4139.

Learned, R. E., Chao, T. T. and Sanzolone, R. F., 1985, A comparative study of stream water and stream sediment as geochemical exploration media in the Rio Tanama porphyry copper district, Puerto Rico. J. Geochem. Explor. 24: pp. 175-195.

Leggo, M. D., 1977, Contrasting geochemical expressions of copper mineralization at Namosi, Fiji. J. Geochem. Explor. 8: pp. 431-456. 
Lovering, T. G. and McCarthy, J. H., 1978, Conceptual models in exploration geochemistry. J. Geochem. Explor. 9: pp. 113-276.

Lovering, T.S., 1929, The New World or Cooke City Mining District, Park County, Montana. U.S. Geol. Surv. Bulletin 811-A.

Marcus, W. A., 1987, Copper dispersion in ephemeral stream sediments. Earth Surf. Proc. 12: pp. 217-228.

McClernan, H. G., 1983, Metallic mineral deposits of Lewis and Clark County, Montana. Montana Bureau of Mines and Geology, Memoir 52.

McLaurin, A. N., 1978, Geochemical dispersion from the Gamsberg Orebody, Northwestern Cape, South Africa. J. Geochem. Explor. 10: pp. 295-306.

Meyer, C., Shea, E. P. and JR., C. C. G., 1968, Ore deposits of the United States, 1933-1967. Ore Deposits of the United States, 1933-1967 Ed. Ridge, J. D. New York, American Institute of Mining, Metallurgical, and Petroleum Engineers. pp. 1373-1416.

Meyer, W. T., Theobald, P. K. and Bloom, H., 1979, Stream sediment geochemistry. Geophysics and Geochemistry in the Search for Metallic Ores Ed. Hood, P. J. Geological Survey of Canada. pp. 411-434.

Mohsen, L. A., 1969, Distribution of manganese in the Phillipsburg Batholith, Montana and its relationship to associated manganese ore deposits. Doctoral Thesis, Boston University.

Moore, J. N., Brook, E. J. and Johns, C. A., 1989, Grain size partitioning of metals in contaminated coarse-grained river floodplain sediment: Clark Fork River, Montana, U.S.A. Environ. Geol. Water. Sci. 14(2): pp. 107-115.

Moore, J. N. and Luoma, S. N., 1990, Hazardous wastes from large-scale metal extraction. Environ. Sci. Technol. 24(9): pp. 1279-1285.

Moore, J. N., Luoma, S. N. and Peters, D., 1991, Downstream effects of mine effluent on an intermontane riparian system. Can. J. Fish. Aquat. Sci. 48(2): pp. 222-232.

Mosser, C. and Zeegers, H., 1988, The mineralogy and geochemistry of two copper-rich weathering profiles in Burkina Faso, West Africa. J. Geochem. Explor. 30: pp. 145-166.

Nimick, D. A., 1990, Stratigraphy and chemistry of metal-contaminated floodplain sediments, Upper Clark Fork River Valley. Clark Fork River Symposium, Missoula, MT, pp. 194-197.

Nagorski, S. and Sjostrom, D., 1994, Metal contamination in Douglas Creek from the Wasa Mining Area, North Flint Creek Range, Montana, U.S.A. Unpublished report, University of Montana. 
Nordstrom, D. K., 1991, Chemical modeling of acid mine waters in the Western United States. U.S. Geol. Surv. Toxic Substance Hydrology Program, Proceedings of the Technical Meeting, Monterey, CA, USGS Water Resource Investigations Report 91-4034: pp. 534-538.

Pagenkopf, G. K. and Cameron, D., 1979, Deposition of trace metals in stream sediments. Water Air Soil Pollut. 11: pp. 429-435.

Pardee, J. T., 1917, The Dunkleberg Mining District, Granite County, Montana. U.S. Geol. Surv. Bulletin 660-G.

Ribeiro, M. J., Santos, M. M. D. and Bressan, S. R., 1979, Geochemical exploration over a mafic-ultramafic complex, Americano Do Brasil, Goias, Brazil. J. Geochem. Explor. 12: pp. 9-19.

Runnels, D. D., Shepherd, T. A. and Angino, E. E., 1992, Determining natural background concentrations in mineralized areas. Environ. Sci. Technol. 26(12): pp. 2316-2323.

Siems, D.F., Welsh, E.P., and Zimbelman, D.R., 1982, Chemical analysis of minus-200 mesh stream sediments of the Anaconda-Pintlar Wilderness, Beaverhead, Deerlodge, Granite, and Ravalli Counties, Montana. U.S. Geol. Surv. Open File Report 82-490.

Smith, K. S., Ranville, J. F. and Macalady, D. L., 1991, Predictive modeling of copper, cadmium, and zinc partitioning between streamwater and bed sediment from a stream receiving acid mine drainage, St. Kevin Gulch, Colorado. Geologic Survey Toxic Substances Hydrology Program; Proceedings of the Technical Meeting, Monterey, CA, USGS Water Resource Investigations Report 91-4034.

Welsh, E.P., Siems, D.F. and Zimbelman, D.R., 1983, Geochemical analysis of rocks of the Anaconda-Pintlar Wilderness, Beaverhead, Deerlodge, Granite, and Ravalli Counties, Montana. U.S. Geol. Surv. Open File Report 83-903.

Yim, W. W. S., 1981, Geochemical investigation on fluvial sediments contaminated by tin-mine tailings, Cornwall, England. Environ. Geol. 3: pp. 245-256. 


\section{Appendix I. Field Area Descriptions and Maps}

\section{A. Senate Mine-Ivanhoe Lake Area}

The Senate Mine and Ivanhoe Lake drainages are adjacent tributaries of the Middle Fork of Rock Creek on the border on the Anaconda-Pintlar Wilderness, Montana (Map 1). An overview of the area is given by Elliott and Close (1984). The area is located in the Anaconda Range, which is made up of sedimentary rocks of Proterozoic and Paleozoic age and plutonic igneous rocks of Cretaceous to Tertiary age. Mineral surveys indicate probable resource potential for $\mathrm{Ag}, \mathrm{Cu}, \mathrm{Mo}, \mathrm{Pb}, \mathrm{W}, \mathrm{Sn}, \mathrm{Au}$, and $\mathrm{Zn}$ in the region. Surveys were conducted in $1978-80$ by the U.S. Bureau of Mines, and in 1980-82 by the U.S. Geological Survey (Welsh et al., 1983; Siems et al., 1982). The Senate Mine area was noted as containing the strongest resource potential. In the Senate Mine area a structurally controlled zone of shearing, quartz veins, and replacement minerals is present. There is sparse sulfide mineralization including chalcopyrite, pyrite, and galena in veins and disseminated in the wall rocks. The mineralization is present in a zone of highly fractured belt rocks that promoted secondary permeability and allowed in ore-bearing fluids.

The Senate Mine produced a small quantity of copper ore from two visible adits. The lower adit is collapsed, but the upper adit is an open narrow tunnel, now flooded. Mine drainage was neutral, and malachite was observed submerged in the pool at the entrance to the adit. Visible copper minerals such as azurite and malachite were common on the surface around the mine, and copper values as high as $20,000 \mathrm{ppm}$ have been reported in the vicinity. Lead values as high as $20,000 \mathrm{ppm}$ have been reported in the adjacent Ivanhoe Lake drainage (Welsh et al., 1983). Senate Mine Creek was sampled August 12-13, 1993. 


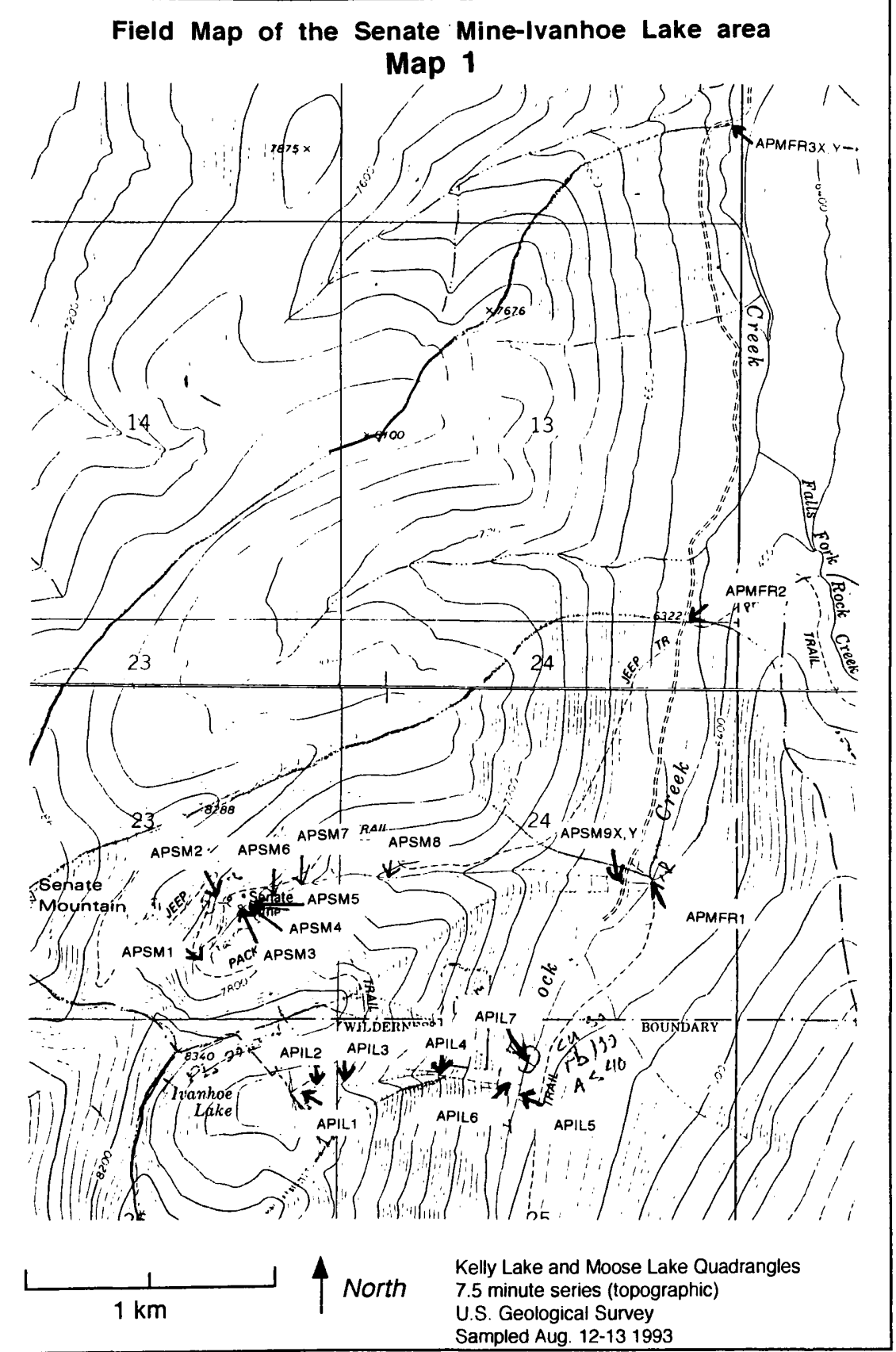




\section{B. New World Mining District}

The New World mining district is located outside of Cooke City, Montana between Yellowstone National Park and the Absaroka-Beartooth Wilderness. Overviews of the district are given by Lovering (1929) and Eyrich (1969). Prospecting and small-scale mining began in the 1870's with sporadic attempts at mining and smelting continuing until 1934, when the McLaren Gold Mines Company started continuous production from 1934 to 1953 . The district produced approximately 370,000 tons of ore, principally gold and copper, worth a total of $\$ 4,000,000$. The bulk of production was processed at the McLaren mill at Cooke City. Plans for further large-scale gold and copper mining continue today. Natural and anthropogenic acid drainage and erosion of enriched sediments form strong metal anomalies in the Miller Creek, Fisher Creek, and Little Daisy Creek drainages (Maps 2-6). Iron oxidation from the weathering of the deposit is visible in the red coloring of Fisher Mountain.

Of these three drainages, the headwaters of Miller Creek were observed as being the least disturbed, but the drainage did contain a small remediated tailings pile on the outskirts of Cooke City (Maps 2,3). Above town, the Miller Creek drainage showed very little evidence of mining impact, and the $\mathrm{pH}$ of the stream was above 7. A few natural looking acidic iron-stained seeps were noted on the banks in the mineralized zone. In the town of Cooke City, the stream has been re-routed around a tailings pile from one of the old mills. The tailings pile had received recent remedial work, and did not seem to be providing additional sediment into the stream. Iron oxide coatings on stream cobbles below the tailings site suggested a possible groundwater input of metal to the creek. Field data revealed no increase in metal levels below the tailings pile, and it is thought to currently have little impact on the drainage. 
The headwaters of Fisher Creek were observed to contain tailings piles and an abandoned pit mine (Maps 4,5). Fisher Creek was observed originating from a tailings pile at a $\mathrm{pH}$ of three. A large deep red platform of iron oxyhydroxides had formed where the acidic water emanated from the tailings and bright orange to red coatings covered all the cobbles for the first few kilometers of the stream. Remedial activities were observed in the headwaters of Fisher Creek during the sampling period of September 20-21, 1993. Some of the Fisher Creek drainage showed scars from the Yellowstone forest fires of 1988. Fisher and Miller Creeks were sampled September 20-21, 1993.

The headwaters of Little Daisy Creek were also impacted by historic mining activities (Map 6). The very top of the drainage showed little sign of disruption, but just a few hundred meters downstream a tributary draining a large disturbed slope entered. On the day Little Daisy Creek was sampled (Sept. $20,1993)$ the slope was undergoing remedial work by bulldozer, and a light snow melt was causing Little Daisy Creek to run a milky orange. The $\mathrm{pH}$ of the Creek below the orange input was near three, and it took two miles to reach neutral. Cobbles in Little Daisy Creek were also covered with orange coatings, and the coatings were still present, but not as thick, two miles downstream. Little Daisy Creek was sampled September 20, 1993. 


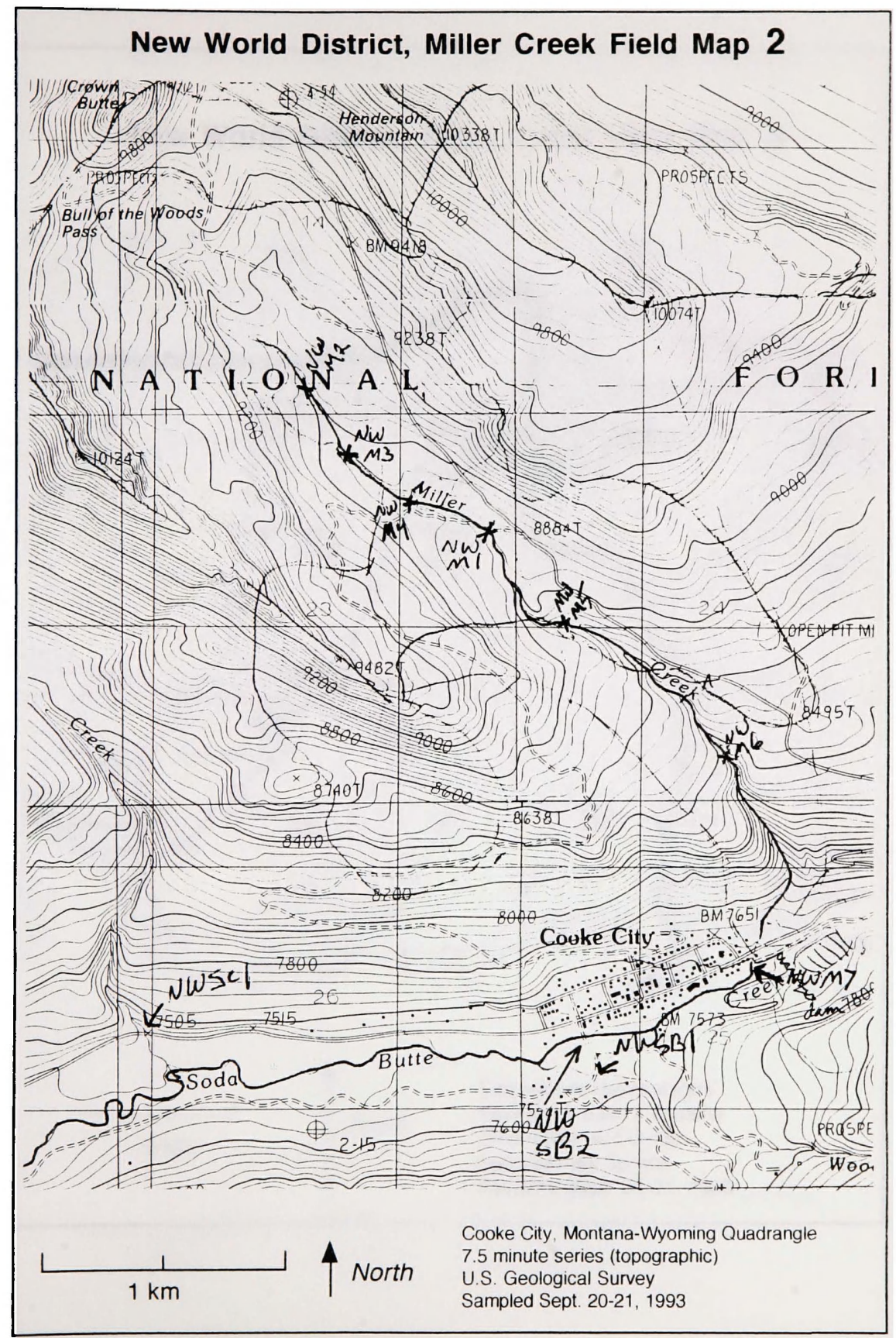




\section{New World District, Miller Creek Field Map 3}
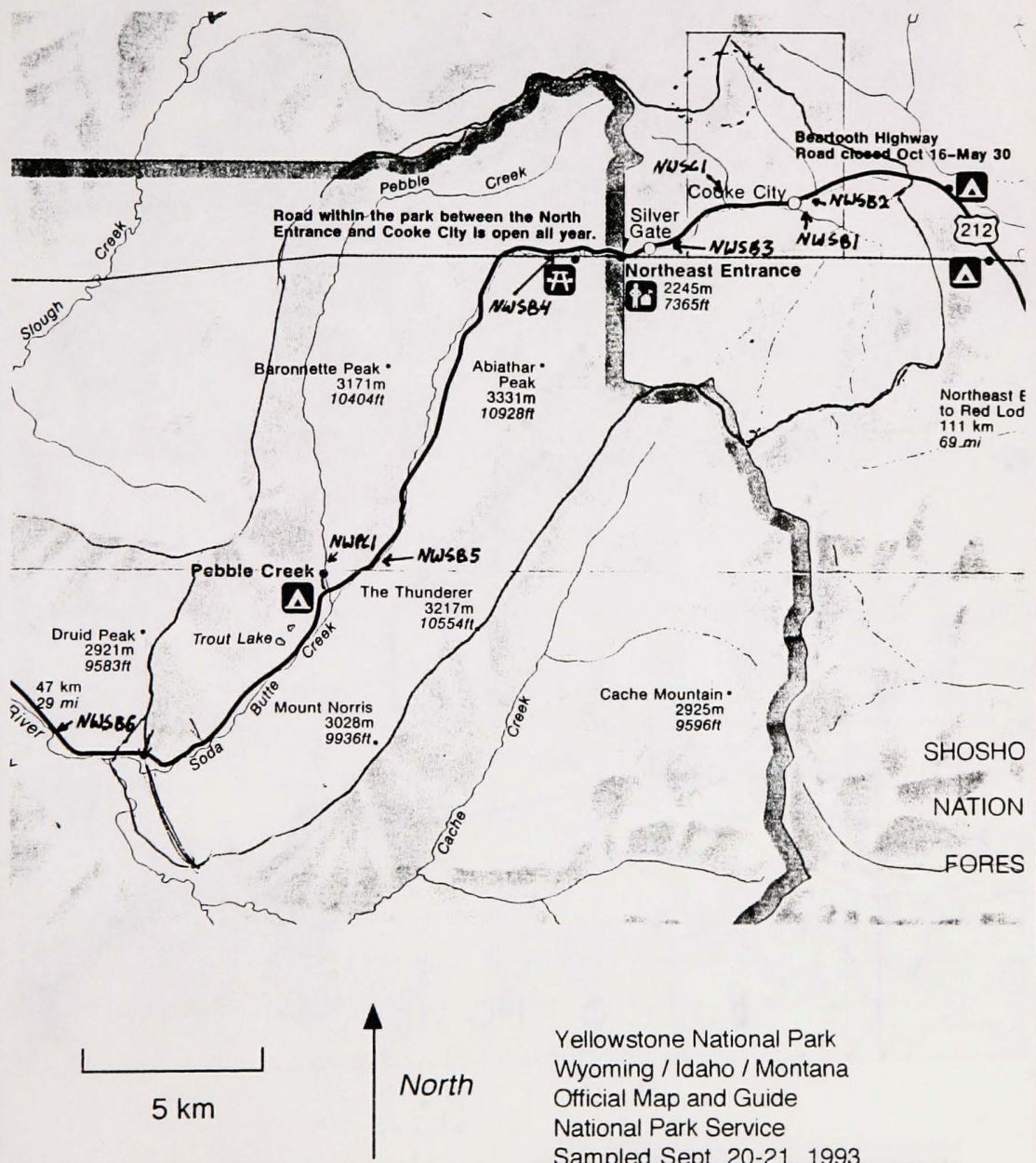

Yellowstone National Park Wyoming / Idaho / Montana Official Map and Guide National Park Service Sampled Sept. 20-21, 1993 


\section{New World District, Fisher Creek Field Map 4}
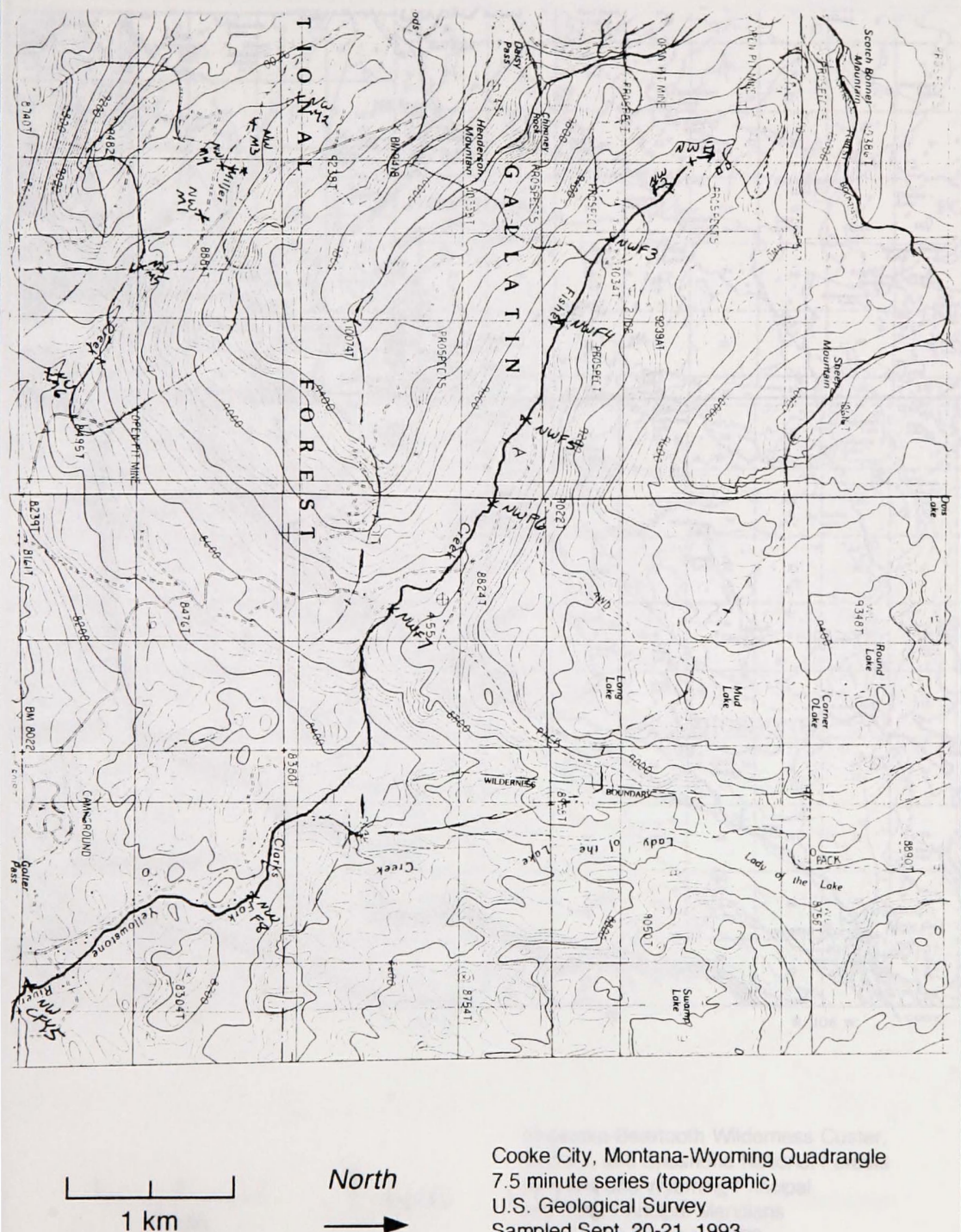

Cooke City, Montana-Wyoming Quadrangle

7.5 minute series (topographic)

U.S. Geological Survey

Sampled Sept. 20-21, 1993 


\section{New World District, Fisher Creek Field Map 5}

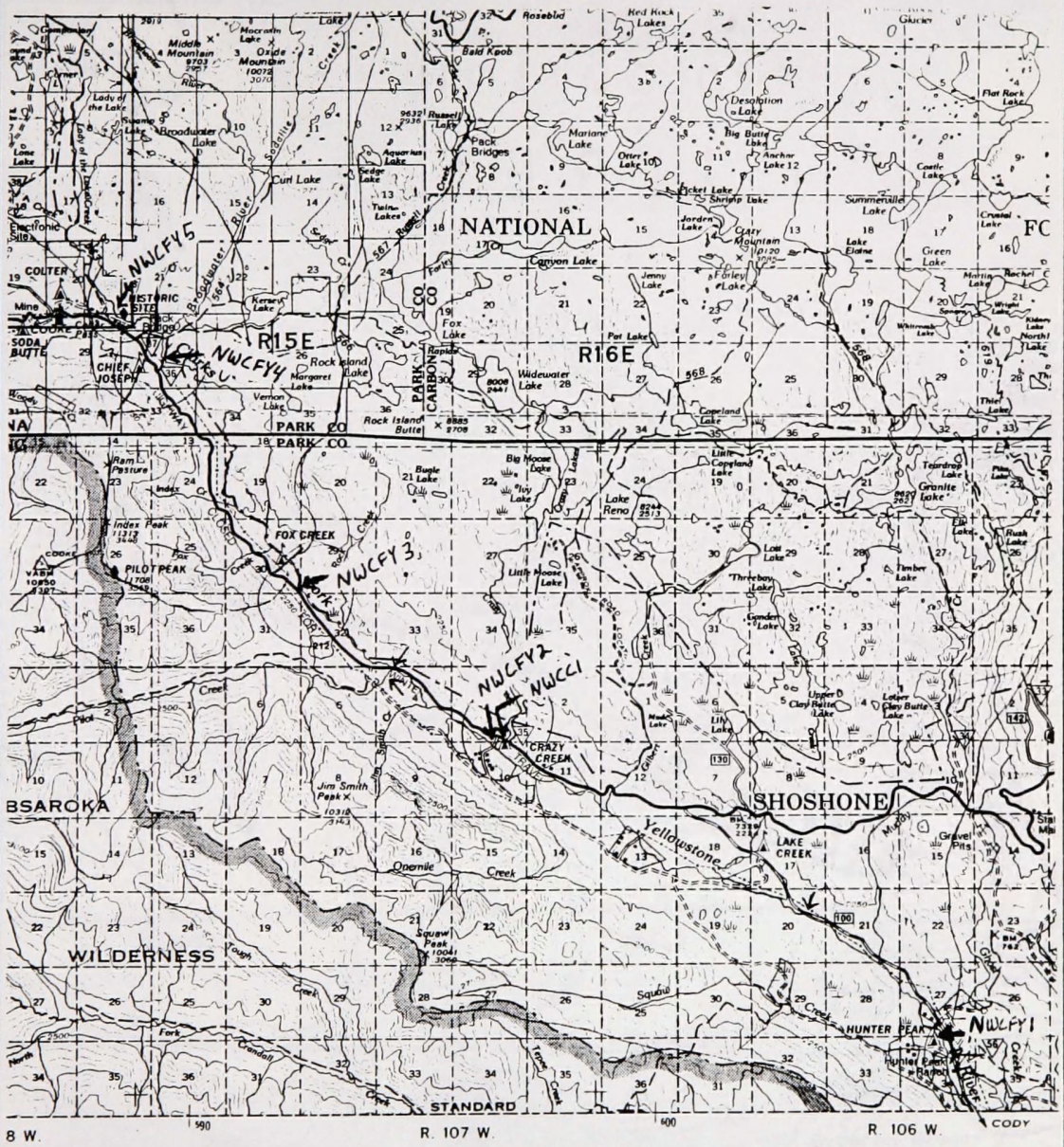

Absaroka-Beartooth Wilderness Custer, Gallatin, and Shoshone National Forests

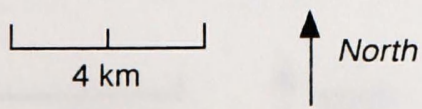
Montana and Wyoming Principal and Sixth Principal Meridians U.S. Forest Service, 1988 Sampled Sept. 20-21, 1993 


\section{New World District, Little Daisy Creek Field Map 6}

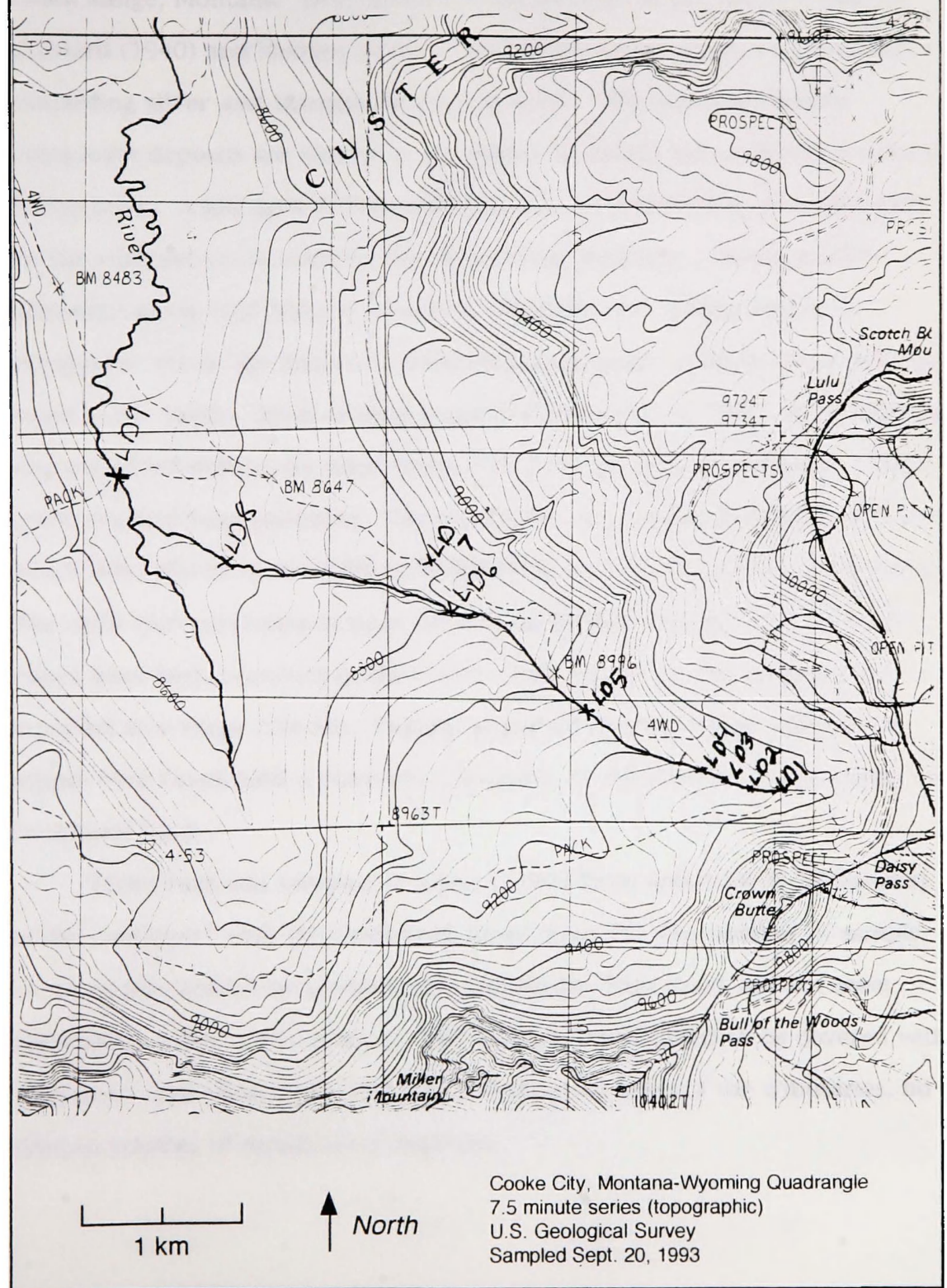




\section{Flint Creek-Phillipsburg Mining District}

The Phillipsburg Mining District is located on the west slope of the Flint Creek Range, Montana. Descriptions of the mining district are provided by Goddard (1940) and Mohsen (1969). The district covers 20 square kilometers containing silver and manganese vein deposits. The limestone-hosted manganese deposits are limited to a 5 square kilometer area east of the town of Phillipsburg. A low arch of Paleozoic limestone was truncated and deformed on the east and south edge by the Phillipsburg Batholith. Hydrothermal alteration along vein fissures produced irregular and tabular bodies of manganese ore in the limestone bordering the steeply dipping silver and zinc veins to the north. Silver mining began in the district in 1864 , but manganese was not mined extensively until World War I. As of 1940, 477,000 tons of high grade ore had been produced. The manganese ore contained from $30-43 \% \mathrm{Mn}$ which was refined in the mills at Phillipsburg to $70 \% \mathrm{MnO}_{2}$ prior to shipping. Two mills were operating at near capacity in Phillipsburg in 1939. Over 40 mines have been reported in the district, and tailings in the basin were reported to average $20 \% \mathrm{Mn}$. Tailings stored on the floodplain continue to supply Flint Creek with a substantial quantity of trace metals, far in excess of its natural load.

Flint Creek was sampled October 3, 1993 from upstream of Phillipsburg to the confluence with the Clark Fork River (Map 7). The number of sample locations was limited by accessibility. Outwardly, Flint Creek did not seem particularly impacted by mining. The floodplain was noted to be covered with vegetation, and aside from some placer tailings in some of the tributaries, no obvious sources of metals were observed. 


\section{Flint Creek Field Map 7}
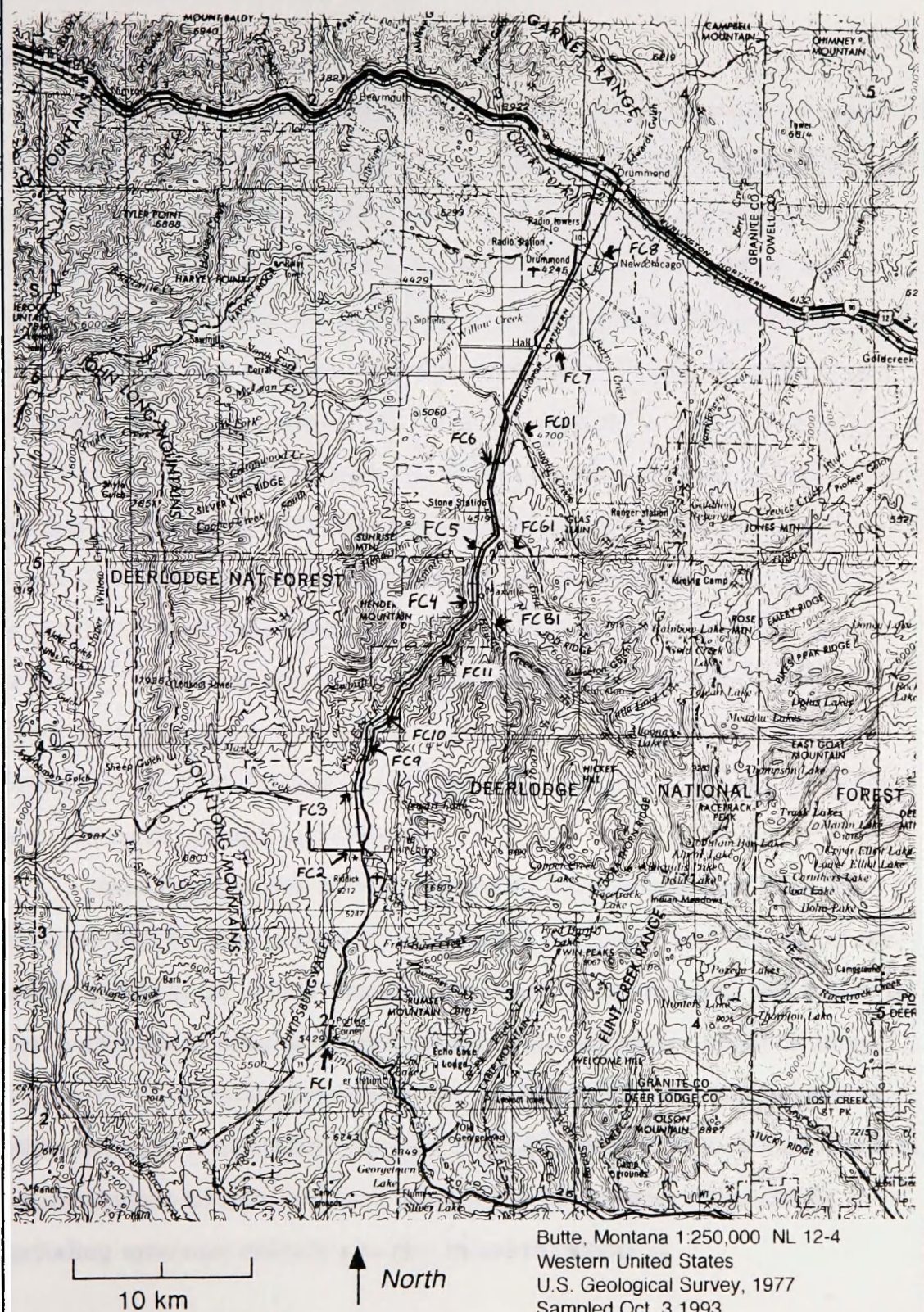

Butte, Montana 1:250,000 NL 12-4

Western United States

U.S. Geological Survey, 1977

Sampled Oct. 3,1993 
Appendix II. Models of Unmined Deposits

\section{A. Ivanhoe Lake Model}

The Ivanhoe lake drainage contains a prospect with reported values of $20,000 \mathrm{ppm} \mathrm{Pb}$. Sediment samples were collected from the outflow of the lake to the confluence with the Middle Fork of Rock Creek, and a few miles downstream. The lead concentration increased down the Ivanhoe lake drainage to a maximum at the edge of a claim on the Wilderness Area boundary (Map 1). The high-gradient drainage contained virtually no fine-grained sediment, and samples were collected in the anomalous reach by squeezing sediment out of moss growing in the stream. Lead levels were so high (>5\%) as to make modeling the anomaly impossible using the standard assumptions. In order to match the high concentration of lead in the anomalous sediment sample, the entire basin upstream would have to contain $>5 \%$ lead. If such numbers are entered into the model, the resulting anomaly is so large that the rapid dilution rate observed can not be matched. It is suspected that the anomaly is of hydromorphic origin and is not the result of sediment erosion and mixing as assumed in the model.

There is still a well defined dispersion train downstream from the anomaly that can be modeled if it is assumed that there is no dilution of the anomaly due to the area of drainage upstream of the anomaly, which may be a reasonable assumption given the sediment-starved nature of the drainage (Model 1). If the actual area above the anomaly is included, the amount of dilution makes it impossible to reach the high concentration of lead found in the anomalous sediment midway down the small drainage. A model fit including upstream dilution was also included (Model 2). 
Model 1

Anaconda-Pintlars Ivanhoe lake $\mathrm{Pb}$ Model, no dilution above anomaly

$\begin{array}{rrrrrr}\text { kilometer } & \text { Sed Pb } & \text { Sed Mn } & \text { km } & \text { At } & \text { Model Pb } \\ 0.05 & 65 & 1130 & 0.6 & 0.00 & 58149 \\ 0.05 & 81 & 1005 & 0.90 & 0.17 & 235 \\ 0.10 & 171 & 3639 & 1.10 & 0.39 & 128 \\ 0.22 & 1684 & 3288 & 1.90 & 1.86 & 62 \\ 0.60 & 58000 & 9916 & 3.00 & 5.13 & 51 \\ 0.90 & 207 & 1249 & 5.10 & 14.57 & 47 \\ 1.10 & 97 & 753 & & & \\ 1.90 & 79 & 390 & & & \\ 3.00 & 81 & 862 & \text { Ao } & \text { Co } & \text { Cb } \\ 5.10 & 47 & 565 & 0.000425 & 75000 & 45 \\ 5.10 & 46 & 451 & & & \end{array}$

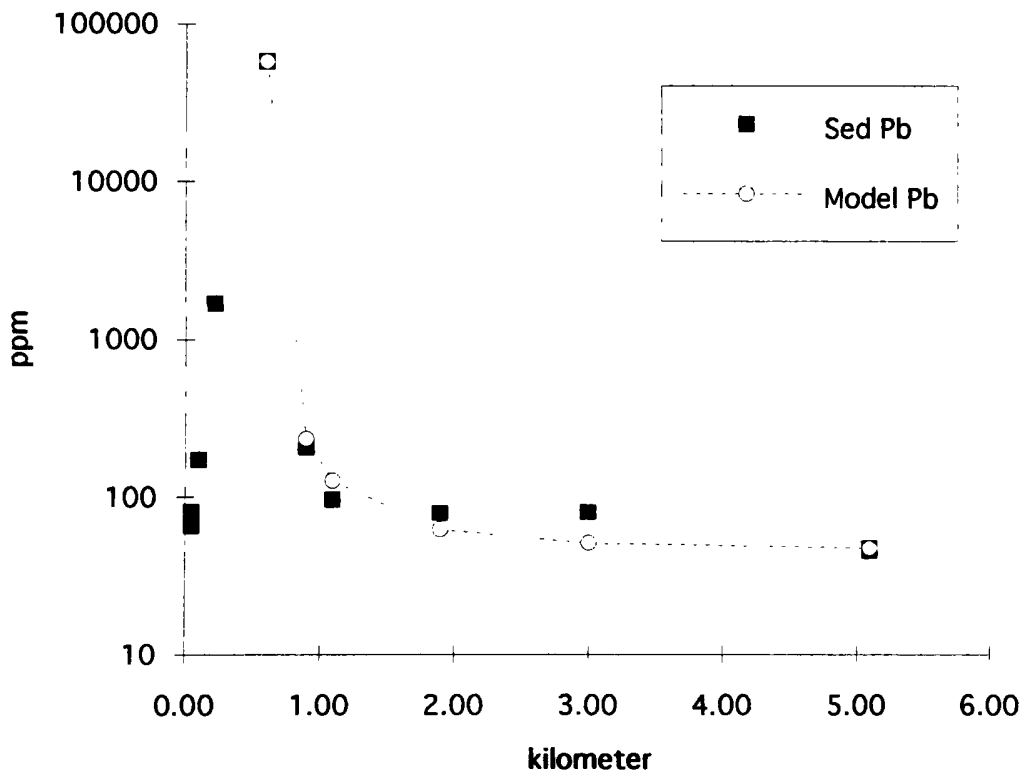


Model 2

Anaconda-Pintlars Ivanhoe lake $\mathrm{Pb}$ Model, dilution from above anomaly

$\begin{array}{rrrrrr}\text { kilometer } & \text { Sed Pb } & \text { Sed Mn } & \text { km } & \text { At } & \text { Model Pb } \\ 0.05 & 65 & 1130 & 0.6 & 0.50 & 108 \\ 0.05 & 81 & 1005 & 0.90 & 0.99 & 77 \\ 0.10 & 171 & 3639 & 1.10 & 1.39 & 68 \\ 0.22 & 1684 & 3288 & 1.90 & 3.45 & 54 \\ 0.60 & 58000 & 9916 & 3.00 & 7.38 & 49 \\ 0.90 & 207 & 1249 & 5.10 & 17.89 & 47 \\ 1.10 & 97 & 753 & & & \\ 1.90 & 79 & 390 & & & \\ 3.00 & 81 & 862 & \text { Ao } & \text { Co } & \text { Cb } \\ 5.10 & 47 & 565 & 0.000425 & 75000 & 45 \\ 5.10 & 46 & 451 & & & \end{array}$

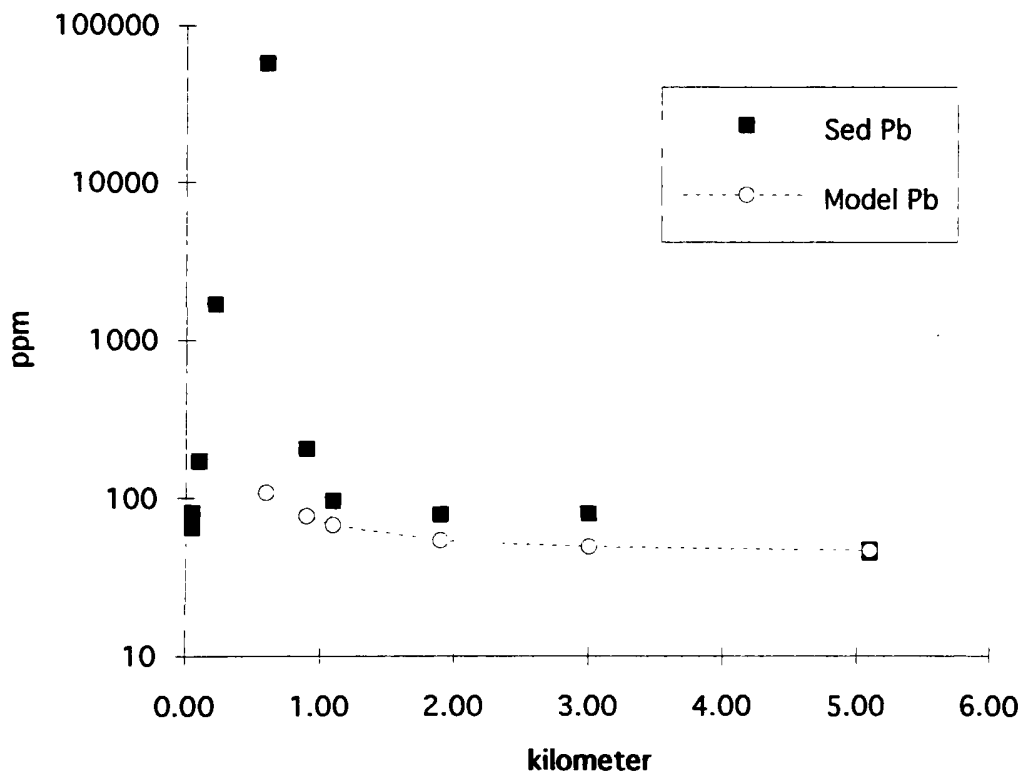




\section{B. Miller Creek Model}

The copper and lead stream sediment anomalies in Miller creek were modeled successfully; no exaggeration of the anomaly was necessary to match the field sediment data (Models 3,4). The area above the starting model point was used for the area of mineralization, and the concentration of the peak sediment sample used for the anomaly grade. Tributary samples established a range of values for basin background, and good model fits were achieved using values from within the range. The small tailings pile at Cooke City seemed to push the start of the dispersion train downstream a kilometer, but otherwise had no noticeable effect on the dispersion train. 
Model 3 New World District Miller Creek Cu

$\begin{array}{lrrrrrr}\text { Sample Name } & \text { Cu } & \text { Pb } & \text { Mile } & \text { Mile } & \text { At } & \text { Model Cu } \\ \text { NWSB1 } & 47 & 46 & & 3.00 & 4.00 & 1100 \\ \text { NWCC1 } & 38 & 44 & & 3.02 & 4.50 & 982 \\ \text { NWPC1 } & 33 & 26 & & 3.35 & 5.98 & 748 \\ \text { NWSC1 } & 40 & 25 & & 3.50 & 6.43 & 697 \\ \text { NWM2 } & 262 & 252 & 0.80 & 4.00 & 8.04 & 565 \\ \text { NWM3 } & 265 & 249 & 1.00 & 4.00 & 8.04 & 565 \\ \text { NWM4 } & 380 & 257 & 1.20 & 6.00 & 15.86 & 304 \\ \text { NWM1 } & 921 & 252 & 1.43 & 10.00 & 37.31 & 149 \\ \text { NWM5 } & 834 & 260 & 1.78 & 15.00 & 73.57 & 93 \\ \text { NWM5D } & 816 & 255 & 1.78 & 20.00 & 119.11 & 71 \\ \text { NWM6 } & 1084 & 268 & 2.38 & 25.00 & 173.07 & 60 \\ \text { NWM7 } & 821 & 264 & 3.03 & & & \\ \text { NWSB2 } & 752 & 203 & 3.53 & & & \\ \text { NWSB3 } & 61 & 38 & 6.03 & & & \\ \text { NWSB4 } & 69 & 44 & 8.23 & & & \\ \text { NWSB5 } & 67 & 40 & 14.53 & \text { A0 } & \text { Co } & \text { Cb } \\ \text { NWSB6 } & 63 & 33 & 22.08 & 4.00 & 1100.00 & 35\end{array}$

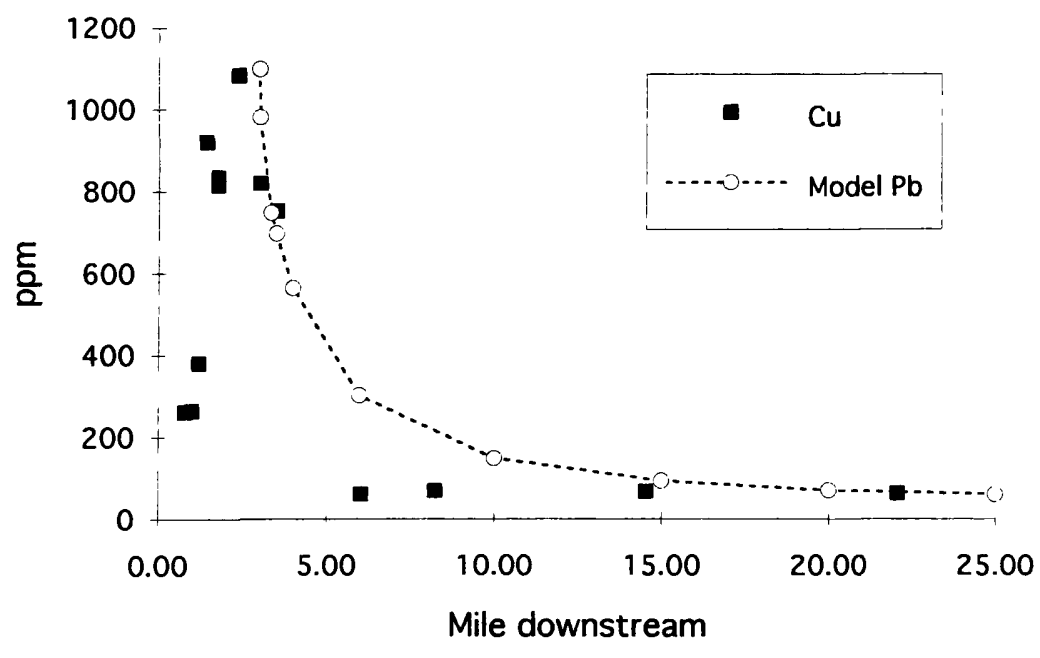


Model 4 New World District Miller Creek Pb

$\begin{array}{lrrrrrr}\text { Sample Name } & \text { Cu } & \text { Pb } & \text { Mile } & \text { Mile } & \text { At } & \text { Model Cu } \\ \text { NWSB1 } & 47 & 46 & & 3.00 & 4.00 & 265 \\ \text { NWCC1 } & 38 & 44 & & 3.02 & 4.50 & 238 \\ \text { NWPC1 } & 33 & 26 & & 3.35 & 5.98 & 186 \\ \text { NWSC1 } & 40 & 25 & & 3.50 & 6.43 & 174 \\ \text { NWM2 } & 262 & 252 & 0.80 & 4.00 & 8.04 & 144 \\ \text { NWM3 } & 265 & 249 & 1.00 & 4.00 & 8.04 & 144 \\ \text { NWM4 } & 380 & 257 & 1.20 & 6.00 & 15.86 & 86 \\ \text { NWM1 } & 921 & 252 & 1.43 & 10.00 & 37.31 & 51 \\ \text { NWM5 } & 834 & 260 & 1.78 & 15.00 & 73.57 & 38 \\ \text { NWM5D } & 816 & 255 & 1.78 & 20.00 & 119.11 & 33 \\ \text { NWM6 } & 1084 & 268 & 2.38 & 25.00 & 173.07 & 31 \\ \text { NWM7 } & 821 & 264 & 3.03 & & & \\ \text { NWSB2 } & 752 & 203 & 3.53 & & & \\ \text { NWSB3 } & 61 & 38 & 6.03 & & & \\ \text { NWSB4 } & 69 & 44 & 8.23 & & & \\ \text { NWSB5 } & 67 & 40 & 14.53 & \text { Ao } & \text { Co } & \text { Cb } \\ \text { NWSB6 } & 63 & 33 & 22.08 & 4.00 & 265 & 25\end{array}$

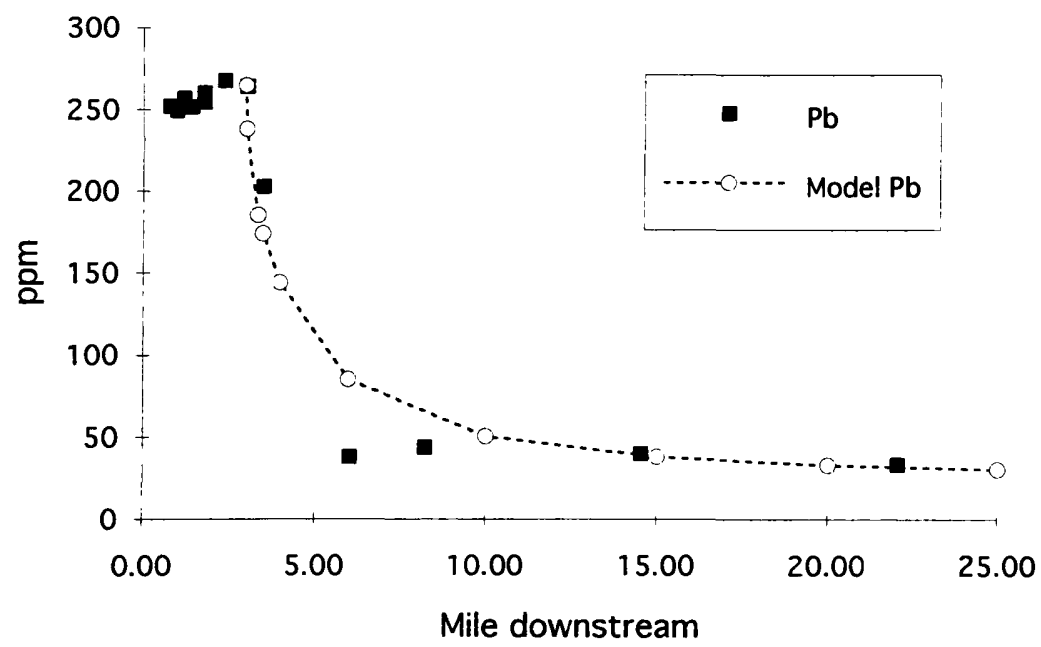




\section{Models of Literature Data}

Data sets for several un-mined ore deposits were located in the exploration literature (Hawkes, 1976; McLaurin, 1978). The Gamsberg deposit, South Africa (Models 5,6), the Rosemont deposit, Arizona (Model 7), the Cerro Colorado deposit, Panama (Model 8), and the Casino deposit, Yukon (Model 9) were all modeled using the values for area and grade provided in the literature. Acceptable fits were obtained for the Gamsberg, Rosemont, and Cerro Colorado deposits, and a marginal fit obtained for the Casino deposit. The Casino data set consisted of only four points, of which the first and last were matched; it is unknown if a better fit would be achieved using a more complete data set, or if there is an unknown violation of one of the model assumptions altering the shape of the dispersion train. The close fits of the model to stream sediment data sets from un-mined deposits provides convincing evidence of the validity of the calculated pre-mining dispersion trains for contaminated river systems. The limitation of the accuracy of the predictions relates primarily to the accurate quantification of the area and grade of the deposit prior to mining. 
Model 5 Gamsberg, South Africa Pb (McLaurin, 1978)

$\begin{array}{rrrrrrr}\text { km } & \text { Mile } & \text { Sed. Zn } & \text { Sed. Pb } & \text { Area } & \text { Mile } & \text { Model Pb } \\ 4 & 2.50 & 1150 & 160 & 9 & 3.75 & 145 \\ 5 & 3.13 & 760 & 110 & 10 & 4.00 & 133 \\ 8 & 5.00 & 1025 & 140 & 15 & 5.00 & 99 \\ 8.6 & 5.38 & 560 & 120 & 20 & 6.00 & 79 \\ 9.6 & 6.00 & 195 & 70 & 32 & 8.00 & 58 \\ 10.8 & 6.75 & 215 & 50 & 46 & 10.00 & 48 \\ 11.8 & 7.38 & 205 & 60 & 63 & 12.00 & 41 \\ 13 & 8.13 & 145 & 60 & 81 & 14.00 & 37 \\ 15.5 & 9.69 & 270 & 60 & 102 & 16.00 & 35 \\ 18 & 11.25 & 130 & 40 & 124 & 18.00 & 33 \\ 19.7 & 12.31 & 155 & 40 & 147 & 20.00 & 31 \\ 33 & 20.63 & 75 & 30 & 173 & 22.00 & 30\end{array}$

$\begin{array}{rrr}\text { Ao } & \text { Co } & \text { Cb } \\ 0.22 & 5000 & 24\end{array}$

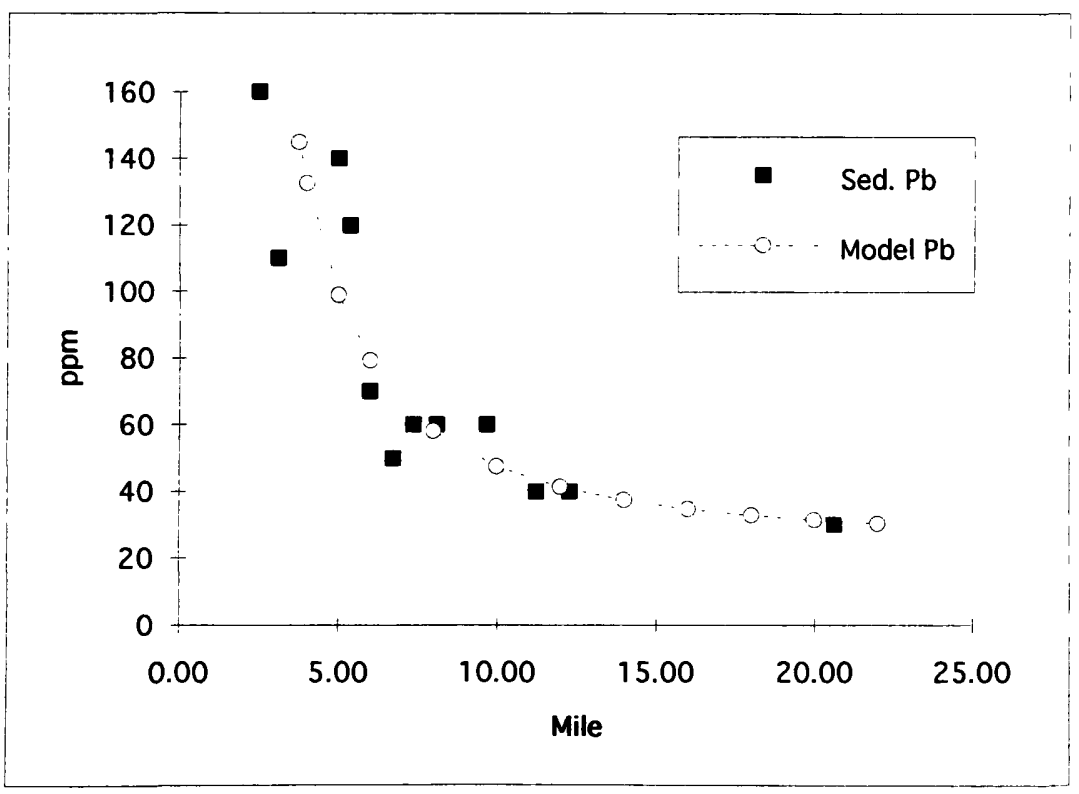


Model 6 Gamsberg, South Africa Zn (McLaurin, 1978)

$\begin{array}{rrrrrrr}\text { km } & \text { Mile } & \text { Sed. Zn } & \text { Sed. Pb } & \text { Area } & \text { Mile } & \text { Model Zn } \\ 4 & 2.50 & 1150 & 160 & 9 & 3.75 & 1057 \\ 5 & 3.13 & 760 & 110 & 10 & 4.00 & 952 \\ 8 & 5.00 & 1025 & 140 & 15 & 5.00 & 664 \\ 8.6 & 5.38 & 560 & 120 & 20 & 6.00 & 497 \\ 9.6 & 6.00 & 195 & 70 & 32 & 8.00 & 317 \\ 10.8 & 6.75 & 215 & 50 & 46 & 10.00 & 226 \\ 11.8 & 7.38 & 205 & 60 & 63 & 12.00 & 174 \\ 13 & 8.13 & 145 & 60 & 81 & 14.00 & 140 \\ 15.5 & 9.69 & 270 & 60 & 102 & 16.00 & 117 \\ 18 & 11.25 & 130 & 40 & 124 & 18.00 & 101 \\ 19.7 & 12.31 & 155 & 40 & 147 & 20.00 & 88 \\ 33 & 20.63 & 75 & 30 & 173 & 22.00 & 79\end{array}$

$\begin{array}{rrr}\text { Ao } & \text { Co } & \text { Cb } \\ 0.22 & 42500 & 25\end{array}$

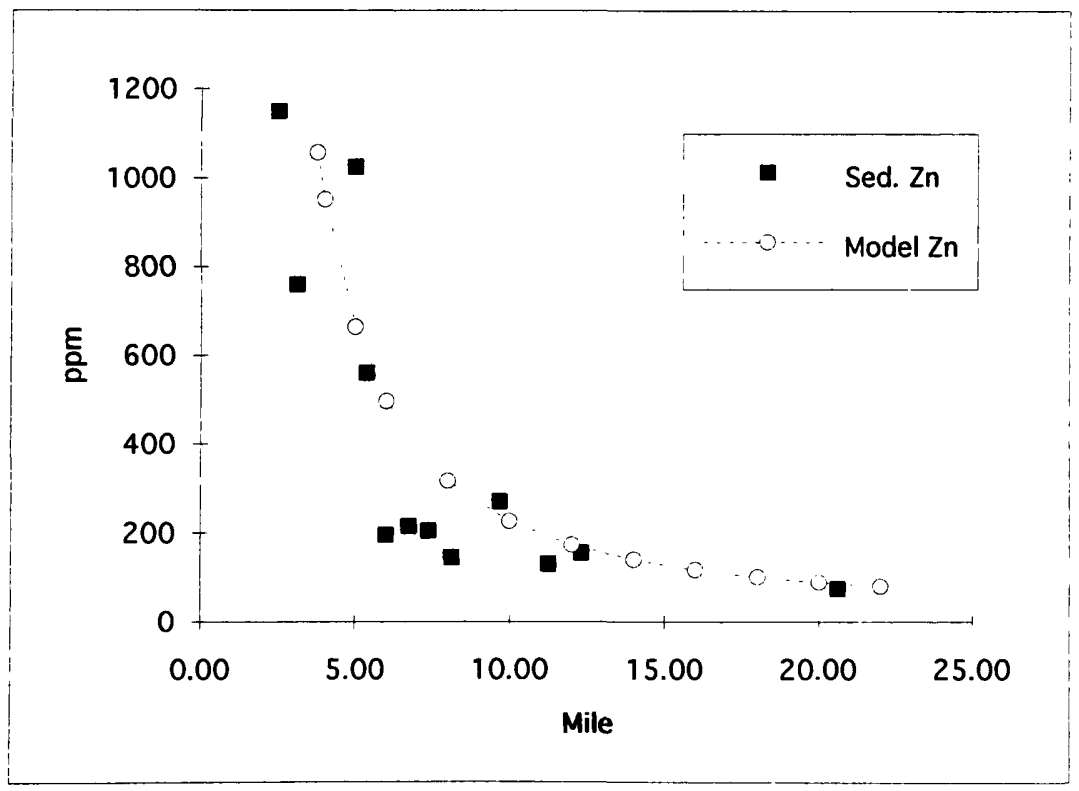


Model 7 Rosemont Deposit, Arizona (Hawkes, 1976)

\begin{tabular}{|c|c|c|c|c|c|c|}
\hline \multicolumn{7}{|c|}{ Rosemont $A O=1, C O=2200, C b=17$} \\
\hline km & area & $\mathrm{Cu}$ & & km & area & Model Cu \\
\hline 26 & 140 & 35 & Ao & 26 & 140 & 33 \\
\hline 23 & 136 & 30 & 1 & 23 & 136 & 33 \\
\hline 22 & 124 & 30 & Co & 22 & 124 & 35 \\
\hline 16 & 109 & 35 & 2200 & 16 & 109 & 37 \\
\hline 15 & 105 & 40 & $\mathrm{Cb}$ & 15 & 105 & 38 \\
\hline 12 & 83 & 45 & 17 & 12 & 83 & 43 \\
\hline 10 & 63 & 55 & & 10 & 63 & 52 \\
\hline 7 & 36 & 100 & & 7 & 36 & 78 \\
\hline 6 & 28 & 100 & & 6 & 28 & 95 \\
\hline 3.5 & 15 & 95 & & 3.5 & 15 & 163 \\
\hline 1.5 & 5.3 & 450 & & 1.5 & 5.3 & 429 \\
\hline
\end{tabular}

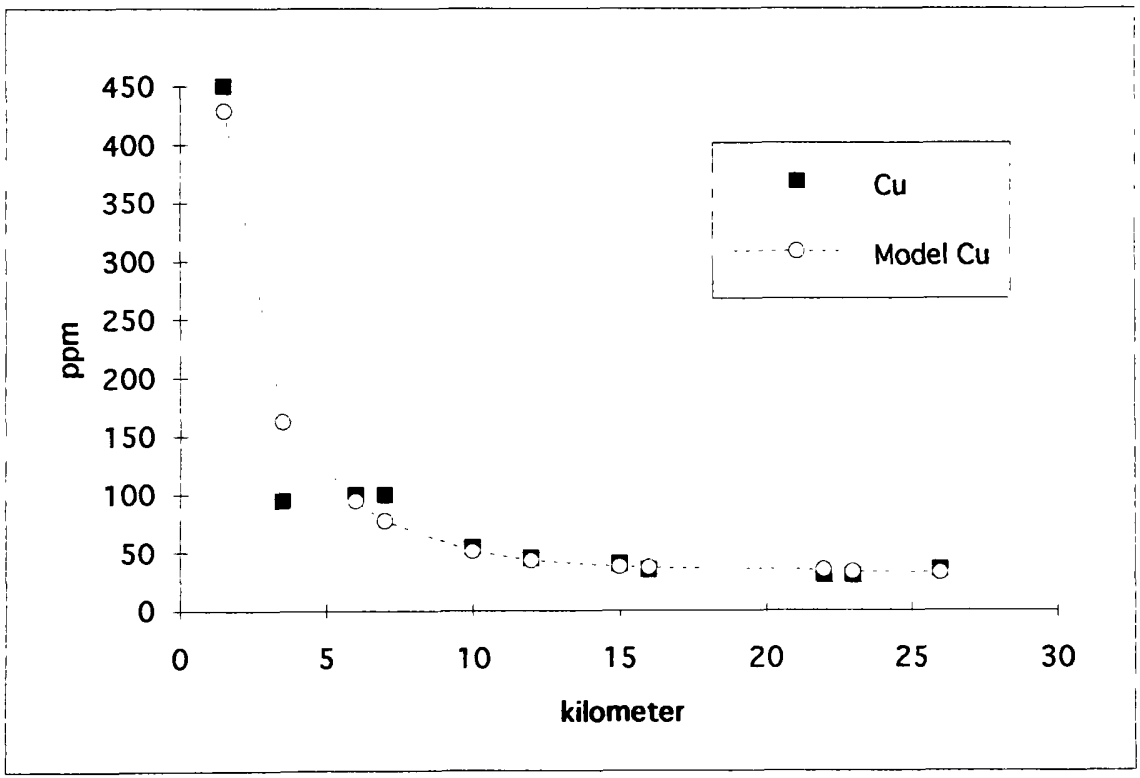


Model 8 Cerro Colorado, Panama (Hawkes, 1976)

Cerro $A O=1.5, C o=7500, C b=115$

$\begin{array}{rrrrrrr}\mathbf{k m} & \text { area } & \mathrm{Cu} & & \mathbf{k m} & \text { area } & \text { Model Cu } \\ 47 & 300 & 160 & \mathrm{Ao} & 47 & 300 & 152 \\ 6 & 48 & 195 & 1.5 & 6 & 48 & 346 \\ 4 & 45 & 350 & \mathrm{Co} & 4 & 45 & 361 \\ 2.5 & 16.5 & 650 & 7500 & 2.5 & 16.5 & 786 \\ 1 & 10.6 & 1308 & \mathrm{Cb} & 1 & 10.6 & 1160\end{array}$

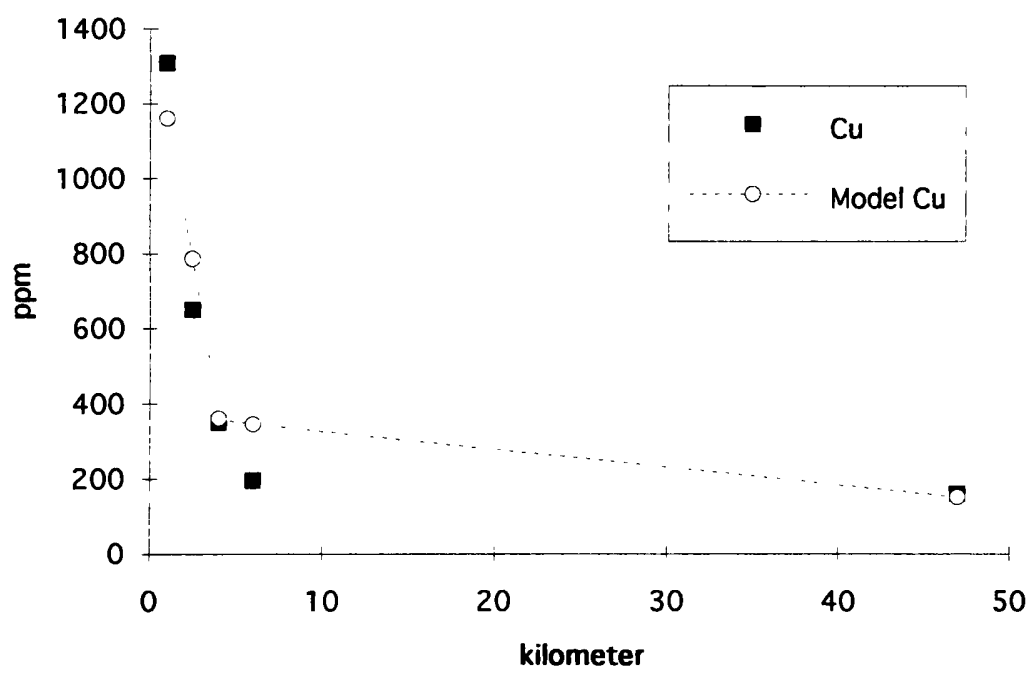


Model 9 Casino, Yukon (Hawkes, 1976)

Casino $A 0=.35, C o=2000, C b=54$

$\begin{array}{rrrrrrr}\text { km } & \text { area } & \text { Sed. Cu } & & \text { km } & \text { area } & \text { Model Cu } \\ 13 & 80.5 & 122 & \text { Ao } & 13 & 80.5 & 81 \\ 10 & 39.4 & 306 & 0.4 & 10 & 39.4 & 109 \\ 5 & 20.2 & 780 & \text { Co } & 5 & 20.2 & 162 \\ 1.6 & 2.34 & 1000 & 5500 & 1.6 & 2.34 & 985 \\ & & & \text { Cb } & & & \end{array}$

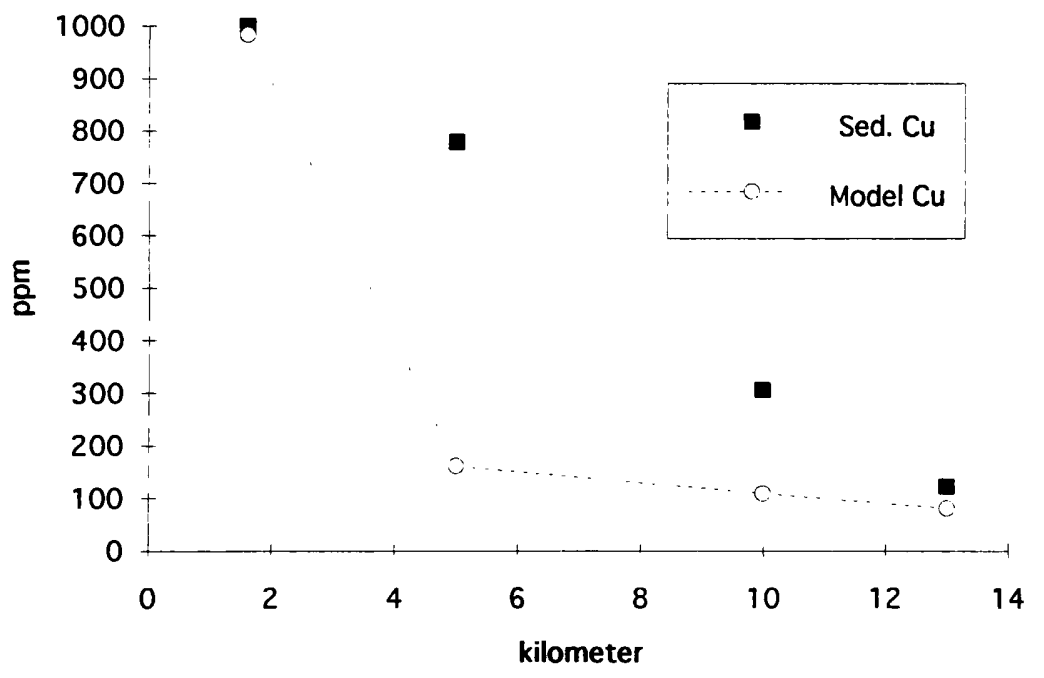


Appendix III. Models of Mined Deposits

\section{A. Silver Bow Creek-Clark Fork River Model}

Silver Bow Creek originates in Butte, Montana, home of one of the world's largest copper deposits. The ore deposit at Butte consists of a central zone of copper mineralization surrounded by a much larger zone of silverlead-zinc veins. Mining began in the late 1800's and continues today. In the early days tailings were discharged directly into Silver Bow Creek, causing aggradation of the floodplain. Improved mining practices have eliminated the direct input of metals, but tailings stored on the floodplain continue to provide a tremendous input of metals to the Clark Fork River.

Silver Bow Creek and the Clark Fork River were modeled in separate sections because the tailings ponds at their confluence alters the slope of the dispersion train. As a result, different values for exaggerated area and concentration were required to fit the dispersion train above and below the tailings ponds. The exaggerated copper, lead and zinc anomalies in the Clark Fork basin were successfulty modeled (Models 10-12). The pre-mining metal anomalies were found to be amplified 150 times for lead, 530 times for copper, and 1400 times for zinc. The relative amplification of the various metals seems to relate to the chemical mobility of the metal. Geochemically mobile metals would have been more depleted in the pre-mining anomaly than more stable elements like lead, and would be readily liberated from the tailings stored on the floodplain after mining. It is possible that the exaggerated anomaly required to match the lead anomaly reflects only the physical erosion of floodplain-stored tailings, while the exaggerated anomalles required to represent the copper and zinc anomalies represent a substantial geochemical component in addition to the physical component. 
Model 10 Clark Fork River $\mathrm{Cu}$

\begin{tabular}{rrrrrrr} 
Mile & Sed. $\mathbf{C u}$ & Pb & Zn & \multicolumn{2}{c}{ mile } & \multicolumn{2}{c}{ Area } & Model Cu \\
23.25 & 8583 & 1699 & 8343 & 18.00 & 124 & 11414 \\
25.35 & 8638 & 2170 & 6630 & 26.00 & 228 & 8322 \\
27.05 & 10240 & 2140 & 7458 & 32.00 & 323 & 6690 \\
29.35 & 10506 & 1663 & 8882 & 35.00 & 374 & 6038 \\
30.05 & 11502 & 1792 & 9556 & 40.00 & 468 & 5140 \\
30.85 & 11595 & 1789 & 9567 & 60.00 & 920 & 1812 \\
31.65 & 11495 & 1531 & 10084 & 80.00 & 1485 & 1211 \\
32.35 & 8529 & 1290 & 9121 & 100.00 & 2154 & 873 \\
34.35 & 9396 & 1255 & 10612 & 120.00 & 2919 & 665 \\
34.85 & 10276 & 1258 & 11554 & 140.00 & 3775 & 527 \\
36.75 & 7404 & 1301 & 8519 & 160.00 & 4716 & 431 \\
37.75 & 7308 & 1165 & 8575 & 200.00 & 6840 & 309 \\
40.35 & 3767 & 537 & 5507 & 250.00 & 9921 & 222 \\
45.95 & 928 & 128 & 1198 & 300.00 & 13444 & 171 \\
46.69 & 2298 & 235 & 3561 & & & \\
46.95 & 1190 & 183 & 1667 & & Ao & Co \\
47.45 & 1067 & 150 & 1757 & & 3 & 2000 \\
50.75 & 1650 & 196 & 1839 & SBC & Ax & Cx \\
51.31 & 1558 & 156 & 2062 & & 160 & 20000 \\
52.15 & 1782 & 231 & 1773 & CFR & Ax & Cx \\
54.05 & 1462 & 195 & 1619 & & 200 & 10000 \\
\hline
\end{tabular}

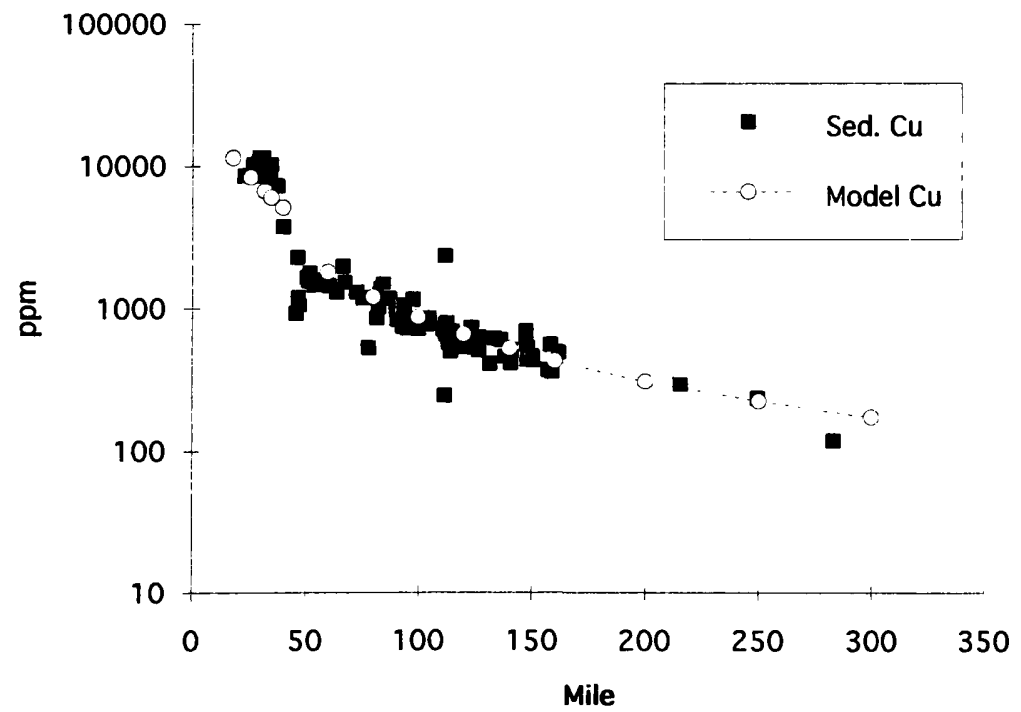


Model 11 Clark Fork River Pb

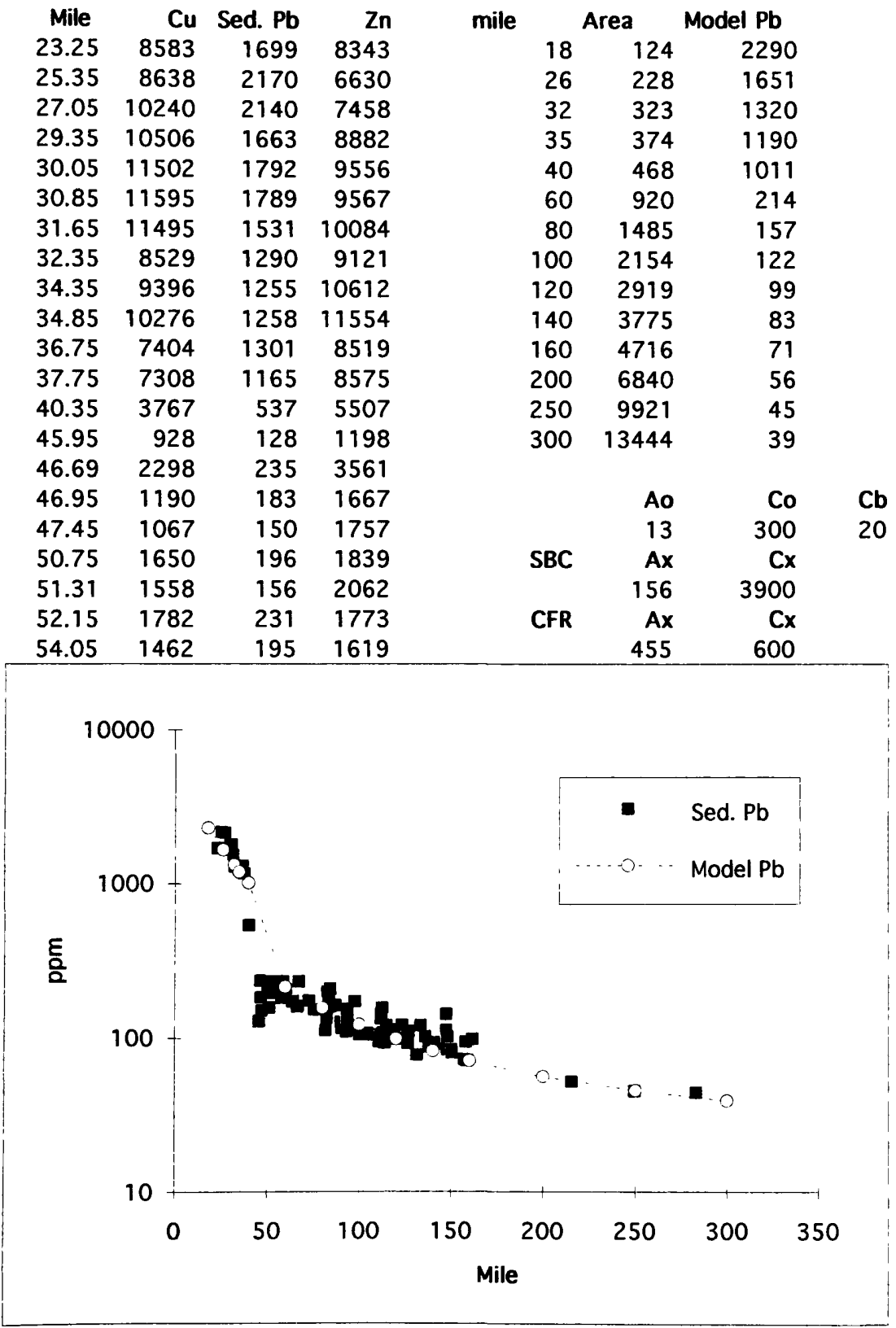


Model 12 Clark Fork River Zn

\begin{tabular}{rrrrrrr} 
Mile & $\mathbf{C u}$ & Pb & Sed. Zn & mile & Area & Model Zn \\
23.25 & 8583 & 1699 & 8343 & 18.00 & 124 & 10992 \\
25.35 & 8638 & 2170 & 6630 & 26.00 & 228 & 8787 \\
27.05 & 10240 & 2140 & 7458 & 32.00 & 323 & 7446 \\
29.35 & 10506 & 1663 & 8882 & 35.00 & 374 & 6871 \\
30.05 & 11502 & 1792 & 9556 & 40.00 & 468 & 6037 \\
30.85 & 11595 & 1789 & 9567 & 60.00 & 920 & 2522 \\
31.65 & 11495 & 1531 & 10084 & 75.00 & 1334 & 2012 \\
32.35 & 8529 & 1290 & 9121 & 100.00 & 2154 & 1452 \\
34.35 & 9396 & 1255 & 10612 & 125.00 & 3125 & 1108 \\
34.85 & 10276 & 1258 & 11554 & 150.00 & 4235 & 883 \\
36.75 & 7404 & 1301 & 8519 & 175.00 & 5475 & 728 \\
37.75 & 7308 & 1165 & 8575 & 200.00 & 6840 & 618 \\
40.35 & 3767 & 537 & 5507 & 250.00 & 9921 & 474 \\
45.95 & 928 & 128 & 1198 & 300.00 & 13444 & 386 \\
46.69 & 2298 & 235 & 3561 & & & \\
46.95 & 1190 & 183 & 1667 & & Ao & Co \\
47.45 & 1067 & 150 & 1757 & & 13 & 240 \\
50.75 & 1650 & 196 & 1839 & Cb & 125 \\
51.31 & 1558 & 156 & 2062 & & Ax & Cx \\
52.15 & 1782 & 231 & 1773 & CFR & Ax & Cx \\
54.05 & 1462 & 195 & 1619 & & 625 & 6000 \\
\hline
\end{tabular}

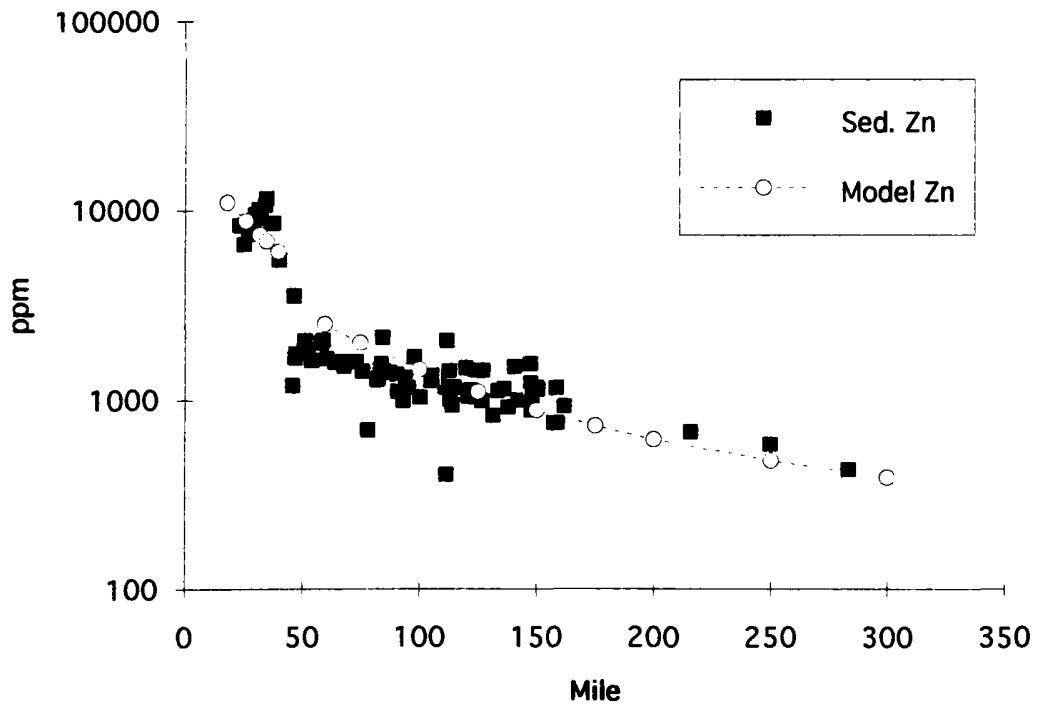




\section{B. Blackfoot River Model}

The Blackfoot River originates in the Heddleston Mining District, western Montana . The Heddleston District hosted several mines, but the bulk of the production in the area is credited to the Mike Horse Mine. Reserves of the Mike Horse Mine were reported to contained 7.14 percent lead and 5.88 percent zinc (McClernan 1983). Substantial metal anomalies extend downstream from the abandoned mine workings (Moore and Luoma, 1991). Of the various metal dispersion trains, copper, lead, and zinc were chosen for modeling. Excellent model fits were obtained for all three metals (Models 1315). Pre-mining anomalies were found to be amplified 700 times for copper and zinc, but only 60 times for lead. As in the Clark Fork River, it is suspected that the relative difference in input relates to the chemical mobility of the metals. The headwaters of the Blackfoot receive acid drainage from the abandoned mines (Moore and Luoma, 1991), apparently contributing far more copper and zinc to the river sediments than lead. It is suspected that the lead anomaly reflects physical erosion of mine wastes, while the copper and zinc anomalies reflect substantial geochemical inputs as well. 
Model 13 Blackfoot River $\mathrm{Cu}$

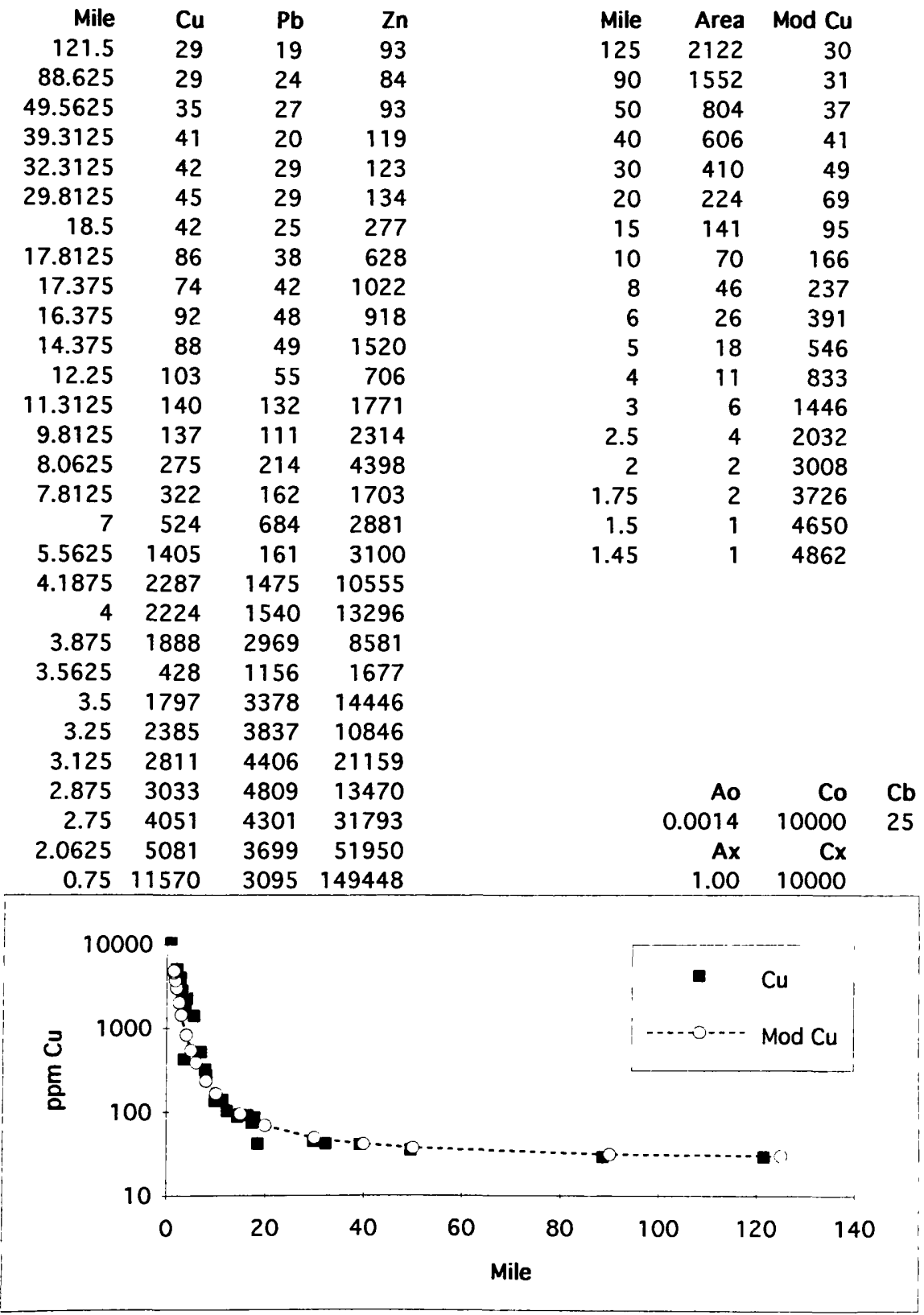


Model 14 Blackfoot River Pb

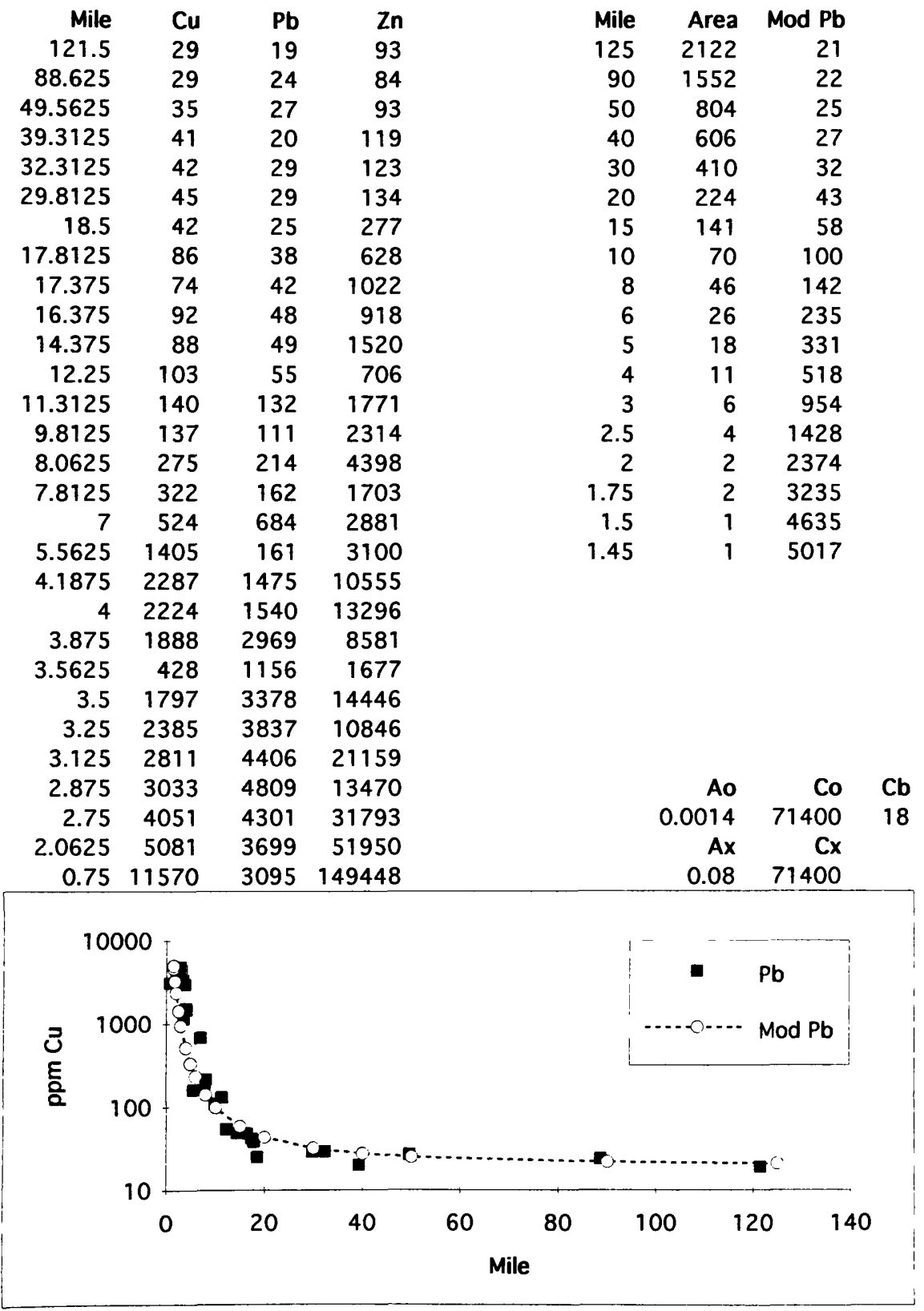


Model 15 Blackfoot River Zn

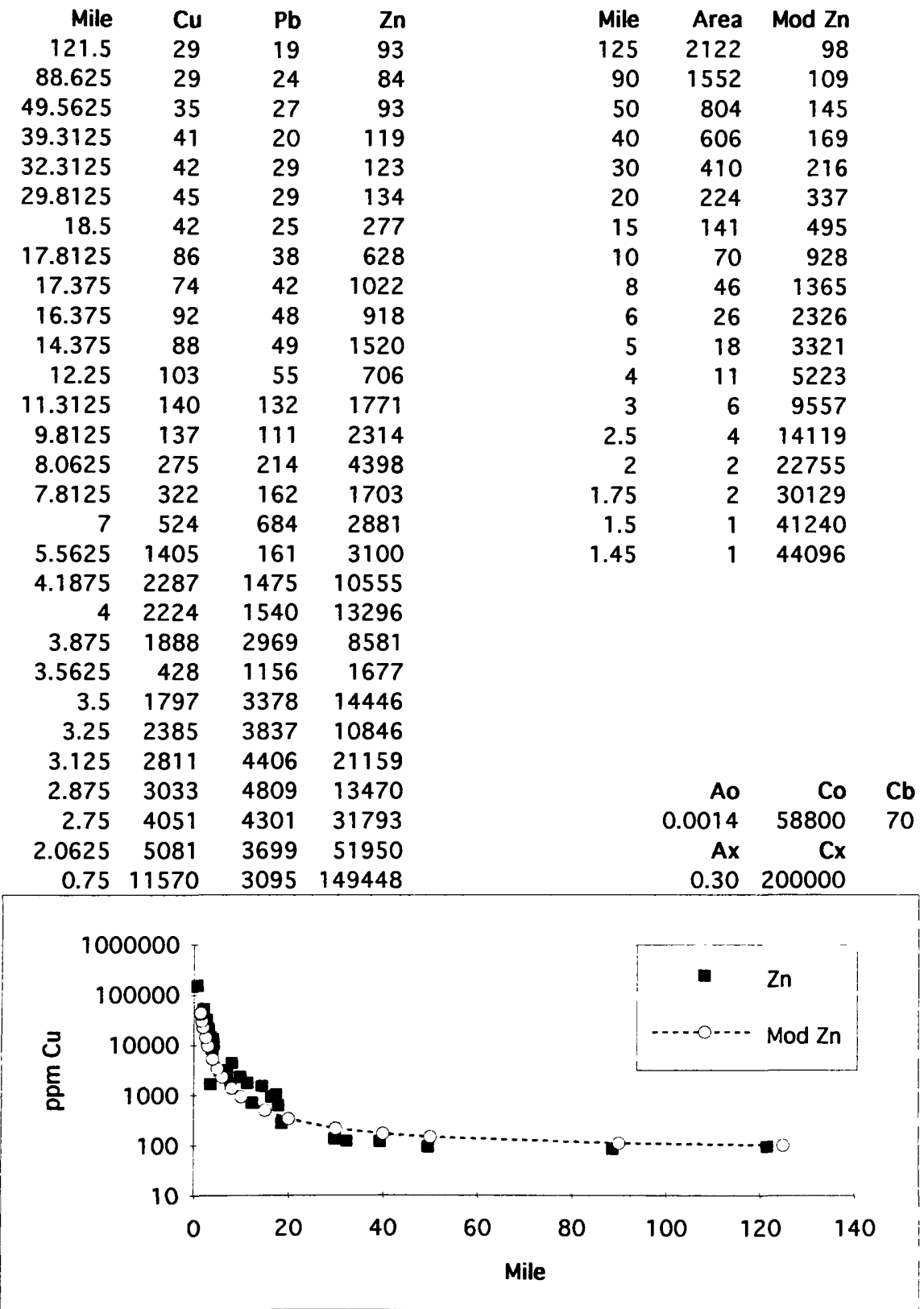




\section{Flint Creek Model}

The large lead and zinc anomalies in the sediments of Flint Creek were successfully modeled using enrichment factors of 325 and 400 respectively (Models 16,17). Manganese was found to be too reactive in the sediments to model reliably. The history of mining in many of the tributary drainages originating in the Flint Creek Range required manual calculation of basin background values for lead as various enriched tributaries enter Flint Creek. Background was calculated at each model point by assigning tributary sediment values to the area of the tributary drainage and updating the total average background as each additional tributary entered. This technique provided a better fit than assuming a uniform single background concentration, which is not the case in the Flint Creek Valley. Another observed feature of the model fits is that the peak of the dispersion train in Flint Creek appears to have been rounded off since mining operations ceased. This is attributed to slight exhaustion of the source material since mining operations ceased. 
Model 16 Flint Creek Pb

$\begin{array}{rrrrrrrrr}\text { Mile } & \text { As } & \text { Mn } & \text { Sed. Pb } & \text { Zn } & \text { Cb Pb } & \text { Mile } & \text { Area } & \text { Mod Pb } \\ 3.50 & 25 & 1644 & 57 & 187 & 110 & 20 & 147 & 712 \\ 12.00 & 307 & 1299 & 161 & 352 & 100 & 23 & 179 & 597 \\ 14.00 & 456 & 2499 & 339 & 931 & 95 & 24 & 204 & 533 \\ 16.00 & 408 & 5119 & 441 & 1091 & 88 & 28 & 251 & 445 \\ 17.00 & 443 & 4527 & 518 & 1291 & 85 & 33 & 331 & 356 \\ 20.00 & 428 & 4978 & 512 & 1303 & 70 & 36 & 392 & 299 \\ 22.50 & 508 & 5336 & 571 & 1547 & & & & \\ 24.30 & 531 & 5136 & 485 & 1490 & & & & \\ 27.50 & 462 & 5416 & 462 & 1320 & & & & \\ 32.50 & 367 & 3612 & 378 & 1092 & & & & \\ 36.00 & 224 & 2562 & 270 & 780 & & & & \end{array}$

$\begin{array}{llrrrrrr}\text { bgd } & 47 & 798 & 280 & 530 & \text { Ao } & \text { Co } & \text { Cb } \\ \text { bgd } & \text { bd } & 394 & 23 & 240 & 0.01 & 28000 & 70 \\ \text { bgd } & \text { bd } & 460 & 27 & 67 & \text { Ax } & \text { Cx } & \end{array}$

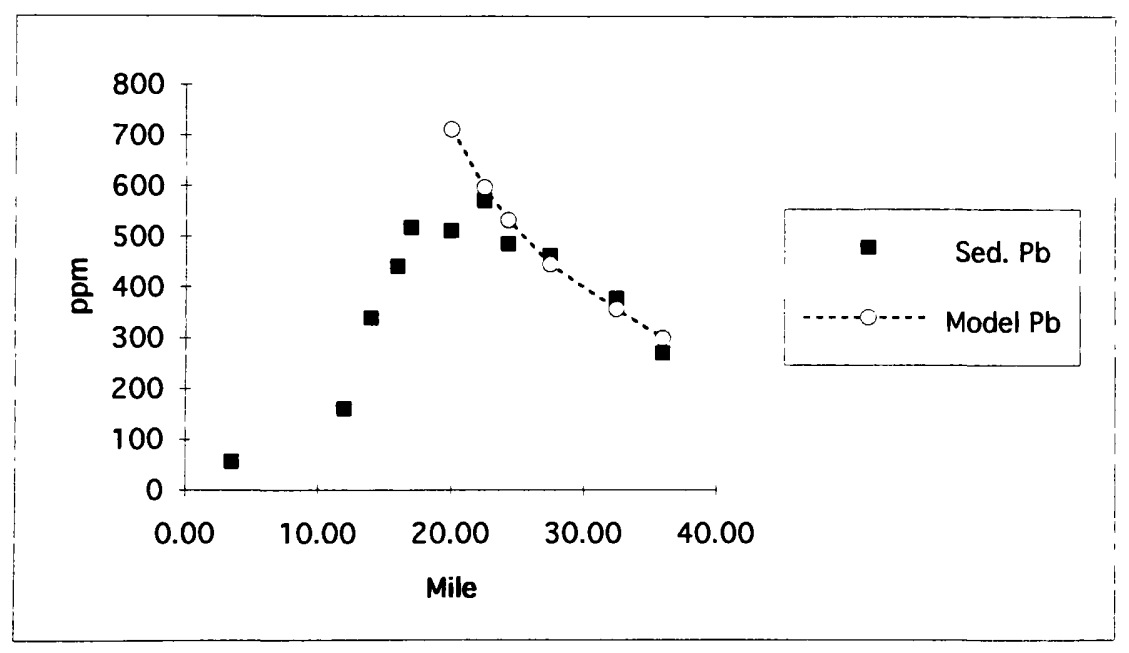


Model 17 Flint Creek Zn

$\begin{array}{rrrrrrrrr}\text { Mile } & \text { As } & \text { Mn } & \text { Pb } & \text { Sed. Zn } & \text { Cb Pb } & \text { Mile } & \text { Area } & \text { Model Zn } \\ 3.50 & 25 & 1644 & 57 & 187 & 50 & 20.00 & 147 & 1913 \\ 12.00 & 307 & 1299 & 161 & 352 & 87 & 22.50 & 179 & 1614 \\ 14.00 & 456 & 2499 & 339 & 931 & 87 & 24.30 & 204 & 1447 \\ 16.00 & 408 & 5119 & 441 & 1091 & 150 & 27.50 & 251 & 1218 \\ 17.00 & 443 & 4527 & 518 & 1291 & 125 & 32.50 & 331 & 974 \\ 20.00 & 428 & 4978 & 512 & 1303 & 110 & 36.00 & 392 & 854 \\ 22.50 & 508 & 5336 & 571 & 1547 & 100 & & & \\ 24.30 & 531 & 5136 & 485 & 1490 & 95 & & & \\ 27.50 & 462 & 5416 & 462 & 1320 & 88 & & & \\ 32.50 & 367 & 3612 & 378 & 1092 & 85 & & & \\ 36.00 & 224 & 2562 & 270 & 780 & 70 & & & \end{array}$

$\begin{array}{lrrrrrrr}\text { bgd } & 47 & 798 & 280 & 530 & \text { Ao } & \text { Co } & \text { Cb } \\ \text { bgd } & \text { bd } & 394 & 23 & 240 & 0.01 & 65000 & 200 \\ \text { bgd } & \text { bd } & 460 & 27 & 67 & \text { Ax } & \text { Cx } & \\ & & & & & 4 & 65000 & \end{array}$

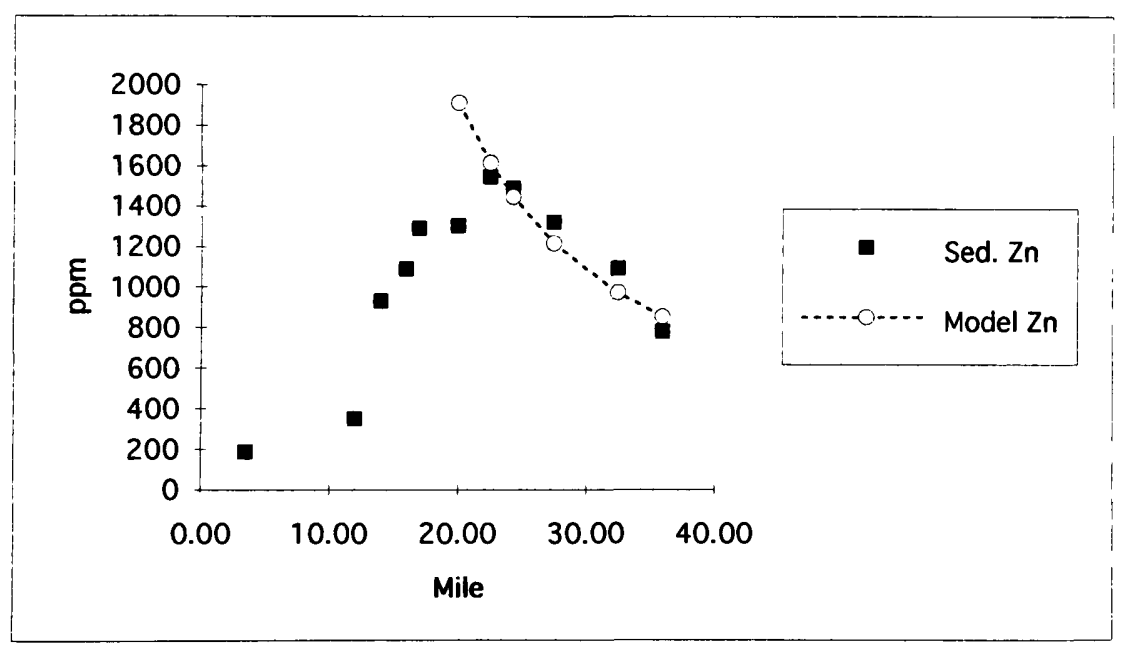




\section{Dunkleberg and Douglas Creek Models}

The Dunkleberg Creek drainage contains the abandoned workings of the Forest Rose Mine, located in the shale and limestone of the Dunkleberg anticline. About 31,000 cubic yards of waste rock and tailings are present on the site, left over from abandoned silver, lead, and zinc mining in the district. Dunkleberg Creek had been allowed to flow through the tailings, but has recently been re-routed following a breach of tailings containment. Anomalous values for several metals have been reported in the sediments of Dunkleberg Creek (Johnson, 1994); lead was chosen for modeling. In order to successfully model the lead anomaly in Dunkleberg Creek, a high local background value of $625 \mathrm{ppm}$ lead was required in order to explain the two mile level portion of the dispersion train at $625 \mathrm{ppm}$ (Model 18). This is a plausible assumption if the district is host to more lead-zinc veins than the Forest Rose mine exploited. If the high background in the drainage is natural, then the impact from the Forest Rose mine is minimal. If, on the other hand, the level portion of the dispersion train is the result of unknown anthropogenic causes, then the contamination of the basin is more severe.

The Douglas Creek drainage is just over a pass from the Dunkleberg drainage in similar geologic terrain. The ruins of the Wasa Mine mark the very headwaters of Douglas Creek. The creek originates from one of the old adits, then disappears under a small pile of waste rock, re-emerging at the lower end. Anomalous dispersion trains were reported for several metals in the sediments of Douglas creek (Nagorski and Sjostrom, 1994). Copper, lead, and zinc were chosen for modeling (Models 19-21). The zinc and copper anomalies were found to be amplified 4000 and 6000 times, respectively, in contrast to an amplification of the lead anomaly of only 20 times. This marked difference is once again attributed to the chemical mobility of the elements. 
Model 18 Dunkleberg Creek-Forest Rose Mine Pb (Johnson, 1994)

\begin{tabular}{|c|c|c|c|c|c|}
\hline Mile & Sed. $\mathrm{Pb}$ & Mile & Area & Model Pb & $\mathrm{Cb} \mathrm{Pb}$ \\
\hline 0.01 & 10361 & 0.001 & 0.002 & 14484 & 625 \\
\hline 0.01 & 10852 & 0.005 & 0.01 & 7088 & 625 \\
\hline 0.01 & 11426 & 0.01 & 0.02 & 4502 & 625 \\
\hline 0.10 & 1403 & 0.1 & 0.2 & 1098 & 625 \\
\hline 0.14 & 1053 & 0.2 & 0.4 & 864 & 625 \\
\hline 0.17 & 936 & 0.4 & 0.8 & 745 & 625 \\
\hline 0.26 & 694 & 0.6 & 1.2 & 705 & 625 \\
\hline 0.71 & 626 & 1 & 2 & 673 & 625 \\
\hline 1.01 & 834 & 2 & 4 & 649 & 625 \\
\hline 1.31 & 631 & 3 & 6 & 516 & 500 \\
\hline 1.61 & 784 & 4 & 8 & 312 & 300 \\
\hline 1.61 & 814 & 5 & 10 & 170 & 160 \\
\hline 2.01 & 726 & 5.6 & 11.2 & 99 & 90 \\
\hline 4.21 & 254 & & & & \\
\hline 3.11 & 504 & Ao & Co & Ax & Cx \\
\hline 5.21 & 137 & 0.00001 & 20000 & 0.005 & 20000 \\
\hline 0.01 & 12253 & $\mathrm{Cb}$ & & & \\
\hline 0.01 & 13495 & 625 & & & \\
\hline
\end{tabular}

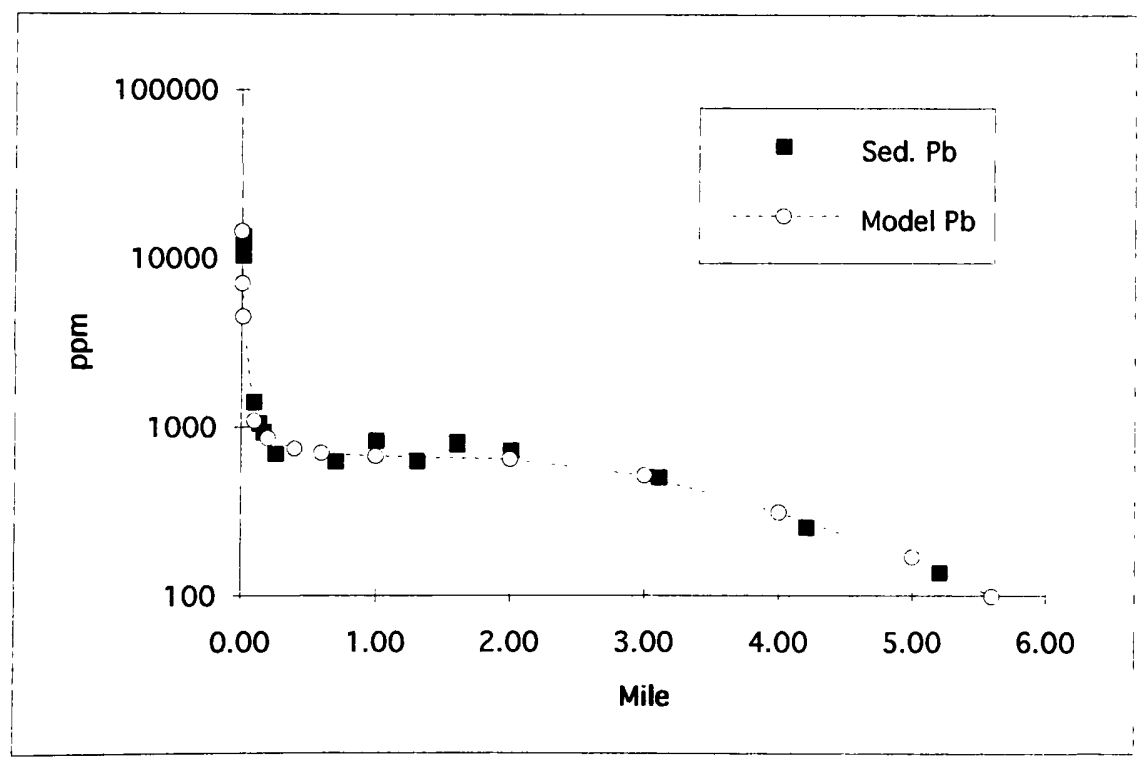


Model 19 Douglas Creek Cu (Nagorski and Sjostrom, 1994)

$\begin{array}{rrrrrrrr}\text { Sed. Cu } & \text { Sed. Pb } & \text { Sed. Zn } & \text { Mile } & \text { Mile } & \text { Area } & \text { Model Cu } & \text { Ao } \\ 1830 & 368 & 14755 & 0.00 & 0 & 0.10 & 1877 & 0.0001 \\ 1818 & 246 & 12762 & 0.01 & 0.01 & 0.11 & 1836 & \text { Co } \\ 3461 & 222 & 27013 & 0.03 & 0.03 & 0.12 & 1757 & 900 \\ 1424 & 190 & 13946 & 0.05 & 0.05 & 0.13 & 1681 & \text { Ax } \\ 987 & 153 & 9911 & 0.06 & 0.06 & 0.14 & 1644 & 0.2 \\ 2076 & 187 & 23589 & 0.08 & 0.08 & 0.16 & 1573 & \text { Cx } \\ 1795 & 206 & 23155 & 0.11 & 0.11 & 0.18 & 1473 & 2800 \\ 1513 & 166 & 22963 & 0.16 & 0.16 & 0.23 & 1322 & \text { Cb } \\ 223 & 77 & 2335 & 0.21 & 0.21 & 0.27 & 1190 & 15 \\ 506 & 95 & 6844 & 0.51 & 0.51 & 0.63 & 684 & \\ 287 & 75 & 3303 & 0.81 & 0.81 & 1.10 & 443 & \\ 293 & 66 & 4809 & 1.31 & 1.31 & 2.10 & 257 & \\ 203 & 53 & 4128 & 2.41 & 2.41 & 5.11 & 120 & \\ 132 & 48 & 2769 & 2.51 & 2.51 & 5.43 & 114 & \\ 85 & 51 & 1420 & 3.21 & 3.21 & 7.92 & 84 & \\ 85 & 48 & 1570 & 3.70 & 3.7 & 9.87 & 70 & \\ 28 & 29 & 384 & 7.42 & 7.42 & 29.83 & 34 & \end{array}$

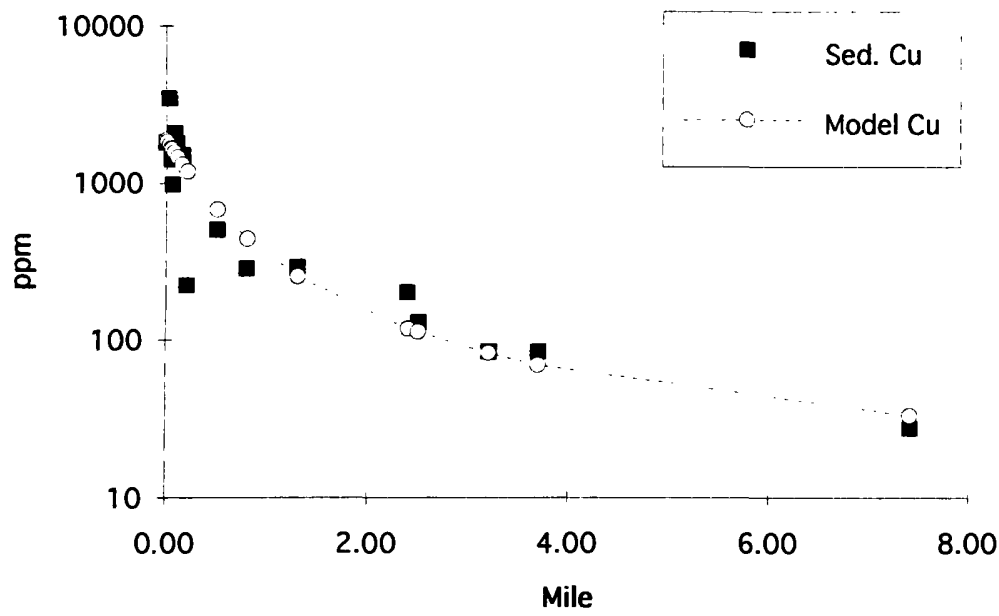


Model 20 Douglas Creek Pb (Nagorski and Sjostrom, 1994)

$\begin{array}{rrrrrrrr}\text { Sed. Cu } & \text { Sed. Pb } & \text { Sed. Zn } & \text { Mile } & \text { Mile } & \text { Area } & \text { Model Pb } & \text { Ao } \\ 1830 & 368 & 14755 & 0.00 & 0 & 0.10 & 341 & 0.0001 \\ 1818 & 246 & 12762 & 0.01 & 0.01 & 0.11 & 322 & \text { Co } \\ 3461 & 222 & 27013 & 0.03 & 0.03 & 0.12 & 291 & 15000 \\ 1424 & 190 & 13946 & 0.05 & 0.05 & 0.13 & 264 & \mathbf{A x} \\ 987 & 153 & 9911 & 0.06 & 0.06 & 0.14 & 253 & 0.002 \\ 2076 & 187 & 23589 & 0.08 & 0.08 & 0.16 & 233 & \mathbf{C x} \\ 1795 & 206 & 23155 & 0.11 & 0.11 & 0.18 & 207 & 15000 \\ 1513 & 166 & 22963 & 0.16 & 0.16 & 0.23 & 176 & \mathbf{C b} \\ 223 & 77 & 2335 & 0.21 & 0.21 & 0.27 & 153 & 45 \\ 506 & 95 & 6844 & 0.51 & 0.51 & 0.63 & 92 & \\ 287 & 75 & 3303 & 0.81 & 0.81 & 1.10 & 72 & \\ 293 & 66 & 4809 & 1.31 & 1.31 & 2.10 & 59 & \\ 203 & 53 & 4128 & 2.41 & 2.41 & 5.11 & 51 & \\ 132 & 48 & 2769 & 2.51 & 2.51 & 5.43 & 51 & \\ 85 & 51 & 1420 & 3.21 & 3.21 & 7.92 & 49 & \\ 85 & 48 & 1570 & 3.70 & 3.7 & 9.87 & 48 & \mathbf{C b} \\ 28 & 29 & 384 & 7.42 & 7.42 & 29.83 & 31 & 30\end{array}$

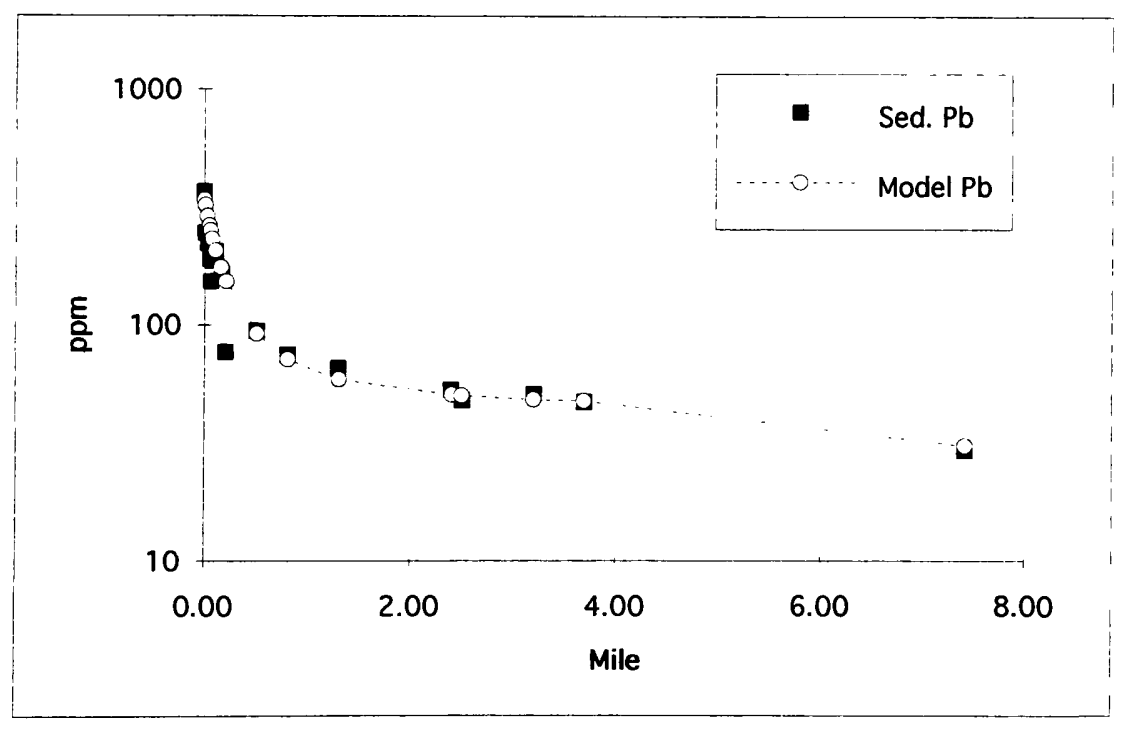


Model 21 Douglas Creek Zn (Nagorski and Sjostrom, 1994)

$\begin{array}{rrrrrrrr}\text { Sed. Cu } & \text { Sed. Pb } & \text { Sed. Zn } & \text { Mile } & \text { Mile } & \text { Area } & \text { Model Zn } & \text { Ao } \\ 1830 & 368 & 14755 & 0.00 & 0 & 0.10 & 19254 & 0.0001 \\ 1818 & 246 & 12762 & 0.01 & 0.01 & 0.11 & 19000 & \text { Co } \\ 3461 & 222 & 27013 & 0.03 & 0.03 & 0.12 & 18494 & 22300 \\ 1424 & 190 & 13946 & 0.05 & 0.05 & 0.13 & 17991 & \text { Ax } \\ 987 & 153 & 9911 & 0.06 & 0.06 & 0.14 & 17742 & 0.4 \\ 2076 & 187 & 23589 & 0.08 & 0.08 & 0.16 & 17248 & \text { Cx } \\ 1795 & 206 & 23155 & 0.11 & 0.11 & 0.18 & 16524 & 24000 \\ 1513 & 166 & 22963 & 0.16 & 0.16 & 0.23 & 15367 & \text { Cb } \\ 223 & 77 & 2335 & 0.21 & 0.21 & 0.27 & 14284 & 100 \\ 506 & 95 & 6844 & 0.51 & 0.51 & 0.63 & 9356 & \\ 287 & 75 & 3303 & 0.81 & 0.81 & 1.10 & 6465 & \\ 293 & 66 & 4809 & 1.31 & 1.31 & 2.10 & 3927 & \\ 203 & 53 & 4128 & 2.41 & 2.41 & 5.11 & 1836 & \\ 132 & 48 & 2769 & 2.51 & 2.51 & 5.43 & 1740 & \\ 85 & 51 & 1420 & 3.21 & 3.21 & 7.92 & 1250 & \\ 85 & 48 & 1570 & 3.70 & 3.7 & 9.87 & 1031 & \\ 28 & 29 & 384 & 7.42 & 7.42 & 29.83 & 416 & \end{array}$

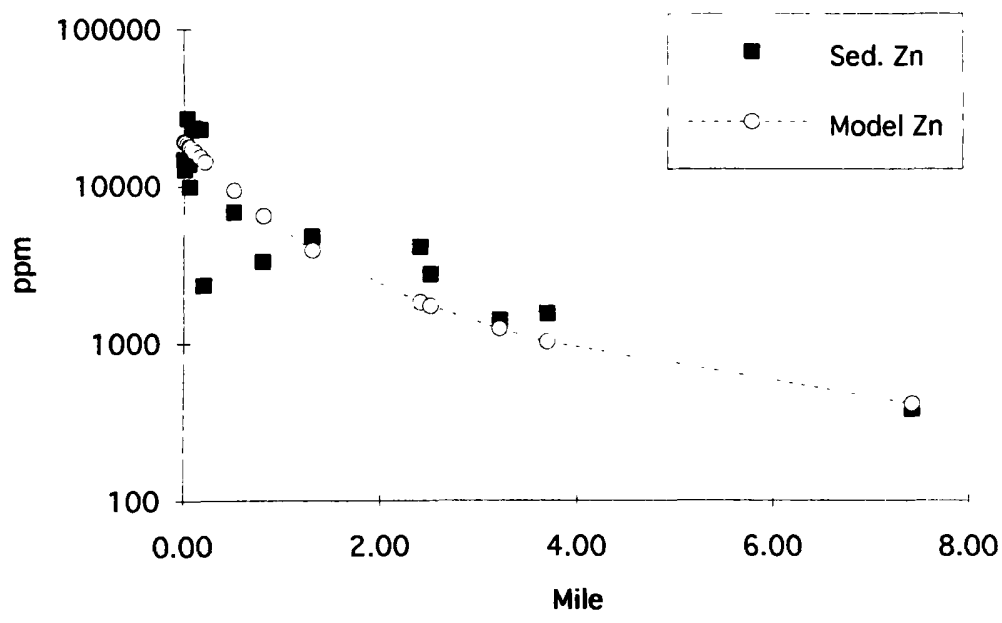


E. Fisher and Little Daisy Creek Models

The acid drainage in the headwaters of Fisher Creek displaces the anomaly downstream. Metals are carried in solution until the pH nears neutral, causing the precipitation and adsorption of the metals onto the stream sediments. The copper and lead anomalies in Fisher Creek were modeled, but required some exaggeration of the estimated anomaly in order to match the downstream portion of the stream sediment data (Models 22, 23). The model was not able to account for the observed sediment metal concentrations within the acidic reach due to downstream displacement of the anomaly by the acid drainage.

Little Daisy Creek was too acidic in the reach sampled to be successfully modeled, but provides an interesting look at the effects of $\mathrm{pH}$ on sediment metal concentrations. An attempt was made to model the copper and lead anomalies in the drainage with little success. The acidity of the sampled stream reach made it impossible to accurately model the copper dispersion train (Model 24). Better results were achieved by modeling the downstream portion of the lead anomaly, which partitions into the sediment at a lower $\mathrm{pH}$ than copper. An acceptable fit was achieved to the sample points where the pH was $>4.9$ (Model 25). The Little Daisy drainage illustrates the problems resulting from the violation of the assumption of conservation caused by acidic stream water. 
Model 22 New World District Fisher Creek Cu

\begin{tabular}{lrrrrrrr} 
sample & mile & Sed. Cu & pb & pH & mile & \multicolumn{2}{c}{ Area Model Cu } \\
NWF1 & 0.65 & 355 & 155 & 3.46 & 1 & 1.00 & 4823 \\
NWF2 & 0.85 & 336 & 148 & 3.42 & 1.5 & 1.97 & 3021 \\
NWF3 & 1.15 & 402 & 159 & 3.74 & 2 & 3.17 & 2065 \\
NWF4 & 1.55 & 981 & 166 & 5 & 2.5 & 4.61 & 1507 \\
NWF5 & 2 & 2758 & 179 & 5.7 & 3 & 6.24 & 1155 \\
NWF6 & 2.35 & 4705 & 178 & 6.35 & 4 & 10.08 & 752 \\
NWF7 & 2.9 & 3815 & 167 & 6.57 & 6 & 19.81 & 410 \\
NWF8 & 4.3 & 3726 & 159 & 7.1 & 10 & 46.42 & 198 \\
NWCFY5 & 5.35 & 3662 & 157 & $>7$ & 15 & 91.23 & 118 \\
NWCFY4 & 6.45 & 677 & 83 & $>7$ & 20 & 147.36 & 87 \\
NWCFY3 & 11.65 & 146 & 28 & $>7$ & & & \\
NWCFY2 & 15.35 & 108 & 32 & $>7$ & Ao & Co & Cb \\
NWCFY1 & 23 & 81 & 26 & $>7$ & 0.5 & 2000 & 35 \\
& & & & & Ax & Cx &
\end{tabular}

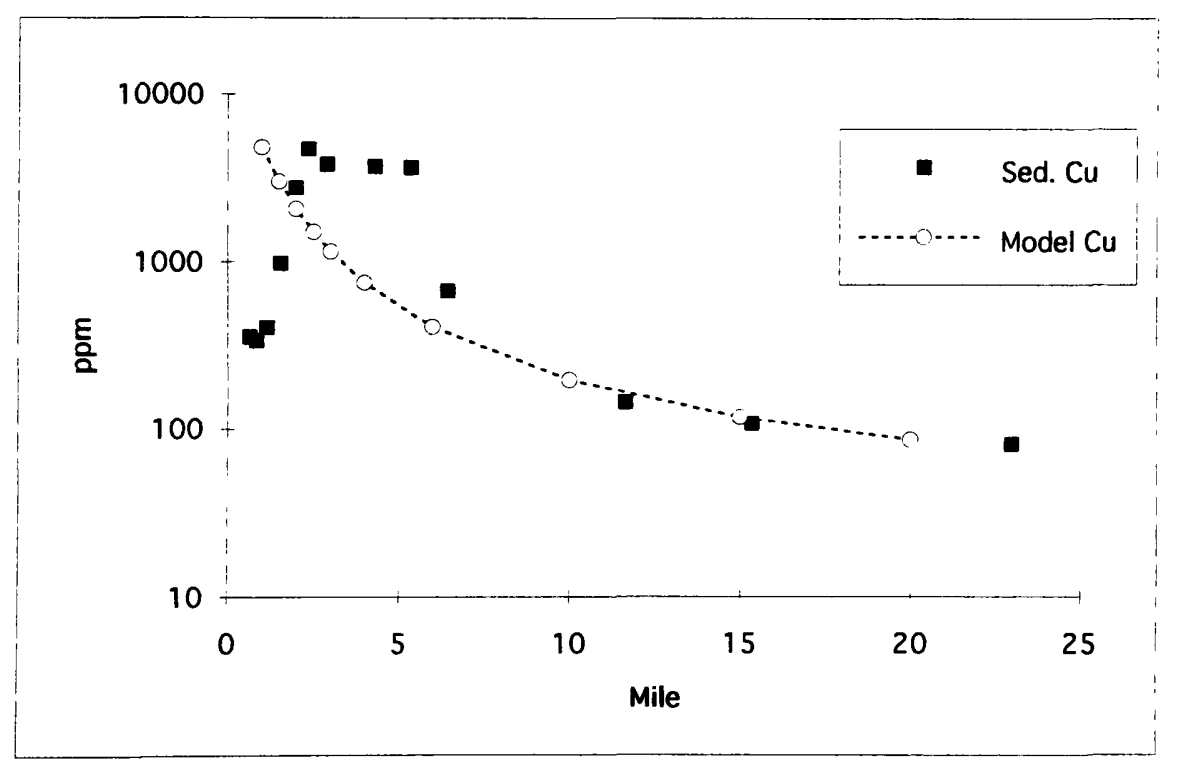


Model 23 New World District Fisher Creek Pb

\begin{tabular}{lrrrrrrr} 
sample & mile & Cu & Sed. Pb & pH & mile & \multicolumn{2}{c}{ Area Model Pb } \\
NWF1 & 0.65 & 355 & 155 & 3.46 & 1 & 1.00 & 204 \\
NWF2 & 0.85 & 336 & 148 & 3.42 & 1.5 & 1.97 & 154 \\
NWF3 & 1.15 & 402 & 159 & 3.74 & 2 & 3.17 & 120 \\
NWF4 & 1.55 & 981 & 166 & 5 & 2.5 & 4.61 & 97 \\
NWF5 & 2 & 2758 & 179 & 5.7 & 3 & 6.24 & 81 \\
NWF6 & 2.35 & 4705 & 178 & 6.35 & 4 & 10.08 & 61 \\
NWF7 & 2.9 & 3815 & 167 & 6.57 & 6 & 19.81 & 43 \\
NWF8 & 4.3 & 3726 & 159 & 7.1 & 10 & 46.42 & 32 \\
NWCFY5 & 5.35 & 3662 & 157 & $>7$ & 17 & 112.40 & 26 \\
NWCFY4 & 6.45 & 677 & 83 & $>7$ & 25 & 213.75 & 24 \\
NWCFY3 & 11.65 & 146 & 28 & $>7$ & & & \\
NWCFY2 & 15.35 & 108 & 32 & $>7$ & Ao & Co & Cb \\
NWCFY1 & 23 & 81 & 26 & $>7$ & 0.5 & 250 & 22 \\
& & & & & Ax & Cx &
\end{tabular}

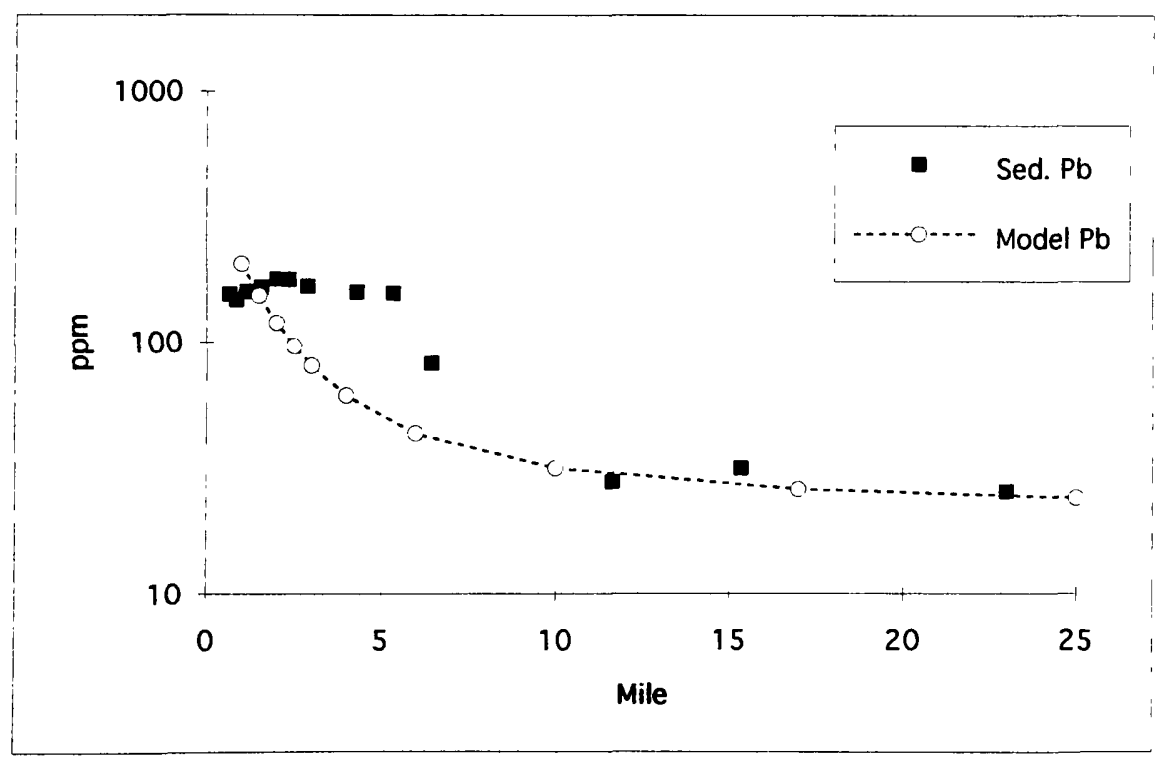


Model 24 New World Little Daisy Cu

$\begin{array}{lrrrrrrr}\text { sample } & \text { mile } & \text { Sed. Cu } & \text { Pb } & \text { pH } & \text { Mile } & \text { At } & \text { Model Cu } \\ \text { NWLD1 } & 0.1 & 600 & 682 & 7.37 & 0.5 & 0.31 & 5912 \\ \text { NWLD2 } & 0.12 & & 334 & 3.26 & 0.75 & 0.62 & 4557 \\ \text { NWLD3 } & 0.2 & 1360 & 369 & 3.43 & 1 & 1.00 & 3544 \\ \text { NWLD4 } & 0.36 & 1610 & 354 & 3.58 & 1.5 & 1.97 & 2273 \\ \text { NWLD5 } & 0.73 & 1588 & 349 & 3.5 & 2 & 3.17 & 1574 \\ \text { NWLD6 } & 1.18 & 598 & 681 & 4.89 & 2.5 & 4.61 & 1159 \\ \text { NWLD8 } & 1.78 & 5752 & 314 & 5.31 & & & \\ \text { NWLD9 } & 2.18 & 4245 & 296 & 7.62 & \text { Ao } & \text { Co } & \text { Cb } \\ & & & & & 0.3 & 2000 & 35 \\ & & & & & \text { Ax } & \text { Cx } & \end{array}$

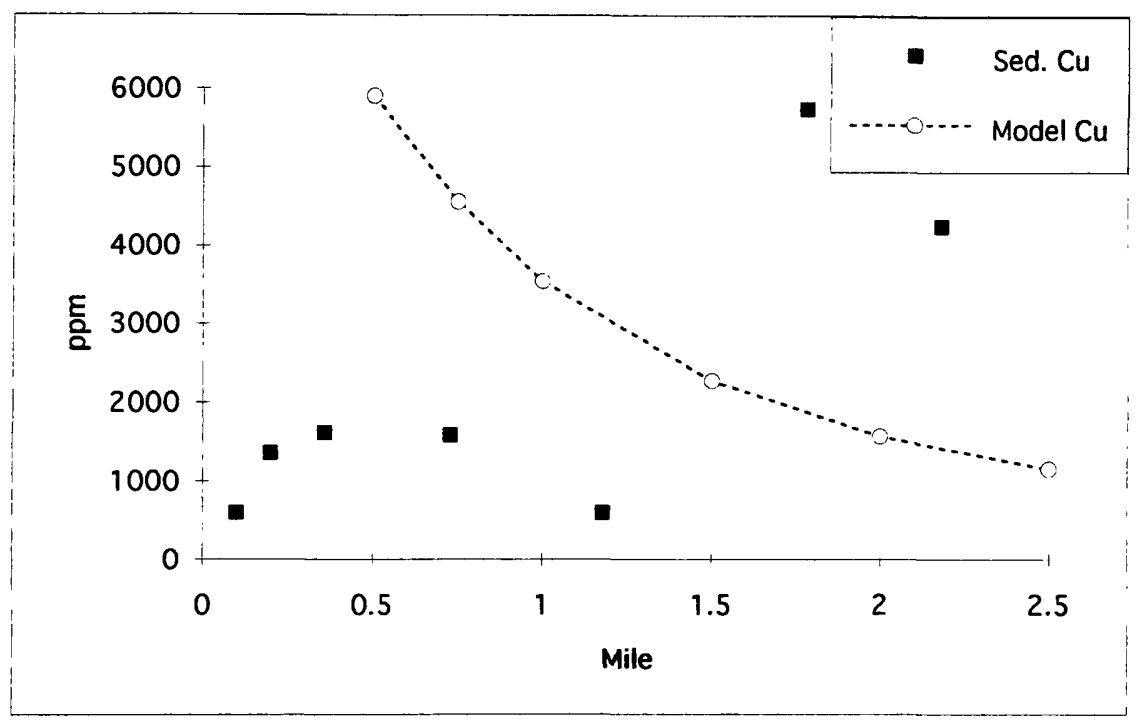


Model 25 New World Little Daisy Pb

$\begin{array}{lrrrrrrr}\text { sample } & \text { mile } & \mathbf{C u} & \text { Sed. Pb } & \mathbf{p H} & \text { Mile } & \text { At } & \text { Model Pb } \\ \text { NWLD1 } & 0.1 & 600 & 682 & 7.37 & 1.2 & 1.36 & 702 \\ \text { NWLD2 } & 0.12 & & 334 & 3.26 & 1.3 & 1.55 & 618 \\ \text { NWLD3 } & 0.2 & 1360 & 369 & 3.43 & 1.5 & 1.97 & 494 \\ \text { NWLD4 } & 0.36 & 1610 & 354 & 3.58 & 1.75 & 2.54 & 389 \\ \text { NWLD5 } & 0.73 & 1588 & 349 & 3.5 & 2 & 3.17 & 317 \\ \text { NWLD6 } & 1.18 & 598 & 681 & 4.89 & 2.25 & 3.86 & 266 \\ \text { NWLD8 } & 1.78 & 5752 & 314 & 5.31 & & & \\ \text { NWLD9 } & 2.18 & 4245 & 296 & 7.62 & \text { Ao } & \text { Co } & \text { Cb } \\ & & & & & 1.36 & 300 & 30 \\ & & & & & \text { Ax } & \text { Cx } & \\ & & & & & 1.36 & 700 & \end{array}$

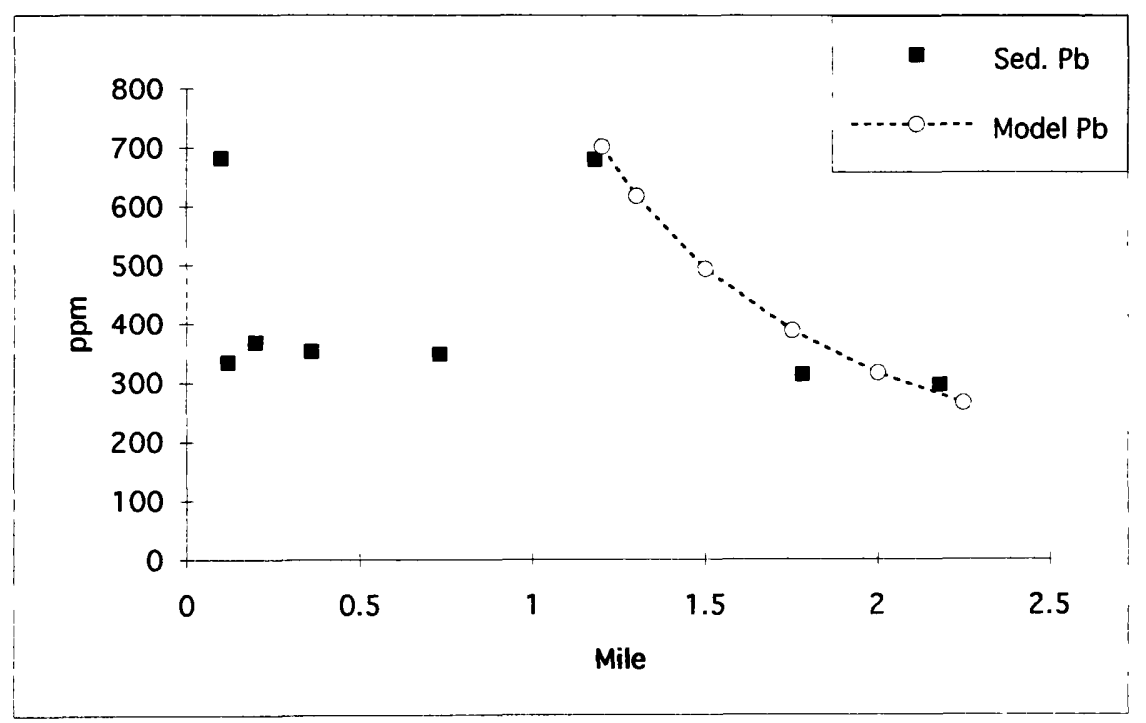




\section{F. Senate Mine Model}

The copper anomaly in the Senate mine drainage was chosen for modeling. The copper dispersion train from the old adit proved to be insignificant, despite a disturbed area of approximately 2500 square meters present on the hillside above the mine. The impact from the old mine seems to be limited to the immediate vicinity of the mine, but an apparently natural copper anomaly was found extending further down the drainage. The extent of mineralization in the drainage is apparently much greater than that exploited by the Senate mine, which would explain the signs of recent exploration activity observed in the drainage.

Modeling was started at the downstream edge of the anomaly, and a good fit to the stream sediment data was achieved (Model 26). No exaggeration of the anomaly was required to match the field data. The anomaly present in the Senate mine drainage was found to have little influence downstream; background values were reached almost immediately below the confluence with the Middle Fork of Rock Creek. 
Model 26 Anaconda-Pintlars Senate Mine Cu

\section{Senate Mine}

kilometer 0.30

0.30

0.55

0.60

0.62

0.64

0.67

0.73

0.90

1.25

2.15

2.15

2.30

3.40

5.50

5.50
Sed. $\mathrm{Cu}$ Sed. Zn

23

25

21666

173

273

324

139

163

242

289

215

213

56

50

32

33
Model Data Mod km

2.1

2.2

2.5

3

4

5

5.6

Ao

1
Area Model $\mathrm{Cu}$

1.13

10.82

12.28

14.88

20.65

27.16

31.40

Co

250
225

50

48

45

41

38

37

$\mathrm{Cb}$

30

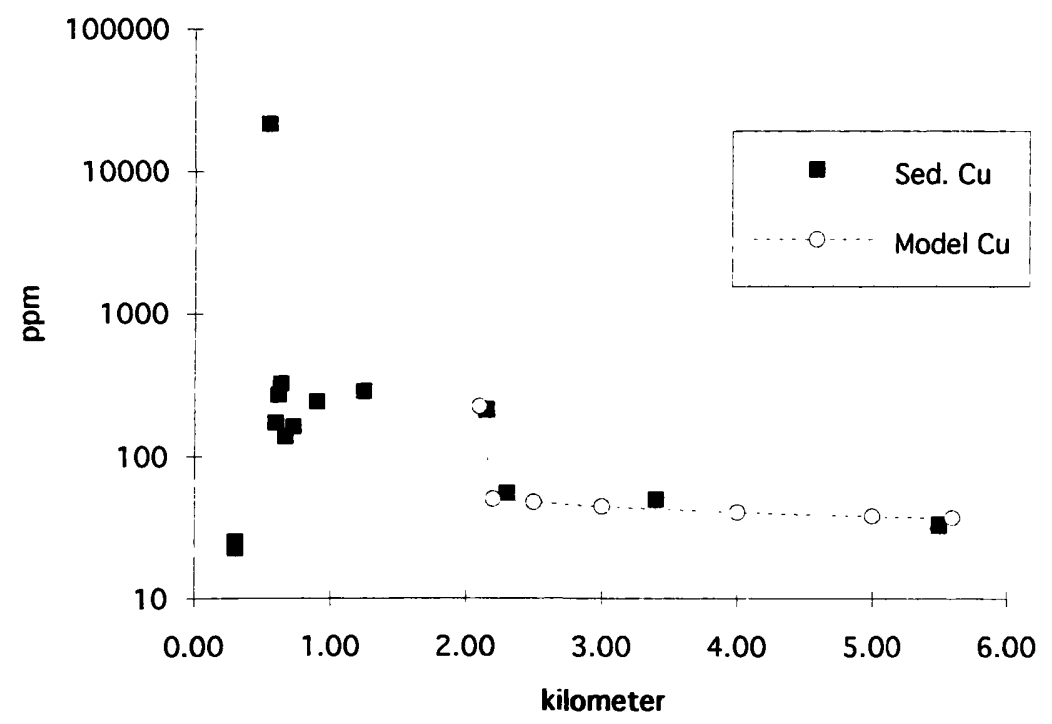




\section{Appendix IV. Complete Methods}

\section{A. Field Methods-Sediment Collection}

Samples of fine-grained active channel sediments were used for modeling. The samples were collected from the top 1-2 centimeters of recently deposited sediment using a plastic scoop. Small scoops of sediment were collected from as many locations as could be found along a 25-50 meter reach of a river. In smaller streams the sampling density was much higher and samples were collected from as many locations as could be found in a 10-20 meter reach. In smaller, high-gradient streams it was often difficult to locate fine-grained sediment, and samples may have been collected from deposits found in eddies, under rocks, amongst the roots of aquatic vegetation, or wherever fine-grained sediment in contact with stream water could be located. The sediment was wet-sieved through a $63 \mu \mathrm{m}$ synthetic sieve mounted in a large plastic funnel housing. The sediment from various points in a stream reach was homogenized and stirred until enough sediment and stream water had passed through the sieve to fill a $250 \mathrm{ml}$ widemouth HDPE bottle (Nalgene $\left.{ }^{\circledR}\right)$. The bottles were then placed on ice in a cooler as soon as practical after collection. The samples were returned to the lab and centrifuged at $1800-2000 \mathrm{rpm}$ for 15 minutes. The excess liquid was decanted and the bottles placed in a drying oven set at 70 degrees $C$. After the samples were dried, they were ground in the original sample bottle using an acidwashed glass rod. The ground sediment was then transferred into a polystyrene vial for storage using a sheet of weighing paper. Samples were stored in a desiccator until they could be digested. 


\section{B. Lab Methods-Sediment Digestion}

1) Dried, ground sediment samples were weighed into tared, serially numbered, $120 \mathrm{ml}$ Teflon digestion vessels (Savillex Corp. \#578) in batches of seven. Large chunks of clay $(>1 \mathrm{~mm})$ not powdered during grinding were avoided. Target sample weight was 0.5 grams; actual weight was recorded to ten-thousandths of a gram.

2) After seven samples had been weighed, $0.5 \mathrm{ml}$ of Milli-q water was added to each sample. Samples selected for spiking received $0.1 \mathrm{ml}$ of spike, and $0.4 \mathrm{ml}$ Milli-q water. Vessels were swirled and tapped to evenly wet the sediment. All samples were then allowed to sit loosely covered for a period of 30 minutes.

3) $3.75 \mathrm{ml}$ of trace metal grade hydrochloric acid and $1.25 \mathrm{ml}$ of trace metal grade nitric acid were then added to each digestion vessel. Vessels were swirled and tapped to break up any lumps that formed after addition of the acids. Caps were threaded on, but not tightened.

4) After a one hour pre-digestion period, vessel caps on the first batch of seven were tightened using the plastic wrenches supplied by the manufacturer. Pressure relief tops were then carefully tightened. Pressure tops were tightened about $1 / 4$ turn after initial contact was made. The pressure tops were tightened by hand, care being taken not to over or undertighten them. If the pressure top felt like it was seating smoothly on the cap base, it was tightened snugly. Interference from the ribs on the vessel cap was remedied by trimming the tops off the ribs with a razor blade. If the pressure top did seat properly, sample venting could occur during digestion. 
5) A batch of seven vessels was then placed in a plastic cake keeper. Vent tubes for each vessel were inserted into the pressure caps and the free ends immersed in vials containing a weak indicator solution ( 5 drops $0.5 \mathrm{M} \mathrm{NaOH}$ in $250 \mathrm{ml} \mathrm{H}_{2} \mathrm{O}$ with several drops phenolphthalein added). The vials were placed in a beaker half full on water in the center of the cake keeper. The indicator vials were used to detect sample venting from the individual digestion vessels. Samples also vented through the threads of the vessel cap, causing all the indicator solutions to lighten, but not turn clear completely. Duplicate samples were used to determine what level of sample venting was acceptable.

6) The sealed cake-keeper with vessels and indicator vials inside was placed on a microwave turntable carefully centered in the microwave oven. Four $250 \mathrm{ml}$ plastic bottles filled with cold tap water were placed in the four corners of the microwave. The turntable was started and the samples were microwaved on high power ( $\sim 570$ watts) for a period of six minutes.

7) Venting during microwave digestion resulted in a chlorine smell in the vicinity of the oven. During severe venting fumes could get quite strong and care was taken to limit exposure. When the oven cycle was complete, the cake keeper was taken directly to a fume hood. Ideally, the oven should have been operated in a fume hood. The cake keeper was never opened outside a fume hood. After removing the top of the cake keeper, indicator vials were examined to determine which samples, if any vented. Notes were made immediately because all solutions could turn clear in a few moments if one of the vessels had vented severely. Sealed vessels were allowed to cool for a period of at least 15 minutes. 
8) Pressure tops on the cooled vessels were carefully opened IN A FUME HOOD with the pressure release opening pointed INTO the hood. Vessels that had vented did not display a sudden release of pressure. Vessel caps were then loosened with the wrenches and the contents transferred to numbered, preweighed (minus cap) $50 \mathrm{ml}$ centrifuge tubes. Quantitative transfer was achieved by at least three rinses of the vessel and cap with Milli-q water. Care was taken not to use too much water in the earlier rinses in order to prevent overfilling the centrifuge tube.

9) Centrifuge tubes were then brought to a target solution weight of 50 grams using Milli-q water. Centrifuge tubes were supported on the balance in a tared Styrofoam block. Actual weights were recorded on a data sheet next to the empty vial weights to allow later calculation of digest weight.

10) Centrifuge tubes were tightly capped and centrifuged for 5 minutes at 2500 rpm to clarify the digest.

11) Clarified digests were transferred into $60 \mathrm{ml}$ polyethylene storage bottles marked with the complete original sample name for later analysis. 


\section{Modeling Methods}

Modeling was performed on a Apple Macintosh computer using Microsoft Excel version 4.0. Spreadsheets were prepared that contained field data broken down by river kilometer and sediment metal concentration. Desired river kilometers for modeling were entered in a column, then the equation used to calculate total basin area was pasted down alongside. Equation 2 was then pasted in to calculate the metal concentration for each particular river kilometer. Single cells containing the values for original anomaly area and concentration, exaggerated area and concentration, and basin background were hard-linked into equation 2. A plot of model points and field data vs. river kilometer was hot-linked to the spreadsheet and sized to allow alteration of the variables and instantaneous visual feedback of the results on one screen. This arrangement allowed easy visual calibration of the exaggerated area to the field data. Once the model parameters were visually calibrated, A best-fit $A_{X}$ was obtained using a non-linear least squares fit in the program Mathcad ${ }^{\circledR}$. 


\section{Appendix V. Field Data}

Quality Control/Quality Assurance on analytical technique

Table 1. Standard recovery

\begin{tabular}{rcrrrrrrrrr} 
& Al & \multicolumn{1}{c}{ As } & \multicolumn{1}{c}{ Cd } & Cu & Fe & Mg & Mn & Ni & Pb & Zn \\
USGS SED2: & 5530 & 159 & 8.09 & 1188 & 22000 & 4370 & 1573 & 10.30 & 154 & 1626 \\
& 5630 & 160 & 8.39 & 1225 & 20300 & 4410 & 1584 & 10.20 & 161 & 1656 \\
& 5880 & 139 & 7.80 & 1196 & 19900 & 4520 & 1530 & 9.10 & 154 & 1517 \\
& 5940 & 137 & 8.60 & 1165 & 21600 & 4650 & 1530 & 9.90 & 158 & 1591 \\
& 6080 & 150 & 8.51 & 1214 & 22000 & 4830 & 1596 & 10.70 & 163 & 1627 \\
& 6040 & 150 & 8.58 & 1210 & 22100 & 4810 & 1600 & 10.50 & 164 & 1631 \\
& 6105 & 161 & 10 & 1283 & 21178 & 4613 & 1548 & 11 & 170 & 1688 \\
Mean: & 5886 & 151 & 8.61 & 1212 & 21297 & 4600 & 1566 & 10.22 & 161 & 1619 \\
StDev: & 225 & 10 & 0.81 & 37 & 884 & 180 & 30 & 0.59 & 6 & 54 \\
USGS reported: & 8800 & 144 & 8.3 & 1100 & 22800 & 5200 & 1500 & 10.8 & 149 & 1500 \\
Std recovery: & $\mathbf{6 7 \%}$ & $105 \%$ & $104 \%$ & $\mathbf{1 1 0 \%}$ & $\mathbf{9 3 \%}$ & $\mathbf{8 8 \%}$ & $\mathbf{1 0 4 \%}$ & $\mathbf{9 5 \%}$ & $\mathbf{1 0 8 \%}$ & $\mathbf{1 0 8 \%}$
\end{tabular}

Table 2. Duplicate sediment samples

\begin{tabular}{|c|c|c|c|c|c|c|c|c|c|c|}
\hline Dupe recovery: & Al & As & Cd & $\mathrm{Cu}$ & $\mathrm{Fe}$ & Mg & Mn & $\mathbf{N i}$ & $\mathbf{P b}$ & Zn \\
\hline \multirow[t]{13}{*}{ Dupe recovery: } & $103 \%$ & & $87 \%$ & $97 \%$ & $117 \%$ & $97 \%$ & $113 \%$ & $123 \%$ & $111 \%$ & $112 \%$ \\
\hline & $88 \%$ & $108 \%$ & $83 \%$ & $86 \%$ & $93 \%$ & $92 \%$ & $91 \%$ & $102 \%$ & $86 \%$ & $88 \%$ \\
\hline & $92 \%$ & $95 \%$ & $98 \%$ & $96 \%$ & $92 \%$ & $94 \%$ & $96 \%$ & $89 \%$ & $96 \%$ & $96 \%$ \\
\hline & $111 \%$ & $105 \%$ & $136 \%$ & $103 \%$ & $111 \%$ & $104 \%$ & $106 \%$ & $122 \%$ & $110 \%$ & $105 \%$ \\
\hline & $117 \%$ & $112 \%$ & $104 \%$ & $105 \%$ & $111 \%$ & $111 \%$ & $105 \%$ & $109 \%$ & $106 \%$ & $103 \%$ \\
\hline & $101 \%$ & & $112 \%$ & $104 \%$ & $104 \%$ & $112 \%$ & $104 \%$ & $110 \%$ & $104 \%$ & $105 \%$ \\
\hline & $95 \%$ & & $98 \%$ & $102 \%$ & $105 \%$ & $102 \%$ & $103 \%$ & $96 \%$ & $102 \%$ & $103 \%$ \\
\hline & $100 \%$ & $102 \%$ & $101 \%$ & $99 \%$ & $99 \%$ & $100 \%$ & $101 \%$ & $105 \%$ & $101 \%$ & 1029 \\
\hline & $111 \%$ & $93 \%$ & $98 \%$ & $102 \%$ & $112 \%$ & $107 \%$ & $100 \%$ & $101 \%$ & $103 \%$ & $101 \%$ \\
\hline & $95 \%$ & $101 \%$ & $86 \%$ & $98 \%$ & $101 \%$ & $99 \%$ & $100 \%$ & $101 \%$ & & $100 \%$ \\
\hline & $103 \%$ & & $121 \%$ & $100 \%$ & $102 \%$ & $103 \%$ & $101 \%$ & $98 \%$ & $103 \%$ & 1019 \\
\hline & $92 \%$ & $107 \%$ & $97 \%$ & $97 \%$ & $90 \%$ & $94 \%$ & $99 \%$ & $101 \%$ & $98 \%$ & $98 \%$ \\
\hline & $120 \%$ & $122 \%$ & $97 \%$ & $105 \%$ & $116 \%$ & $112 \%$ & $104 \%$ & $114 \%$ & $105 \%$ & $102 \%$ \\
\hline Mean: & $102 \%$ & $105 \%$ & $101 \%$ & $100 \%$ & $104 \%$ & $102 \%$ & $102 \%$ & $106 \%$ & $102 \%$ & 1019 \\
\hline St Dev: & $10 \%$ & $9 \%$ & $15 \%$ & $5 \%$ & 9\% & $7 \%$ & $5 \%$ & $10 \%$ & $7 \%$ & \\
\hline
\end{tabular}

Table 3. Spike recovery from contaminated sediments*

$\begin{array}{rrrrrrr} & \text { As } & \text { Cd } & \text { Cu } & \text { Pb } & \text { Zn } & \text { *-Low spike recoveries due to } \\ \text { Spike Rec.: } & 90 \% & 96 \% & 98 \% & 100 \% & 80 \% & \text { spiked amount being less than } \\ & 113 \% & 114 \% & 103 \% & 110 \% & 159 \% & 10 \% \text { of sample concentration. } \\ 90 \% & 113 \% & 57 \% & 102 \% & 78 \% & \\ 116 \% & 136 \% & 36 \% & 144 \% & 365 \% & \\ & 15 \% & 113 \% & 34 \% & 106 \% & 68 \% & \\ \text { Mean: } & \mathbf{8 5 \%} & 111 \% & 73 \% & 110 \% & 143 \% & \\ \text { St Dev: } & 41 \% & 14 \% & 33 \% & 18 \% & 126 \% & \end{array}$

Table 4. Spike recovery from background sediments

\begin{tabular}{|c|c|c|c|c|c|}
\hline \multicolumn{2}{|c|}{$105 \%$} & $103 \%$ & $85 \%$ & $111 \%$ & $113 \%$ \\
\hline & & & $110 \%$ & $103 \%$ & $110 \%$ \\
\hline & 1059 & $98 \%$ & 97\% & $107 \%$ & $111 \%$ \\
\hline
\end{tabular}


Field data from the Senate Mine-Ivanhoe Lake Area

Table 5A. Senate Mine

$\begin{array}{lrrrrrrrrr}\text { Sample Name } & \text { kilometer } & \mathrm{Al} & \mathrm{Cd} & \mathrm{Cu} & \mathrm{Fe} & \mathrm{Mn} & \mathrm{Ni} & \mathrm{Pb} & \mathrm{Zn} \\ \text { APSM1X } & 0.30 & 5836 & 0.42 & 23 & 19720 & 1185 & 7 & 34 & 60 \\ \text { APSM1Y } & 0.30 & 4481 & 0.59 & 25 & 19461 & 1377 & 6 & 41 & 56 \\ \text { APSM2 } & 0.55 & 4195 & 1.16 & 21666 & 79896 & 6595 & 48 & 226 & 422 \\ \text { APSM3X } & 0.60 & 12648 & 0.80 & 173 & 17266 & 1288 & 9 & 58 & 76 \\ \text { APSM3Y } & 0.62 & 6836 & 0.65 & 273 & 14192 & 822 & 9 & 47 & 74 \\ \text { APSM4 } & 0.64 & 4913 & 0.82 & 324 & 12432 & 692 & 9 & 46 & 76 \\ \text { APSM5 } & 0.67 & 8717 & 0.67 & 139 & 13964 & 612 & 10 & 58 & 96 \\ \text { APSM6 } & 0.73 & 8065 & 0.80 & 163 & 17110 & 1137 & 10 & 71 & 104 \\ \text { APSM7 } & 0.90 & 7382 & 1.06 & 242 & 16161 & 1516 & 15 & 71 & 115 \\ \text { APSM8 } & 1.25 & 7250 & 1.05 & 289 & 14041 & 1836 & 12 & 67 & 127 \\ \text { APSM9X } & 2.15 & 8497 & 0.84 & 215 & 16893 & 1885 & 14 & 61 & 135 \\ \text { APSM9Y } & 2.15 & 8660 & 0.73 & 213 & 16902 & 2718 & 13 & 57 & 114 \\ \text { APMFR1 } & 2.30 & 17379 & 0.29 & 56 & 28865 & 390 & 17 & 79 & 99 \\ \text { APMFR2 } & 3.40 & 10475 & 0.48 & 50 & 22247 & 862 & 15 & 81 & 96 \\ \text { APMFR3X } & 5.50 & 11180 & 0.38 & 32 & 18067 & 565 & 12 & 47 & 65 \\ \text { APMFR3Y } & 5.50 & 12339 & 0.44 & 33 & 16979 & 451 & 12 & 46 & 67\end{array}$

Table 5B. Ivanhoe Lake

Sample Name kilometer

APIL1X

$\begin{array}{lll}0.05 & 8160 & 0.69\end{array}$

$\mathrm{Cu} \quad \mathrm{Fe} \mathrm{Mn} \mathrm{Ni}$

$\mathrm{Pb} \quad \mathrm{Zn}$

APIL1Y

$\begin{array}{llll}0.05 & 9201 & 0.86\end{array}$

$\begin{array}{lllll}77 & 20850 & 1130 & 6\end{array}$

$65 \quad 45$

APIL $2 X$

$\begin{array}{llll}0.10 & 10367 & 1.81\end{array}$

$\begin{array}{llll}81 & 16320 & 1005 & 9\end{array}$

8160

APIL3X

$\begin{array}{lll}0.22 & 7196 & 1.20\end{array}$

$\begin{array}{llll}142 & 21730 & 3639 & 18\end{array}$

$\begin{array}{ll}171 & 129\end{array}$

APIL $4 X$

$\begin{array}{lll}0.60 & 5250 & 0.69\end{array}$

$\begin{array}{llll}102 & 21648 & 3288 & 19\end{array}$

1684109

APIL 6

$\begin{array}{llll}0.90 & 7442 & 0.88\end{array}$

$\begin{array}{llll}308 & 75952 & 9916 & 26\end{array}$

58000189

$\begin{array}{llllll}270 & 17235 & 1249 & 17 & 207 & 119\end{array}$

APIL7

$\begin{array}{lll}1.10 & 11931 & 0.53\end{array}$

$\begin{array}{llll}43 & 21255 & 753 & 15\end{array}$

$\begin{array}{ll}97 & 105\end{array}$

APMFR 1

$\begin{array}{lll}1.90 & 17379 & 0.29\end{array}$

$\begin{array}{llll}56 & 28865 & 390 & 17\end{array}$

$79 \quad 99$
8

APMFR2

$\begin{array}{llll}3.00 & 10475 & 0.48\end{array}$

$\begin{array}{llll}50 & 22247 & 862 & 15\end{array}$

8196

APMFR3X

$\begin{array}{llll}5.10 & 11180 & 0.38\end{array}$

$\begin{array}{llll}32 & 18067 & 565 & 12\end{array}$

$47 \quad 65$

APMFR3Y

$\begin{array}{lll}5.10 & 12339 & 0.44\end{array}$

$\begin{array}{llll}33 & 16979 & 451 & 12\end{array}$

$46 \quad 67$

APIL5

upstream

122240.68

$\begin{array}{llll}47 & 20641 \quad 911 & 15\end{array}$

$64 \quad 98$ 
Table 6. New World Mining District Field Data

\begin{tabular}{|c|c|c|c|c|c|c|c|c|c|}
\hline Sample Name & Al & $\mathrm{Cd}$ & $\mathrm{Cu}$ & $\mathrm{Fe}$ & $\mathrm{Mg}$ & Mn & $\mathbf{N i}$ & $\mathbf{P b}$ & $\mathrm{Zn}$ \\
\hline NWCC1 & 19496 & 1.80 & 38 & 32591 & 4539 & 2589 & 26 & 44 & 81 \\
\hline NWCFY1 & 10304 & 0.51 & 81 & 33413 & 24410 & 723 & 78 & 26 & 87 \\
\hline NWCFY1Spike & 10882 & 2.34 & 135 & 35022 & 24634 & 741 & 80 & 76 & 140 \\
\hline NWCFY2 & 12974 & 0.56 & 108 & 44112 & 28443 & 859 & 100 & 32 & 104 \\
\hline NWCFY3 & 11463 & 0.51 & 146 & 38576 & 29107 & 870 & 101 & 28 & 107 \\
\hline NWCFY4 & 15179 & 1.43 & 677 & 39404 & 13671 & 1799 & 64 & 83 & 224 \\
\hline NWCFY5 & 16229 & 2.44 & 3662 & 59006 & 2444 & 1561 & 58 & 157 & 656 \\
\hline NWF1 & 5864 & 0.05 & 355 & 92522 & 1313 & 201 & 7 & 155 & 78 \\
\hline NWF2 & 4484 & 0.19 & 336 & 94837 & 731 & 185 & 5 & 148 & 68 \\
\hline NWF3 & 7129 & 0.23 & 402 & 102549 & 1762 & 244 & 9 & 159 & 89 \\
\hline NWF4 & 13516 & 0.42 & 981 & 80602 & 1213 & 268 & 7 & 166 & 88 \\
\hline NWF5 & 16617 & 0.60 & 2758 & 838 & 1552 & 306 & 10 & 179 & 141 \\
\hline NWF6 & 20842 & 0.86 & 4705 & 79860 & 1653 & 436 & 16 & 178 & 252 \\
\hline NWF7 & 18411 & 1.11 & 3815 & 71843 & 3552 & 508 & 29 & 167 & 313 \\
\hline NWF8 & 14897 & 1.95 & 3726 & 66287 & 2240 & 1301 & 43 & 159 & 552 \\
\hline NWLD1 & 8816 & 2.28 & 600 & 679 & 2816 & 1675 & 33 & 682 & 528 \\
\hline NWLD2 & 9258 & & & & 2871 & 199 & 7 & 334 & \\
\hline NWLD3 & 8773 & 0.75 & 1360 & 170863 & 28 & 181 & 9 & 369 & 194 \\
\hline NWLD4 & 9877 & 1.07 & 1610 & 161 & 35 & 257 & 10 & 354 & 227 \\
\hline NWLD5 & 10605 & 1.11 & 1588 & 144 & & 318 & 12 & 349 & 239 \\
\hline NWLD5Dupe & 10609 & 1.00 & 1545 & 141 & & 308 & 11 & 337 & 229 \\
\hline NWLD6 & 8982 & 2.28 & 598 & & & 1665 & 34 & 681 & 528 \\
\hline NWLD7 & 6558 & 0.72 & 203 & & & 733 & 23 & 126 & 202 \\
\hline NWLD8 & 21582 & 3.46 & 5752 & 109 & & 893 & 35 & 314 & 638 \\
\hline NWLD9 & 19338 & 2.35 & 4245 & & & 523 & 25 & 296 & 547 \\
\hline NWM1 & 8935 & 1.49 & 921 & & & 930 & 36 & 252 & 365 \\
\hline NWM2 & 100 & 1.35 & 262 & & & 999 & 27 & 252 & 396 \\
\hline NWM3 & 10458 & 1.33 & 265 & & & 1008 & 29 & 249 & 397 \\
\hline NWM4 & 11010 & 1.39 & 380 & & & 1078 & 33 & 257 & 408 \\
\hline NWM5 & 11774 & 1.61 & 834 & & 97 & 1029 & 41 & 260 & 431 \\
\hline NWM5Dupe & 12336 & 1.63 & 816 & 446 & 5561 & 996 & 42 & 255 & 417 \\
\hline NWM6 & 12442 & 1.96 & 1084 & 51375 & 6733 & 1068 & 51 & 268 & 526 \\
\hline NWM7 & 12460 & 1.58 & 821 & 57416 & 7456 & 963 & 38 & 264 & 381 \\
\hline NWPC1 & 12310 & 0.27 & 33 & 29023 & 23119 & 517 & 77 & 26 & 58 \\
\hline NWSB 1 & 12025 & 0.54 & 47 & 40250 & 25243 & 764 & 70 & 46 & 114 \\
\hline NWSB2 & 9270 & 3.42 & 752 & 143000 & 6280 & 2776 & 52 & 203 & 537 \\
\hline NWSB3 & 17565 & 0.57 & 61 & 42715 & 39920 & 974 & 131 & 38 & 91 \\
\hline NWSB4 & 12232 & 0.54 & 69 & 39081 & 26054 & 781 & 88 & 44 & 111 \\
\hline NWSB5 & 10745 & 0.63 & 67 & 36453 & 26009 & 714 & 77 & 40 & 101 \\
\hline NWSBG & 10553 & 0.27 & 63 & 32964 & 20402 & 667 & 63 & 33 & 82 \\
\hline NWSC1 & 14724 & 0.38 & 40 & 36759 & 35356 & 682 & 148 & 25 & 64 \\
\hline
\end{tabular}


Table 7. Flint Creek sediment data (collected 10/3\&29/94)

\begin{tabular}{lrrrrrrrrrr}
\multicolumn{1}{c}{ Sample Name } & Al & As Cd & Cu & Fe & Mg & Mn & Ni & Pb & Zn \\
FC1 10/3/93 & 8223 & 25 & 1 & 52 & 16722 & 5872 & 1644 & 11 & 57 & 187 \\
FC10 10/29 & 8318 & 443 & 2 & 134 & 14115 & 4910 & 4527 & 7 & 518 & 1291 \\
FC11 10/29 & 8318 & 428 & 2 & 136 & 14418 & 5243 & 4978 & 7 & 512 & 1303 \\
FC2 & 7794 & 307 & bd & 41 & 12495 & 3620 & 1299 & 7 & 161 & 352 \\
FC3 & 7093 & 456 & 1 & 85 & 12086 & 4230 & 2499 & 6 & 339 & 931 \\
FC4 & 7752 & 508 & 2 & 147 & 14086 & 5544 & 5336 & 8 & 571 & 1547 \\
FC5 & 5680 & 531 & 2 & 170 & 12037 & 5651 & 5136 & 6 & 485 & 1490 \\
FC6 & 6043 & 462 & 2 & 117 & 12266 & 5228 & 5416 & 6 & 462 & 1320 \\
FC6DUP & 5401 & 438 & 1 & 112 & 11002 & 5011 & 5089 & 5 & 417 & 1252 \\
FC7 & 7344 & 367 & 2 & 101 & 13278 & 5209 & 3612 & 8 & 378 & 1092 \\
FC8 & 7025 & 224 & 2 & 81 & 12043 & 4988 & 2562 & 8 & 270 & 780 \\
FC910/29 & 8435 & 408 & 2 & 116 & 14076 & 4715 & 5119 & 7 & 441 & 1091 \\
FCB1 & 7606 & 47 & 3 & 180 & 19457 & 17394 & 798 & 13 & 280 & 530 \\
FCBLANK & bd & bd & bd & bd & bd & bd & bd & bd & bd & bd \\
FCD1 & 7639 & bd & 3 & 20 & 11966 & 3919 & 394 & 13 & 23 & 240 \\
FCG1 & 8049 & bd & 1 & 14 & 11957 & 5114 & 460 & 10 & 27 & 67
\end{tabular}

